INSTITUTO DE PESQUISAS ENERGÉTICAS E NUCLEARES

Autarquia associada à Universidade de São Paulo

\title{
ESTUDO DOS MICROMECANISMOS DE DEFORMAÇÃO E FRATURA DA LIGA DE TITÂNIO Ti-6AI-4V UTILIZANDO-SE TÉCNICAS DE MICROSCOPIA ELETRÔNICA E DIFRAÇÃO DE RAIOS X.
}

Aparecido Edilson Morcelli

Tese apresentada como parte dos requisitos para obtenção do Grau de Doutor em Ciências na Área de Tecnologia Nuclear - Materiais

Orientador:

Dr. Arnaldo H. Paes de Andrade

SÃO PAULO 
Aos meus pais.

À minha esposa Claudia

e aos meus filhos

Caio e Lucas 


\section{AGRADECIMENTOS}

Ao Dr. Arnaldo Homobono Paes de Andrade, meu orientador, pelo incentivo, apoio, amizade e confiança em meu trabalho.

Ao Dr. Waldemar Alfredo Monteiro pela amizade e sugestões no presente trabalho.

A banca examinadora pelas valiosas sugestões que complementaram e engrandeceram o trabalho, nas pessoas do orientador Dr. Arnaldo Homobono Paes de Andrade, Dr. Pedro Kunihiko Kiyohara, Dr. Jan Vatavuk, Dr. Wilson Aparecido Parejo Calvo e Dr. Sidnei José Buso.

Ao Dr. Antonio Couto pelo fornecimento da amostras utilizadas no presente trabalho.

À Dra. Raquel Lobo pela amizade.

Ao corpo técnico do CCTM/IPEN, Nildemar Aparecido, René, Luis Carlos, Celso, Glauson e Genedite.

Ao IPEN, pelo apoio material.

Aos colegas da Universidade de Santo Amaro pelo incentivo e amizade.

Aos colegas do núcleo de Física do IC pela amizade.

Em memória dos meus pais Apparecido e Maria Angélica.

Ao meu padrasto Maurício, aos meus irmãos Celso, Silvia, Robson e Vanessa pelo incentivo.

A todos aqueles que de alguma forma ajudaram na realização deste trabalho. 


\section{ESTUDO DOS MICROMECANISMOS DE DEFORMAÇÃO E FRATURA DA LIGA DE TITÂNIO Ti-6AI-4V UTILIZANDO-SE TÉCNICAS DE MICROSCOPIA ELETRÔNICA E DIFRAÇÃO DE RAIOS X.}

\section{Aparecido Edilson Morcelli}

\section{RESUMO}

A realização do presente trabalho permitiu o estudo dos micromecanismos de deformação e fratura da liga de titânio Ti-6Al-4V, utilizada comercialmente para a fabricação de biomateriais metálicos. As técnicas empregadas para a análise do material em estudo foram: microscopia eletrônica de varredura (MEV), microscopia eletrônica de transmissão (MET) e a difração de raios $X$ (DRX). Estudar a influência e comportamento das diversas fases existentes em ligas de titânio é importante para se avaliar o comportamento de trincas nas ligas de titânio com alta resistência mecânica, que possuem microestrutura fina, relacionando a presença das fases alfa $(\alpha)$, beta $(\beta)$ e alfa+beta $(\alpha+\beta)$ com a resistência do material. A avaliação in situ dos micromecanismos de deformação e fratura foi realizada por MET e também foi feito o estudo das transformações de fase durante o resfriamento em ligas de titânio, por MET, utilizando-se as técnicas de campo claro, campo escuro e difração de elétrons (DEAS), em área selecionada. Após tratamento térmico foram observadas as diferenças entre a quantidade das fases $\alpha$ e $\beta$, em relação à microestrutura original do material para diferentes condições utilizadas no tratamento térmico aplicado à liga metálica. Observou-se a presença da microestrutura lamelar, formada durante o resfriamento no campo $\beta$, promovendo a transformação de parte da estrutura alfa secundária em beta, que se encontrava retida entre as lamelas de alfa. 


\title{
STUDY OF DEFORMATION AND FRACTURE MICROMECHANISMS OF TITANIUM ALLOY Ti-6AI-4V USING ELECTRON MICROSCOPY AND X-RAY DIFRACTION TECHNIQUES
}

\section{Aparecido Edilson Morcelli}

\begin{abstract}
This present work allowed the study of deformation and fracture micromechanisms of titanium alloy Ti-6Al-4V, used commercially for the manufacture of metallic biomaterials. The techniques employed for the analysis of the material under study were: scanning electron microscopy (SEM), transmission electron microscopy (TEM) and X-ray diffraction (XRD). The study of the influence and behavior of the phases present in titanium alloys is important to evaluate the behavior of cracks in titanium alloys with high mechanical strength, which have fine alpha $(\alpha)$, beta $(\beta)$ and alpha+beta $(\alpha+\beta)$ microstructure, linking the presence of the phases with the strength of the material. The evaluation in situ of deformation and fracture micromechanisms were performed by TEM and was also a study of phase transformations during cooling in titanium alloys, using the techniques of bright field, dark field and diffraction of electrons in the selected area. After heat treatment differences were observed between the amount of in relation to the original microstructure of the $\beta$ and $\alpha$ phases material for different conditions used in heat treatment applied to the alloy. The presence of lamellar microstructure formed during cooling in the $\beta$ field was observed, promoting the conversion of part of the secondary alpha structure in $\beta$ phase, which was trapped between the lamellar of alpha.
\end{abstract}




\section{SUMÁRIO}

Página

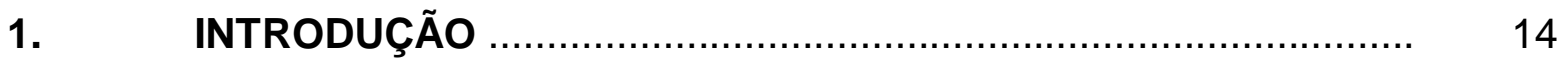

1.1. Objetivos ….................................................................... 16

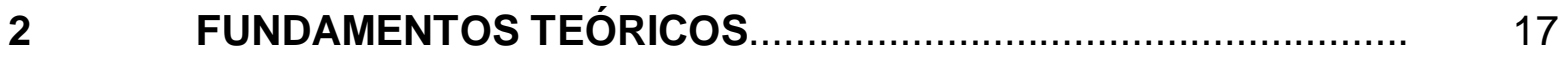

2.1. Propriedades do elemento titânio................................................ 17

2.2. Ligas de Titânio .................................................................. 19

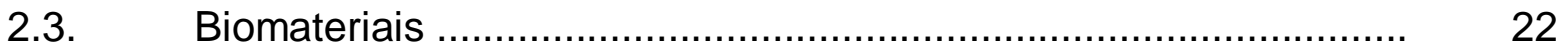

2.3.1. Aplicações dos biomateriais .................................................. 22

2.3.2. Características esperadas para os biomateriais ............................ 22

2.3.2.1. Requisitos necessários a um biomaterial ..................................... 24

2.3.3. Utilização dos biomateriais e seus efeitos ..................................... 25

2.3.4. Aplicações biomédicas do titânio e suas ligas ............................... 28

3. METALURGIA FÍSICA DA LIGA TI-6AI-4V _............................... 31

3.1. Aspectos básicos da metalurgia do titânio .................................... 31

3.2. A liga de titânio Ti-6Al-4V ................................................... 34

3.2.1. Processamento termomecânico, microestrutura e comportamento 39 mecânico da liga Ti-6Al-4V forjada e fundida

3.2.2. Mecanismos de deformação no titânio e suas ligas.......................... 40

4. MATERIAIS E MÉTODOS EXPERIMENTAIS ............................. 50

4.1. Procedimento para análise microestrutural MO e MEV (EDS e

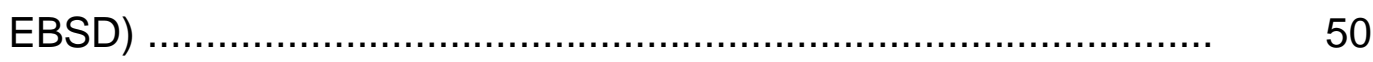

4.1.1. Procedimento utilizado no preparo da amostra para análise microestrutural MO e MEV (EDS e EBSD) ................................... 50

4.1.2. Equipamentos utilizados na análise microestrutural MEV (EDS e 51 EBSD)

4.2. Procedimento para análise microestrutural por MET 
4.2.1. Procedimento a ser utilizado no preparo da amostra na análise microestrutural (MET)

4.2.2. Procedimento a ser utilizado no preparo da amostra na análise microestrutural (MET) para ensaios de tração in situ

4.2.3. Equipamentos utilizados na análise microestrutural (MET) ........... 56

4.3. Procedimento para análise microestrutural (DRX) ..................... 58

4.3.1. Procedimento de preparo das amostras para análise microestrutural Difração de Raios X

4.3.2. Equipamento utilizado na análise microestrutural (DRX) ............... 59

4.4. Tratamento Térmico da amostra de titânio Ti-6Al-4V ................... 59

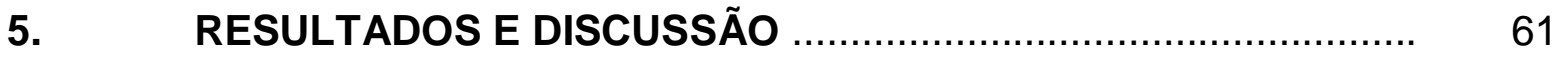

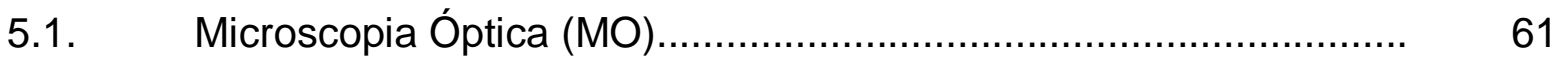

5.2. Microscopia Eletrônica de Varredura (MEV) .............................. 66

5.2.1. Caracterização morfológica e semiquantitativa da liga Ti-6Al-4V... 66

5.2.2. Caracterização quantitativa da liga Ti-6Al-4V ............................... 72

5.3. Microscopia Eletrônica de Varredura (MEV) associada à Difração de Elétrons Retroespalhados (EBSD) ................................ 74

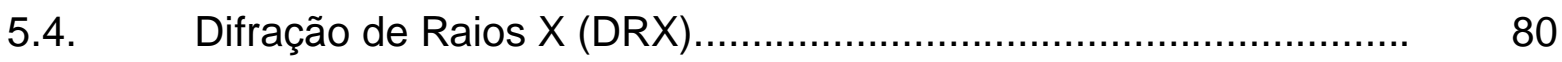

5.5. Microscopia Eletrônica de Transmissão (MET) $\quad$.......................... 87

5.5.1. Análise microestrutural de grãos........................................ 87

5.5.2. Tração in situ e fractografia............................................... 96

5.5.3. Transformação de fase in situ ................................................ 108

5.5.4. Análise de sub-grãos utilizando-se MET de alta resolução ............. 112

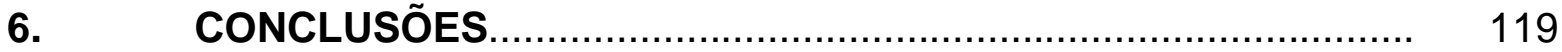

REFERÊNCIAS BIBLIOGRÁFICAS ................................ 121 


\section{TABELAS}

Página

TABELA 1 Classificação ASTM do Titânio e suas ligas

TABELA 2 Modos independentes de deformação em metais com estrutura hexagonal compacta (hc)

TABELA 3 Resultado da análise semiquantitativa relativo ao EDS da Figura 30.

TABELA 4 Resultado das análises semiquantitativas relativos aos EDS obtidos da amostra conforme Figura 31.

TABELA 5 Comparação dos resultados obtidos nas análises semiquantitativas realizadas nas fases alfa e beta, presentes na amostra de Ti-6Al-4V.

TABELA 6 Resultado da análise quantitativa relativo ao EDS (FIG.33).

TABELA 7 Resultados obtidos a partir do difratograma da Figura 38 relacionando os valores da distância interplanar (d) e 0 ângulo $2 \theta$ (graus).

TABELA 8 Resultados obtidos a partir do difratograma da análise da amostra Ti-6Al-4V tratada termicamente a $1000{ }^{\circ} \mathrm{C}$ por uma hora, relacionando os valores da distância interplanar (d) e o ângulo $2 \theta$ (graus).

TABELA 9 Resultados obtidos a partir do difratograma da análise da amostra Ti-6Al-4V tratada termicamente a $1000{ }^{\circ} \mathrm{C}$ por duas horas em tubo de quartzo e resfriada em água, relacionando os valores da distância interplanar (d) e o ângulo $2 \theta$ (graus). 


\section{FIGURAS}

Página

FIGURA 1 Módulo de Elasticidade de alguns biomateriais................................. 26

FIGURA 2 Formação da camada de dióxido de titânio e hidroxiapatita sobre biomaterial à base de titânio

FIGURA 3 Interação entre o titânio e os fluidos corporais

FIGURA 4 Representação esquemática de tipos de diagramas de fase entre o titânio e elementos presentes na liga metálica.

FIGURA 5 Diagrama parcial das fases do titânio e elementos $\beta$ estabilizadores

FIGURA 6 Diagrama de fases para a liga Ti-6Al-4V

FIGURA 7 Curvas de escoamento obtidas em testes de compressão a quente para velocidades de deformação de 0,$001 ; 0,1$ e $10 \mathrm{~s}^{-1}$ (a) $815^{\circ} \mathrm{C}$, (b) $900{ }^{\circ} \mathrm{C} \mathrm{e} \mathrm{(c)} 955^{\circ} \mathrm{C}$

FIGURA 8 Curva Tensão $x$ Deformação da liga Ti-6Al-4V em ensaio de tração in situ

FIGURA 9 Sistemas possíveis de escorregamento para cristais com estrutura hc.

FIGURA 10 Ilustração esquemática da maclação para um cristal hc. (A) ilustração planos $x, z$; (B) ilustração planos $x, y, z$ e (C) célula unitária definida nos planos $\mathrm{K}_{1}$ e $\mathrm{S}$.

FIGURA 11 Dependência da temperatura em relação à tensão crítica de cisalhamento para $(11 \overline{2} 2) \quad[11 \overline{2} \overline{3}]$ macla/sistema de escorregamento, normalizado para um módulo de cisalhamento, à temperatura ambiente para cristais de $\mathrm{Ti}$.

FIGURA 12 Descrição esquemática da nucleação de maclas heterogêneas: (a) macla de formação inicial associada com o local da concentração de tensão representada por uma super discordância, e (b) geração das discordâncias de maclas como resultado da dissociação não-planar de uma discordância.

FIGURA 13 Mecanismos de origem das discordâncias para o sistema de escorregamento piramidal $<c+a\rangle$ : (a) discordância, (b) formação da junção $<c+a>$ e (c) escorregamento transversal da discordância $<\mathrm{c}+\mathrm{a}>$.

FIGURA 14 Dois tipos de dissociação <c+a> discordância em cunha, obtidas a partir de simulação atomística: (a) tipo planar e (b) tipo não planar.......

FIGURA 15 Crescimento de uma macla, embryo, no plano (11̄ㄷ) e direção [ $\overline{1} \overline{1} 26]$ sob deformação de tração.

FIGURA 16 Equipamentos utilizados na preparação da amostra de titânio Ti-6Al4V 
FIGURA 17 Porta amostra do Microscópio eletrônico de transmissão analítico (MET-AR) da marca JEOL utilizado para análise das amostras de Ti-6Al-4V.

FIGURA 18 Esquema da amostra de Ti-6Al-4V para ensaio de tração in situ no MET

FIGURA 19 Detalhe da amostra Ti-6Al-4V preparada para ensaio para tração in situ......

FIGURA 20 Microscópio eletrônico de transmissão analítico marca JEOL utilizado para análise das amostras de Ti-6Al-4V.

FIGURA 21 Detalhe do sistema de tração e obtenção de medidas utilizado para análise tração in situ das amostras de Ti-6Al$4 \mathrm{~V}$.

FIGURA 22 Porta-amostra para tração "in situ" do microscópio eletrônico de transmissão marca JEOL com detalhe do sistema de tração e obtenção de medidas utilizado para análise tração das amostras de Ti-6Al-4V.

FIGURA 23 Detalhe da amostra de Ti-6Al-4V preparada para ensaio de tração "in situ" no microscópio eletrônico de transmissão marca JEOL

FIGURA 24 Difratômetro de raios $X$ marca RIGAKU utilizado para análise das amostras de Ti-6Al-4V......

FIGURA 25 Forno Resistivo (A) Forno da marca Carbolite (B) detalhe do tubo de alumina para colocação da amostra

FIGURA 26 Micrografia obtida por Microscopia óptica da amostra de Ti-6Al-4V tratada termicamente a $800^{\circ} \mathrm{C}$ por duas horas (amostra como recebida).

FIGURA 27 Micrografia obtida por Microscopia óptica da amostra de Ti-6Al-4V tratada termicamente sob tubo de quartzo a $1000^{\circ} \mathrm{C}$ por duas horas e resfriada em água. (A), (B) e (C) amostra submetida ao ataque químico da superfície por 45 segundos e (D) e (E) por 90 segundos.

FIGUAR 28 Micrografia obtida por Microscopia óptica da amostra de Ti-6Al-4V tratada termicamente a $1000^{\circ} \mathrm{C}$ por duas horas e resfriada em água. Amostra submetida ao ataque por 90 segundos.

FIGURA 29 Micrografia da superfície atacada quimicamente da amostra de Ti$6 \mathrm{Al}-4 \mathrm{~V}$, revelando regiões contendo a fase Tiß (regiões claras) e a matriz Ti $\alpha$ (regiões escuras) obtida por MEV, através de imagem de elétrons retroespalhados.

FIGURA 30 Espectro por Energia Dispersiva (EDS) das regiões claras reveladas após ataque químico obtidas por MEV/EDS, revelando a fase Ti $\beta$ com a presença dos elementos Al, Ti e $\mathrm{V}$

FIGURA 31 Espectro por Energia Dispersiva (EDS) das regiões escuras reveladas após ataque químico obtidas por MEV/EDS, revelando a fase Ti $\alpha$ com a presença dos elementos Al, Ti V.

FIGURA 32 Micrografia eletrônica da amostra de Ti-6Al-4V, atacada quimicamente com tempo de exposição de cinco minutos ..... 
FIGURA 33 Micrografias da superfície da amostra de Ti-6Al-4V, atacada quimicamente, com tempo de exposição de cinco minutos. (a) e (c) imagem de elétrons secundários, (b) e (d) imagem de elétrons retroespalhados

FIGURA 34 Espectro de Energia Dispersiva (EDS) obtido após a microanálise da superfície da amostra, onde se observa a sobreposição dos picos dos elementos químicos $\mathrm{Ti}$ e $\mathrm{V}$, presentes na amostra de Ti$6 \mathrm{Al}-4 \mathrm{~V}$.

FIGURA 35 Micrografia eletrônica da amostra de Ti-6Al-4V (como recebida), onde se pode observar as regiões contendo a presença da fase $\beta$ ao longo da superfície da amostra, obtidas por MEV/EBSD .....

FIGURA 36 Micrografia eletrônica da amostra de Ti-6Al-4V das regiões contendo a presença da fase $\beta$ na liga de titânio Ti-6Al-4V e o respectivo triângulo de referência de orientações dos respectivos planos apresentados, obtido por MEV/EBSD

FIGURA 37 Micrografia eletrônica da amostra de Ti-6Al-4V de regiões com a presença da fase $\alpha$ do titânio (vermelho, cinza e roxo) e da fase $\beta$ distribuída nos contornos de grão da fase $\alpha$, obtida por MEV/EBSD..

FIGURA 38 Micrografia eletrônica da amostra de Ti-6Al-4V de regiões com a presença da fasea da liga de âtitio $\mathrm{Ti}$-6Al-4V e o respectivo triângulo de referência de orientações dos planos cristalinos dispostos na superfície da amostra, obtido por MEV/EBSD

FIGURA 39 Difratograma obtido por DRX da liga de titânio Ti-6Al-4V, da amostra como recebida recozida a $800^{\circ} \mathrm{C}$ por 2 horas. Velocidade de varredura para análise de $2^{\circ}$ por minuto.

FIGURA 40 Difratograma obtido por DRX da liga de titânio Ti-6Al-4V, da amostra tratada a $1000^{\circ} \mathrm{C}$ por 1 hora e resfriada em água. Velocidade de varredura para análise de $2^{\circ}$ por minuto.

FIGURA 41 Difratograma obtido por DRX da liga de titânio Ti-6AI-4V, da amostra tratada a $1000^{\circ} \mathrm{C}$ por 2 horas em tubo de quartzo e resfriada em água. Velocidade de varredura para análise de $2^{\circ}$ por minuto.

FIGURA 42 Micrografia obtida por microscopia eletrônica de transmissão (MET) da amostra de Ti-6Al-4V $\left(1000^{\circ} \mathrm{C} / 2 \mathrm{~h}\right)$, contendo uma partícula ......

FIGURA 43 Micrografia obtida por microscopia eletrônica de transmissão (MET) em campo escuro da amostra de Ti-6Al-4V $\left(1000^{\circ} \mathrm{C} / 2 \mathrm{~h}\right)$. Na região em destaque realizou-se a difração de elétrons.

FIGURA 44 Padrão de difração de elétrons realizado na área selecionada da Figura 43 sendo identificada a presença da fase beta (ccc), após a indexação...

FIGURA 45 Micrografia obtida por microscopia eletrônica de transmissão (MET) em campo claro da amostra de Ti-6Al-4V $\left(1000^{\circ} \mathrm{C} / 2 \mathrm{~h}\right) \ldots$

FIGURA 46 Micrografia obtida por microscopia eletrônica de transmissão (MET) em campo escuro da amostra de Ti-6Al-4V $\left(1000^{\circ} \mathrm{C} / 2 \mathrm{~h}\right)$, relativa à Figura 45 evidenciando a existência da fase lamelar alfa.

FIGURA 47 Padrão de difração de elétrons realizado na área selecionada da Figura 46 sendo identificada a presença da fase alfa (hc), após a indexação. 
FIGURA 48 Micrografia obtida por microscopia eletrônica de transmissão (MET) da amostra de Ti-6Al-4V $\left(1000^{\circ} \mathrm{C} / 2 \mathrm{~h}\right)$, mostrando as lamelas $\alpha \mathrm{e}$ discordâncias (campo claro).

FIGURA 49 Micrografia obtida por microscopia eletrônica de transmissão (MET) da amostra de Ti-6Al-4V $\left(1000^{\circ} \mathrm{C} / 2 \mathrm{~h}\right)$, mostrando as lamelas $\alpha$ e discordâncias (campo escuro).

FIGURA 50 (a) Micrografia obtida por microscopia eletrônica de transmissão (MET) da amostra de Ti-6Al-4V $\left(1000^{\circ} \mathrm{C} / 2 \mathrm{~h}\right)$, evidenciando a interface lamelar e (b) respectivo padrão de difração de Micrografia obtida por microscopia eletrônica de transmissão (MET) da amostra de Ti-6Al-4V $\left(1000^{\circ} \mathrm{C} / 2 \mathrm{~h}\right)$, evidenciando a interface lamelar e difração de elétrons da área selecionada da Figura 50 (a), identificação da presença da fase beta (ccc)

FIGURA 51 Modelo utilizado para representar os sistemas de escorregamento em metais hexagonais ( $\mathrm{hc}$ ).

FIGURA 52 (A) Micrografia eletrônica da amostra de Ti-6Al-4V e (B) o respectivo padrão de difração realizado na região indicada em (A)

FIGURA 53 Micrografia eletrônica da amostra de Ti-6Al-4V, relativa à análise de tração in situ para um deslocamento de $0,05 \mathrm{~mm}$ em relação à posição inicial.

FIGURA 54 Micrografia eletrônica da amostra de Ti-6Al-4V, relativa à análise de tração in situ para um deslocamento de $0,10 \mathrm{~mm}$ em relação à posição inicial.

FIGURA 55 Micrografia eletrônica da amostra de Ti-6Al-4V, relativa à análise de tração in situ para um deslocamento de $0,15 \mathrm{~mm}$ em relação à posição inicial.

FIGURA 56 Micrografia eletrônica da amostra de Ti-6Al-4V, relativa à análise de tração in situ para um deslocamento de 0,20mm em relação à posição inicial.

FIGURA 57 Micrografia eletrônica da amostra de Ti-6Al-4V, relativa à análise de tração in situ para um deslocamento de $0,25 \mathrm{~mm}$ em relação à posição inicial.

FIGURA 58 Micrografia eletrônica da amostra de Ti-6Al-4V, relativa à análise de tração in situ para um deslocamento de $0,25 \mathrm{~mm}$ em relação à posição inicial.

FIGURA 59 Micrografias da amostra de Ti-6Al-4V relativas às análises de tração in situ para diferentes deslocamentos: (A) 0,05 $\mathrm{mm}$, (B) 0,10 mm, (C) 0,15 mm, (D) 0,20 mm, (E) e (F) 0,25 mm

FIGURA 60 Micrografia eletrônica da face (A) da amostra de Ti-6Al-4V utilizada no ensaio de tração "in situ"; (B) Detalhe da região de área fina da amostra de Ti-6Al-4V,onde se observa in situ o início da fratura. 
FIGURA 61 Micrografia eletrônica em detalhe da região de área fina da amostra de Ti-6Al-4V, análise por MEV, onde se observa in situ o início da fratura, (A) área fina superior e (B) área fina inferior (aumento 440 vezes).....

FIGURA 62 Micrografia eletrônica em detalhe da região de área fina da amostra de Ti-6Al-4V, análise por MEV, onde se observa in situ o início da fratura.

FIGURA 63 Micrografia eletrônica em campo escuro da amostra de Ti-6Al-4V apresentando em sua estrutura lamelas longitudinais.

FIGURA 64 Padrão de difração de elétrons realizado na área selecionada da Figura. 63, sendo identificada a presença da fase alfa (hc), após a indexação

FIGURA 65 Micrografia eletrônica da amostra de Ti-6Al-4V, (A) amostra no início do ensaio e (B) após a elevação da temperatura in situ aplicada à amostra de $600^{\circ} \mathrm{C}$......

FIGURA 66 Padrão de difração de elétrons realizado na área selecionada da Figura 65 (B) sendo identificada a presença da fase beta (ccc), após a indexação

FIGURA 67 Micrografia eletrônica da amostra de Ti-6Al-4V recozida $800^{\circ} \mathrm{C}$ por duas horas.

FIGURA 68 Micrografia eletrônica da amostra de Ti-6Al-4V recozida a $800^{\circ} \mathrm{C}$ por duas horas, apresentando franjas

FIGURA 69 Micrografia eletrônica da amostra de Ti-6Al-4V recozida a $800^{\circ} \mathrm{C}$ por duas horas

FIGURA 70 Micrografia eletrônica da amostra de Ti-6Al-4V, após o tratamento térmico $1000^{\circ} \mathrm{C} / 1 \mathrm{~h}$ e resfriamento rápido em água, apresentando maclas longitudinais em $(A)$ e $(B)$...

FIGURA 71 Micrografia eletrônica da amostra de Ti-6Al-4V, após o tratamento térmico $1000^{\circ} \mathrm{C} / 1 \mathrm{~h}$ e resfriamento rápido em água..

FIGURA 72 Micrografia eletrônica da amostra de Ti-6Al-4V ,após o tratamento térmico $1000^{\circ} \mathrm{C} / 1 \mathrm{~h}$ e resfriamento rápido em água

FIGURA 73 Micrografia eletrônica da amostra de Ti-6Al-4V, após o tratamento térmico $1000^{\circ} \mathrm{C} / 1 \mathrm{~h}$ e resfriamento rápido em água 


\section{INTRODUÇÃO}

A crescente utilização dos biomateriais em sistemas biológicos tem levado ao estudo e desenvolvimento de materiais que atendam de forma mais eficiente este mercado.

Os biomateriais são substâncias de origem natural ou sintética que podem ser utilizadas por tempo indeterminado na substituição total ou parcial de sistemas biológicos. Os benefícios do uso dos biomateriais são inúmeros, como na reparação de partes do corpo humano. Eles podem, por exemplo, auxiliar na recuperação de um tecido lesionado e com isso melhorar a qualidade de vida do ser humano (Oliveira \& Nanci, 2004).

Os biomateriais possuem a característica fundamental da biocompatibilidade, ou seja, são inertes biologicamente, não causando nenhum efeito nocivo ao organismo. Eles atendem ao requisito de funcionalidade para o qual foram desenvolvidos, provocando, assim, o mínimo de reações alérgicas ou inflamatórias, quando em contato com tecidos vivos ou fluidos orgânicos (Niinomi, 1998).

O titânio e suas ligas são amplamente utilizados nas áreas aeroespacial, química e de equipamentos esportivos e industriais. Desde 1960 as ligas de titânio começaram a ser utilizadas como material para implantes cirúrgicos devido à sua biocompatibilidade e compatibilidade mecânica (Yue et al., 2002).

A resistência a corrosão do titânio e suas ligas é obtida devido a formação de óxidos estáveis em sua superfície, porém esta resistência pode ser afetada se estiver em meio nos quais existam fluídos fisiológicos à temperatura do corpo humano. Por outro lado apenas a liga Ti-6Al-4V e quatro tipos de titânio puro estão disponíveis comercialmente e são habitualmente utilizadas no corpo humano. O titânio puro é utilizado nos casos onde há baixa exigência de carga mecânica no implante, enquanto a liga Ti-6Al-4V é utilizada quando há a solicitação de maiores cargas mecânicas no implante (Gurappa, 2002). 
O titânio possui a característica de polimorfismo, ou seja, existe em mais de uma forma cristalográfica, o que o diferencia de outros metais leves como alumínio e magnésio, permitindo o desenvolvimento de novas ligas. Sua decomposição em soluções sólidas metaestáveis é possível e também as transformações alotrópicas, fases intermediárias e intermetálicas permitem a obtenção de diferentes microestruturas e propriedades (ASM,1980).

O Brasil importa diversas ligas metálicas utilizadas como biomateriais e seria de grande utilidade pública o desenvolvimento de tecnologia nacional própria para a fabricação e comercialização desses biomateriais que são desenvolvidos em escala laboratorial, porém necessitam serem estudados com o intuito de melhorar sua performance para uma possível aplicação comercial. 


\subsection{Objetivos}

O presente trabalho realiza uma avaliação microestrutural dos micromecanismos de deformação e fratura na liga de titânio Ti-6Al-4V, uma liga comercial, utilizada como biomaterial, tendo como objetivo estudar a influência e comportamento das diversas fases presentes, através da utilização da microscopia eletrônica de transmissão. A literatura descreve a importância de se avaliar o comportamento de trincas em ligas de titânio com alta resistência à fadiga que possuem microestrutura fina relacionando a presença das fases $\operatorname{alfa}(\alpha)$, beta $(\beta)$ e alfa+beta $(\alpha+\beta)$ com a fadiga do material.

A avaliação in situ dos micromecanismos de deformação e fratura, que é uma área muito pouco explorada na literatura, bem como o estudo das transformações de fase, durante o resfriamento na liga de titânio em estudo também foram realizadas.

As técnicas de Microscopia Eletrônica de Varredura (MEV) associada a Espectroscopia de Energia Dispersiva (EDS), MEV associada a Difração de elétrons retroespalhados (EBSD), Difração de Raios X (DRX) e Microscopia Eletrônica de Transmissão (MET) foram utilizadas na realização das análises. 


\section{FUNDAMENTOS TEÓRICOS}

\subsection{Propriedades do elemento titânio}

O elemento titânio é um metal de transição. $\mathrm{Na}$ natureza suas principais fontes são os minerais rutilo e ilmenita. O rutilo é composto basicamente por dióxido de titânio $\left(\mathrm{TiO}_{2}\right)$ e a ilmenita por óxido de ferro e titânio $(\mathrm{FeTiO})_{3}$.

O titânio apresenta excelentes propriedades físicas, dentre as quais se destacam o elevado ponto de fusão $\left(1668^{\circ} \mathrm{C}\right)$, o ponto de ebulição $\left(3287^{\circ} \mathrm{C}\right)$, a baixa massa específica $\left(4,54 \mathrm{~g} \mathrm{~cm}^{-3}\right)$ e o módulo de elasticidade (acima de 127 $\mathrm{GPa})$.

Destas propriedades, destacam-se a massa específica e o módulo de elasticidade. A maioria dos aços apresenta massa específica em torno de 7,87 $\mathrm{g}$ $\mathrm{cm}^{-3}$, ou seja, quase o dobro da massa específica do titânio; somando-se a isto, tem-se o fato de que as propriedades mecânicas do titânio podem ser melhores que as das referidas ligas, visto que o mesmo apresenta tensão específica e rigidez muito altas. Pelo fato do módulo de elasticidade do titânio ser muito maior que de outros metais leves, como $\mathrm{Mg}$ e $\mathrm{Al}$, o mesmo compete com estes para aplicações estruturais espaciais e nanoaeroespaciais, uma vez que seu ponto de fusão é muito maior. O Mg, por exemplo, não pode ser usado acima de $121{ }^{\circ} \mathrm{C}$, enquanto que o Ti pode ser usado sob temperaturas de até $426{ }^{\circ} \mathrm{C}$ no ar. Temperaturas maiores que esta provoca sua fragilização pelo oxigênio do ar (Braga, 2007).

Inúmeros trabalhos, no âmbito internacional, têm sido realizados para melhorar o desempenho das ligas de titânio utilizadas como biomateriais (Niinomi \& Kobayashi, 1996; Oehring et al.,1998; Chang \& Lee, 2002; Xue et al., 2002; Majorell et al., 2002; Reissig et al., 2004). A avaliação microestrutural tem sido uma importante ferramenta para avaliar o desempenho desses novos materiais, que têm por finalidade melhorar a resistência à corrosão e fratura que apesar de 
serem excelentes para as ligas de titânio, em meio biológico podem sofrer alterações.

Dentre as propriedades químicas, destaca-se a alta reatividade deste metal, o que constitui uma desvantagem no seu processamento. O titânio combina-se muito facilmente com outros elementos, principalmente gases como nitrogênio e oxigênio, os quais se dissolvem rapidamente no metal líquido ou sólido acima de aproximadamente $400{ }^{\circ} \mathrm{C}$, provocando a perda de ductilidade deste. Como conseqüência desta alta reatividade frente a gases, é comumente encontrado na crosta terrestre sob a forma de dióxido de titânio $\left(\mathrm{TiO}_{2}\right)$, chamado rutilo, na concentração de $0,6 \%$ sendo, com isso, o quarto elemento mais abundante dentre os metais estruturais, ficando atrás apenas de Al, Fe e Mg. Em relação aos metais, o titânio apresenta limitada solubilidade com estes, mas tem uma forte tendência a se combinar formando compostos intermetálicos frágeis (Braga, 2007).

O titânio apresenta alotropia. À temperatura ambiente, tem uma estrutura cristalina hexagonal compacta, chamada de fase alfa, a qual é estável até $882{ }^{\circ} \mathrm{C}$; acima desta temperatura a estrutura muda para cúbica de corpo centrado, um alótropo chamado de fase beta. O titânio alfa é o titânio cuja tensão de escoamento é aumentada pela adição de pequenas quantidades de elementos estabilizadores desta fase, como Al, Sn, Ni e Cu. As ligas nas quais este elemento apresenta estrutura alfa não têm sua dureza aumentada com o resfriamento, mas têm maior tensão que o Ti puro comercial. Ligas $\alpha+\beta \square$ são ligas de Ti com estrutura parcialmente $\alpha$ e parcialmente $\beta$ Elementos como Mo, $\mathrm{V}$ e Ta, quando adicionados ao Ti puro à temperatura ambiente, tendem a promover a presença da fase $\beta$. Uma liga importante do ponto de vista industrial é a Ti-6Al-4V, a qual contém, percentualmente em massa, $6 \%$ de $\mathrm{Al}$ e $4 \%$ de $\mathrm{V}$ e apresenta as duas fases estruturais. Elementos como o Mo e $\mathrm{V}$ são estabilizadores das ligas $\beta$, as quais são produzidas pela adição de grandes quantidades destes. As ligas $\beta$ $\square$ têm boa ductilidade e maleablidade quando não sofrem tratamento térmico (Braga, 2007).

Outra propriedade química muito importante é a elevada resistência à corrosão. O Ti e suas ligas têm excelente resistência à corrosão em água do mar e em soluções aquosas de cloretos. A maior parte das ligas é resistente a uma 
grande variedade de meios oxidantes como $\mathrm{HNO}_{3}$ e agentes redutores como $\mathrm{HCl}$ e $\mathrm{H}_{2} \mathrm{SO}_{4}$, quando estes se encontram diluídos. O titânio é, ainda, resistente à maior parte dos ácidos orgânicos.

O titânio não é tóxico, mas apesar de fisiologicamente inerte, o pó é carcinogênico. Outra conseqüência importante da sua atoxidade é a grande utilização deste metal e suas ligas como biomaterial devido à excelente resistência à corrosão, alta resistência específica e biocompatibilidade.

O titânio é um elemento muito reativo a altas temperaturas queimando na presença de oxigênio e por isso requer uma atmosfera inerte para seu processamento. O oxigênio se difunde no titânio rapidamente fragilizando o metal. O titânio puro possui bons níveis de soldabilidade e conformabilidade, sendo um elemento alotrópico que existe em mais de uma forma cristalográfica. A fase alfa é caracterizada pela estrutura hexagonal compacta (hc) à temperatura ambiente, podendo esta temperatura ser alterada através da adição de elementos de liga, dentre os quais se destacam Al, Sn, Ga, C, O e N. A fase beta é obtida a $883^{\circ} \mathrm{C}$, e possui uma estrutura cúbica de corpo centrado (ccc), e elementos estabilizadores da fase beta, como V, Mo, Ni, Cu, Fe, Cr e Ta diminuem esta temperatura (ASM, 1980). A manipulação das fases presentes através de adições de elementos de liga e de tratamentos termomecânicos constitui a base para o desenvolvimento de diversas ligas com diferentes propriedades (Weiss \& Semiatin, 1998).

\subsection{Ligas de titânio}

O titânio e suas ligas são amplamente utilizados como biomateriais e, além dos estudos de biocompatibilidade, o estudo de sua microestrutura é importante, pois permite conhecer o comportamento do mesmo em relação às suas propriedades mecânicas e, desta forma, fornecer informações importantes sobre o biomaterial a ser utilizado.

As ligas de titânio da classe $+\beta$ ão as mais comuns dentro dos vários tipos de ligas de titânio. A Ti-6Al-4V é a mais conhecida por possuir estruturas cristalinas hexagonal compacta (fase alfa) e cúbica de corpo centrado (beta) presentes a temperatura ambiente, combinando resistência mecânica e resistência a corrosão com conformabilidade e usinabilidade. Com excelentes 
combinações de resistência / peso e ótima resistência à corrosão, as ligas de titânio têm sido um excelente atrativo para aplicações nas indústrias aeronáutica e automobilística, e na fabricação de próteses ortopédicas (Jesuino et al., 2001).

$\mathrm{Na}$ Tabela 1 é possível observar algumas características do titânio e suas ligas.

Segundo Markovsky (1995), as ligas de titânio em seu estado bruto de fusão exibem grãos beta $(\beta)$ relativamente grandes, regiões com finas estruturas lamelares dentro dos grãos, e conseqüentemente, modestas propriedades mecânicas. Este mesmo autor afirma que, a aplicação de tratamentos térmicos rápidos reverte a estrutura das ligas de titânio, causando uma mudança no arranjo das fases dentro dos grãos beta, portanto, um aumento na resistência mecânica. A quebra da estrutura bruta de fusão através de tratamentos térmicos rápidos e subseqüente aumento de resistência mecânica, resulta da formação de martensíta, proveniente de resfriamentos rápidos a partir do campose $\alpha+\beta$. Manero et al.(2000), afirmam que a transformação da martensita está diretamente ligada a diversas reações que dependem da estrutura martensítica e da composição química da liga.

É de grande importância avaliar a ocorrência e a influência da martensita e de outras morfologias da fase $\alpha$, formadas dentro do campo $\alpha+\beta$ e $\beta$ sob diferentes ciclos de aquecimento, permanência à temperatura e resfriamentos rápidos, nas propriedades mecânicas e na resistência à corrosão. Os ensaios de tração monotônica, dureza e impacto Charpy bem como, a imersão do material com diferentes condições de tratamentos, em meios corrosivos artificiais, fornecem dados que direcionam à condição ótima dos tratamentos térmicos.

As avaliações das transformações ocorridas na microestrutura da liga, provenientes dos tratamentos térmicos, o comportamento da fratura e a resistência à corrosão, têm sido realizadas com o auxílio de técnicas de microscopia óptica sob luz polarizada e do processamento digital de imagens. Com os objetivos principais de identificar as fases presentes, suas morfologias e distribuições, o processamento digital de imagens serve como ferramenta de controle aos tratamentos térmicos 
TABELA 1. Classificação ASTM do Titânio e Ligas de Titânio (Melo, 2003)

\begin{tabular}{|c|c|c|c|c|c|c|c|c|c|c|c|c|}
\hline \multirow[b]{2}{*}{ Designação } & \multirow{2}{*}{$\begin{array}{l}\text { Resistência à } \\
\text { Tração (MPa) }\end{array}$} & \multirow{2}{*}{$\begin{array}{l}\text { Tensão de } \\
\text { Escoam. }(0,2 \%)(\mathrm{MPa})\end{array}$} & \multicolumn{5}{|c|}{ Limite de Impurezas Máx. (\% em Peso) } & \multicolumn{5}{|c|}{ Composição Nominal. (\% em Peso) } \\
\hline & & & $\mathrm{N}$ & c & $\mathrm{H}$ & $\mathrm{Fe}$ & 0 & $\mathrm{Al}$ & Sn & $\mathrm{Zr}$ & Mo & Outros \\
\hline \multicolumn{13}{|l|}{ Näo Ligado } \\
\hline ASTM Grau 1 & 240 & 170 & 0.03 & 0,10 & 0,015 & 0,20 & 0,18 & $\ldots$ & $\ldots$ & $\ldots$ & $\ldots$ & $\ldots$ \\
\hline ASTM Grau 2 & 340 & 280 & 0,03 & 0,10 & 0,015 & 0,30 & 0.25 & $\ldots$ & $\ldots$ & $\ldots$ & & $\ldots$ \\
\hline ASTM Grau 3 & 450 & 380 & 0.05 & 0,10 & 0.015 & 0,30 & 0,35 & $\ldots$ & $\ldots$ & $\ldots$ & $\ldots$ & $\ldots$ \\
\hline ASTM Grau 4 & 550 & 480 & 0,05 & 0,10 & 0,015 & 0,50 & 0,40 & $\ldots$ & $\ldots$ & $\ldots$ & $\ldots$ & $\ldots$ \\
\hline ASTM Grau 7 & 340 & 280 & 0.03 & 0,10 & 0.015 & 0,30 & 0.25 & $\ldots$ & $\ldots$ & $\ldots$ & $\ldots$ & $0.2 \mathrm{Pd}$ \\
\hline \multicolumn{13}{|l|}{ Ligas $\alpha$ e quase $\alpha$} \\
\hline $\mathrm{Ti}-0,3 \mathrm{Mo}-0,8 \mathrm{Ni}$ & 480 & 380 & 0,03 & 0,10 & 0.015 & 0,30 & 0.25 & $\ldots$ & $\ldots$ & $\ldots$ & 0.3 & $0,8 \mathrm{Ni}$ \\
\hline Ti-5 Al-2,5Sn & 790 & 780 & 0.05 & 0,08 & 0,02 & 0,50 & 0,20 & 5,0 & 2,5 & $\ldots$ & $\ldots$ & $\ldots$ \\
\hline Ti-5AI-2,5Sn ELI & 690 & 620 & 0.07 & 0,08 & 0,012 & 0,25 & 0,12 & 5,0 & 2,5 & $\ldots$ & $\ldots$ & $\ldots$ \\
\hline Ti-8Al-1Mo-1V & 900 & 830 & 0.05 & 0,08 & 0,015 & 0,30 & 0,12 & 8,0 & $\ldots$ & $\ldots$ & 1,0 & $1 \mathrm{~V}$ \\
\hline Ti-6Al-2Sn-4Zr-2Mo & 900 & 830 & 0.05 & 0,05 & 0.012 & 0,25 & 0,15 & 6.0 & 2,0 & 4,0 & 2,0 & $\ldots$ \\
\hline Ti-6Al-2Nb-1 Ta-0,8Mo & 790 & 690 & 0.02 & 0,03 & 0,012 & 0,12 & 0,10 & 6.0 & $\ldots$ & $\ldots$ & 1,0 & $2 \mathrm{Nb}, 1 \mathrm{Ta}$ \\
\hline $\mathrm{Ti}-2,25 \mathrm{Al}-11 \mathrm{Sn}-5 \mathrm{Zr}-1 \mathrm{Mo}$ & 1000 & 900 & 0.04 & 0,04 & 0,008 & 0,12 & 0,17 & 2,25 & 11,0 & 5,0 & 1,0 & $0,2 \mathrm{Si}$ \\
\hline Ti-5AI-5Sn-2Zr-2Mo & 900 & 830 & 0.03 & 0,05 & 0,012 & 0,15 & 0.13 & 5,0 & 5,0 & 2,0 & 2,0 & $0,25 \mathrm{Si}$ \\
\hline \multicolumn{13}{|l|}{ Ligas $\alpha+\beta$} \\
\hline Ti- $6 \mathrm{Al}-4 \mathrm{~V}$ & 900 & 830 & 0,05 & 0,10 & 0,012 & 0,30 & 0.20 & 6.0 & $\ldots$ & $\ldots$ & $\ldots$ & $4 \mathrm{~V}$ \\
\hline Ti-6Al-4V ELI & 830 & 760 & 0.05 & 0,08 & 0.012 & 0,25 & 0,13 & 6.0 & $\ldots$ & $\ldots$ & $\ldots$ & $4 \mathrm{~V}$ \\
\hline Ti-6AI-6V $-2 \mathrm{Sn}$ & 1030 & 970 & 0,04 & 0,05 & 0.015 & 1,0 & 0.20 & 6,0 & 2,0 & $\ldots$ & & $0,75 \mathrm{Cu}, 6 \mathrm{~V}$ \\
\hline Ti-8Mn & 860 & 760 & 0.05 & 0,08 & 0.015 & 0,50 & 0.20 & $\cdots$ & $\cdots$ & $\ldots$ & $\ldots$ & $8 \mathrm{Mn}$ \\
\hline TiTi-7Al-4Mo & 1030 & 970 & 0.05 & 0,10 & 0,013 & 0,30 & 0.20 & 7,0 & $\ldots$ & $\ldots$ & 4,0 & $\ldots$ \\
\hline Ti-6AI-2Sn-4Zr-6Mo & 1170 & 1100 & 0.04 & 0,04 & 0,012 & 0,15 & 0.15 & 6,0 & 2,0 & 4,0 & 6,0 & $\ldots$ \\
\hline Ti-5 Al-2Sn-2Zr-4Mo-4Cr & 1125 & 1055 & 0.04 & 0,05 & 0.012 & 0,30 & 0,13 & 5,0 & 2,0 & 2,0 & 4,0 & $4 \mathrm{Cr}$ \\
\hline Ti-6 Al-2Sn-2Zr-4Mo-2Cr & 1030 & 970 & 0,03 & 0,05 & 0.012 & 0,25 & 0,14 & 5,7 & 2,0 & 2,0 & 2,0 & $2 \mathrm{Cr}, 0,25 \mathrm{Si}$ \\
\hline Ti-3Al-2,5V & 620 & 520 & 0.015 & 0,05 & 0,015 & 0,30 & 0.12 & 3,0 & $\cdots$ & $\ldots$ & $\cdots$ & $2,5 \mathrm{~V}$ \\
\hline \multicolumn{13}{|l|}{ Ligas $\beta$} \\
\hline Ti-10V-2Fe-3Al & 1170 & 1100 & 0,05 & 0,05 & 0,015 & 2,5 & 0.16 & 3,0 & $\ldots$ & $\ldots$ & $\ldots$ & $10 \mathrm{~V}$ \\
\hline $\mathrm{Ti}-13 \mathrm{~V}-11 \mathrm{Cr}-3 \mathrm{Al}$ & 1170 & 1100 & 0.05 & 0,05 & 0,025 & 0,35 & 0.17 & 3,0 & $\ldots$ & $\ldots$ & $\ldots$ & $11 \mathrm{Cr}, 13 \mathrm{~V}$ \\
\hline Ti-8Mo-8V-2Fe-3AI & 1170 & 1100 & 0,05 & 0,05 & 0,015 & 2,5 & 0,17 & 3,0 & $\ldots$ & $\ldots$ & 8.0 & $8 \mathrm{~V}$ \\
\hline Ti-3AI-8V-8Cr-4Mo4Zr & 900 & 830 & 0.03 & 0,05 & 0.020 & 0,25 & 0,12 & 3,0 & $\ldots$ & 4,0 & 4,0 & $8 \mathrm{Cr}, 8 \mathrm{~V}$ \\
\hline $\mathrm{Ti}-11,5 \mathrm{Mo}-6 \mathrm{Zr}-4,5 \mathrm{Sn}$ & 690 & 620 & 0,05 & 0,10 & 0,020 & 0,35 & 0,18 & $\ldots$ & 4,5 & 6,0 & 11,5 & $\ldots$ \\
\hline
\end{tabular}

BS: ELI (Extra Low Interstitials) Ligas com baixos teores de elementos intersticiais. 
O titânio forma compostos intermetálicos com o alumínio. Extensas pesquisas são feitas com ligas de TiAl de duas fases, consistindo de TiAl e pequena quantidade de $\mathrm{Ti}_{3} \mathrm{Al}$. O constituinte da fase maior, é chamado de fase gamma (CFC)(Yamagushi et al.,1996).

\subsection{Biomateriais}

A área de biomateriais ganhou reconhecimento após o primeiro encontro em biomateriais realizado em Clemson University, Carolina do Sul em 1969 e continua a receber atenção substancial desde então (Geetha et.al.,2009).

Os biomateriais são substâncias de origem natural ou sintética que podem ser utilizadas por tempo indeterminado na substituição total ou parcial de sistemas biológicos. Os benefícios do uso dos biomateriais são inúmeros, como na reparação de partes do corpo humano. Eles podem, por exemplo, auxiliar na recuperação de um tecido lesionado e com isso melhorar a qualidade de vida do ser humano (Oliveira \& Nanci, 2004).

\subsubsection{Aplicações dos biomateriais}

Os biomateriais são utilizados em diferentes partes do corpo humano: como válvulas artificiais do coração, stents (endopróteses extensíveis), em vasos sangüíneos, como implante (em substituição de ombros, joelhos, quadris, cotovelos) e em estruturas orodental (Geetha et.al.,2009).

As articulações humanas sofrem com as doenças degenerativas, tais como artrite, levando a dor ou a perda de função. As doenças degenerativas levam à degradação das propriedades mecânicas dos ossos, em função da excessiva carga ou ausência de processos biológicos normais de auto-cura. Estima-se que $90 \%$ da população mundial com mais de 40 anos sofre com esses tipos de doenças degenerativas (Geetha et.al.,2009).

A população idosa mundial tem aumentado enormemente nos últimos anos e estima-se que a mesma aumente em sete vezes nos últimos 8 anos (de 4,9 milhões em 2002 para 39,7 milhões até 2010). Os problemas de ordem músculo-esquelético são os mais presentes na saúde humana com gastos estimados em cerca de 254 bilhões de dólares para a sociedade mundial até os 
dias de hoje. Os biomateriais artificiais têm sido uma excelente solução na área de implantes cirúrgicos já que auxiliam na restauração da função de estruturas comprometidas. Outra questão é a do reimplante devido ao aumento da longevidade na população humana (no caso de implantes ortopédicos o tempo de vida útil do implante é de cerca de 15 anos) (Geetha et.al.,2009).

Diante deste quadro um grande aumento significativo na fabricação de implantes é esperado nos próximos anos. A procura de implantes tem sido crescente e leva à necessidade do estudo e desenvolvimento dos biomateriais.

\subsubsection{Características esperadas dos biomateriais}

Os biomateriais possuem a característica fundamental da biocompatibilidade, ou seja, são inertes biologicamente, não causando nenhum efeito nocivo ao organismo. Eles atendem ao requisito de funcionalidade para 0 qual foram desenvolvidos, provocando, assim, o mínimo de reações alérgicas ou inflamatórias, quando em contato com tecidos vivos ou fluidos orgânicos (Niinomi, 1998).

Especificamente os materiais utilizados para implantes ortopédicos devem possuir excelente biocompatibilidade, alta resistência à corrosão no organismo, combinação de alta resistência e baixo módulo de elasticidade, alta resistência à fadiga e ao desgaste, alta ductilidade e não apresentar citotoxidade. Atualmente, os materiais utilizados para essas aplicações são o aço inoxidável 316L, ligas cobalto-cromo e ligas a base de titânio. Infelizmente, estes materiais têm apresentado falhas após uma utilização prolongada devido a diversos razões, tais como: elevada resistência do módulo de elasticidade, comparada com a resistência do osso, baixo desgaste, baixa resistência à corrosão e falta de biocompatibilidade (Geetha et.al.,2009).

Materiais cirúrgicos compostos por materiais como ouro, prata e açocarbono ao vanádio já foram utilizados na confecção de peças destinadas a implantes, porém as ligas de cobalto-cromo, titânio e os aços inoxidáveis são os materiais que apresentaram os melhores resultados e, por isso, continuam a ser muito utilizados com essa função (INOX, 2003).

O estudo da microestrutura de materiais a serem utilizados como biomateriais é importante, pois permite conhecer seu comportamento em relação 
às suas propriedades mecânicas, como prováveis fraturas, permitindo facilitar estudos da aplicação desses materiais in vivo, já que os parâmetros mais importantes na determinação de biomateriais adequados para a fabricação de implantes são a biocompatibilidade, módulo de elasticidade e resistência à corrosão. A sua substituição e recuperação de partes do corpo por materiais, englobam aspectos como a reação do tecido ao implante, corrosão do implante, capacidade funcional e de projeto e implicações cirúrgicas (Wang, 1996).

Embora vários materiais sejam atualmente utilizados como biomateriais, as ligas de titânio são a primeira escolha para a maioria das aplicações.

\subsubsection{Requisitos necessários a um biomaterial}

A concepção e seleção do biomaterial a ser utilizado depende de sua aplicação médica. O desenvolvimento de novos biomateriais é um esforço interdisciplinar e, muitas vezes, exige um esforço e colaboração entre cientistas, engenheiros, biomédicos, patologistas e clínicos. Para que o biomaterial tenha um período mais longo como implante sem rejeição, deve também apresentar boas propriedades mecânicas.

Algumas das propriedades mecânicas que são de importância primordial são: dureza, resistência à tração, módulo de elasticidade e alongamento. A resposta do material às repetidas cargas cíclicas é determinado pela resistência à fadiga do material. Esta propriedade determina o sucesso à longo prazo do implante submetido a cargas cíclicas.

Se um implante apresentar fratura decorrente da consolidação ou de ajustes nas propriedades mecânicas entre o osso e o implante, pode-se dizer que há incompatibilidade biomecânica. É esperado do material colocado para substituir o osso que tenha um módulo de elasticidade equivalente ao do osso. $\mathrm{O}$ módulo de elasticidade do osso varia na magnitude de 4 a $30 \mathrm{GPa}$, dependendo do tipo de osso e da direção de medição. Os implantes atuais possuem maior rigidez quando comparado ao osso. Isto provoca um estresse que é transferido aos ossos adjacentes, resultando na reabsorção óssea ao redor do implante e, conseqüentemente, no afrouxamento da implantação. Esta incompatibilidade biomecânica leva à morte as células ósseas e é denominado efeito "stress 
shielding". Para evitar o afrouxamento dos implantes e maior durabilidade, o material utilizado deve possuir uma excelente combinação de alta resistência e baixo módulo de elasticidade (Katz, 1980).

Espera-se dos materiais utilizados como implante que sejam atóxicos e não causem inflamações ou reações alérgicas no organismo humano. O sucesso dos biomateriais depende essencialmente da reação do corpo humano com o implante, ou seja, a biocompatibilidade (Geetha et.al.,2009).

A baixa resistência à corrosão e desgaste dos implantes ao fluído do corpo resulta na liberação de íons metálicos não compatíveis provenientes do implante. Os íons liberados podem causar alergia e reações tóxicas. O período de vida do material é determinado principalmente pela sua resistência à corrosão e resistência ao desgaste. A baixa resistência e desgaste também resultam no afrouxamento do implante, causando diversas reações nos tecidos próximos ao implante. Assim, o desenvolvimento de implantes com alta resistência à corrosão e ao desgaste é de primordial importância para a longevidade do material no organismo (Geetha et.al. ,2009).

A Osteointegração em implantes é desejada, pois a incapacidade de um implante para a integração com a superfície óssea adjacente e de outros tecidos resulta no afrouxamento do implante. Um tecido fibroso é formado entre o osso e o implante, se o implante não está bem integrado com o osso. Assim, um material com superfície adequada é extremamente essencial para o implante se integrar bem com o osso adjacente. A composição química da superfície, a rugosidade superficial e a topografia da superfície têm um papel importante no desenvolvimento de boas osteointegrações.

\subsubsection{Utilização dos biomateriais e seus efeitos}

Atualmente entre os materiais utilizados para implantes cirúrgicos incluem-se o aço inoxidável 316L (316L SS), ligas de cobalto-cromo (Co-Cr) e o titânio e suas ligas.

Elementos como o Ni, Cr e Co são liberados para o organismo, devido à corrosão provocada pelo meio biológico, a partir do aço inoxidável e das ligas cobalto-cromo. Os efeitos tóxicos dos metais, $\mathrm{Ni}$, Co e $\mathrm{Cr}$, liberados a partir de próteses em implantes têm sido observados. Doenças de pele como a dermatite 
relacionadas à toxicidade do $\mathrm{Ni}$ foram relatadas e numerosos estudos em animais demonstraram carcinogenicidade, devido à presença de Co. Além disso, tanto o $316 \mathrm{~L} \mathrm{SS}$ e as ligas de Co-Cr possuem módulo de elasticidade muito mais alto que os ossos, provocando estresse ósseo, transferência de reabsorção óssea e afrouxamento do implante, após alguns anos de implantação.

Na FIGURA 1 é mostrado o módulo de elasticidade de diferentes ligas utilizadas como biomaterial em comparação com os ossos.

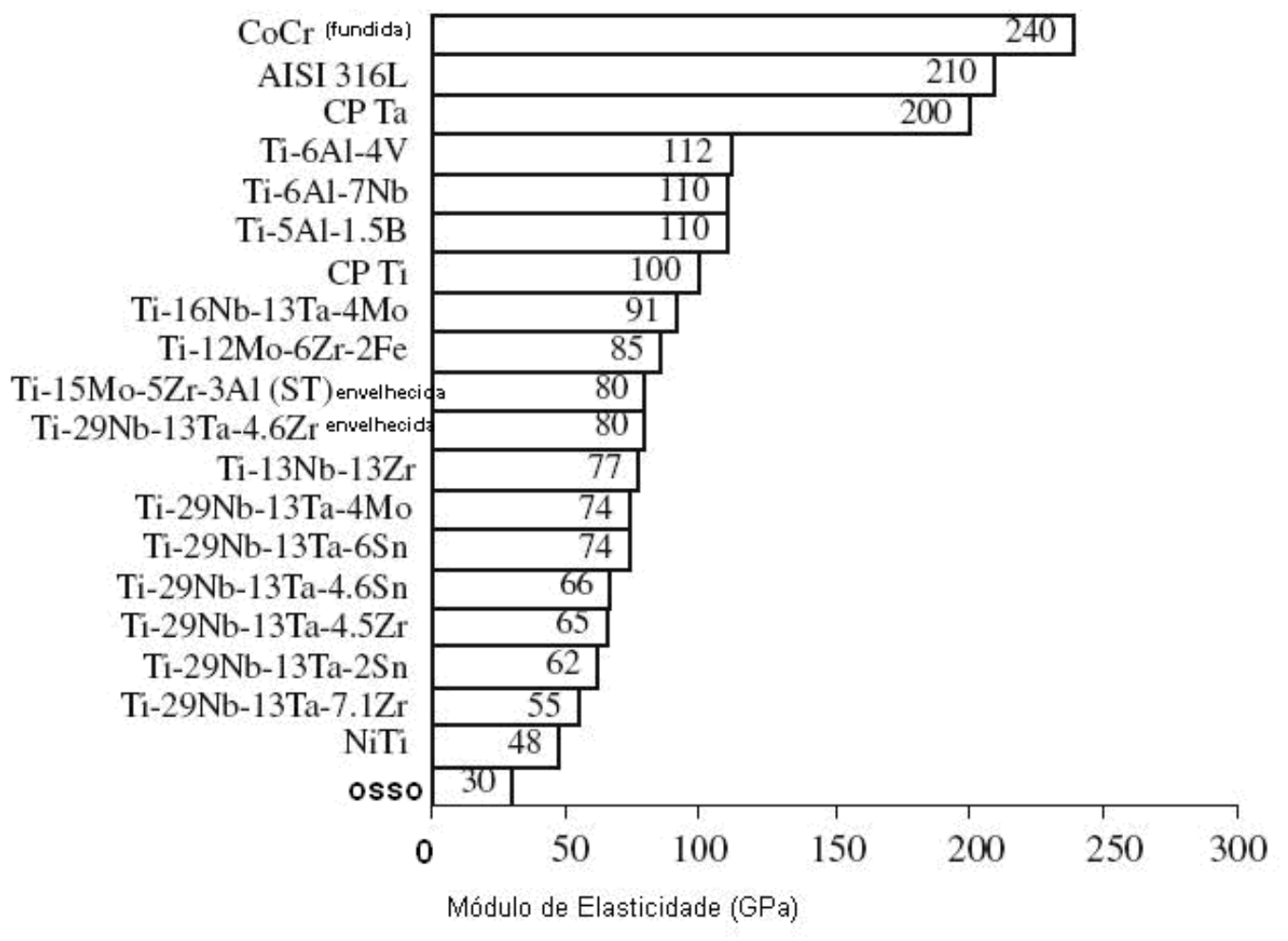

FIGURA 1: Módulo de Elasticidade de alguns biomateriais.

O titânio é reconhecido como um dos materiais mais biocompatíveis devido a sua habilidade de formar uma camada de óxido de titânio estável em sua superfície. Esta camada formada permite uma excelente osteointegração com os ossos e é capaz de formar uma camada rica em fosfato de cálcio, como apresentado na FIGURA 2, muito similar à hidroxiapatita (fosfato de cálcio cristalino), a qual também previne a corrosão. 


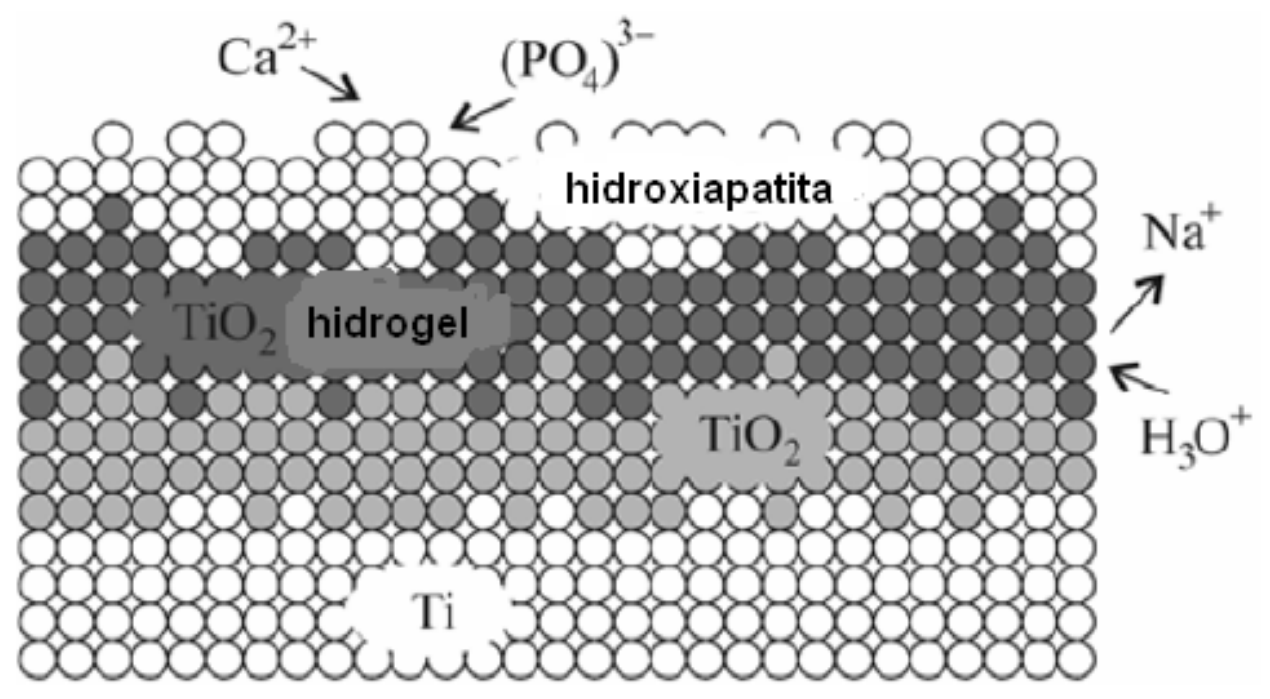

FIGURA 2: Formação da camada de dióxido de titânio e hidroxiapatita sobre biomaterial à base de titânio (Balazic et al, 2007).

A boa resistência à corrosão do titânio depende da formação de óxido de titânio, como exemplificado acima, com espessura e profundidade de $10 \mathrm{~nm}$. Após o implante a base de titânio ser implantado o material imediatamente reage com os fluidos corporais, que consiste em moléculas de água, íons dissolvidos e proteínas, como mostra a FIGURA 3.

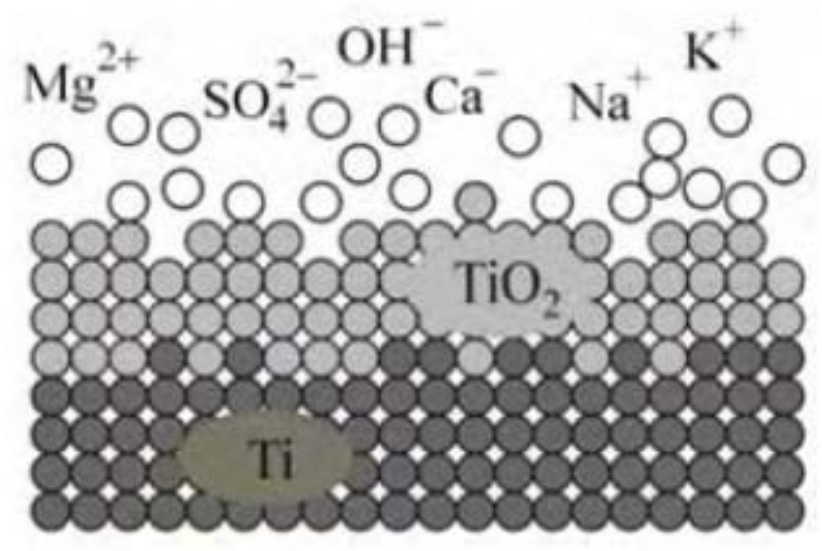

FIGURA 3: Interação entre o titânio e os fluidos corporais (Balazic et al, 2007).

Morais et al. (2007) realizaram mini-implantes ortodônticos de Ti-6Al-4V em coelhos para observarem a liberação de íons metálicos devido à corrosão in 
vivo da liga em fluidos corporais. O objetivo do estudo foi determinar as concentrações de titânio, alumínio e vanádio nos órgãos de coelhos (rins, fígado e pulmões), após a inserção de mini-implantes ortodônticos fabricados a partir da liga Ti-6Al-4V. Dezoito coelhos da raça Nova Zelândia tiveram quatro miniimplantes inseridos em sua tíbia esquerda e cinco coelhos foram usados como controle. Após 1, 4 e 12 semanas os coelhos foram submetidos à eutanásia, os tecidos selecionados foram removidos e preparados para análise por espectroscopia de absorção atômica com forno de grafite. Quantidades variadas Ti, Al e $V$ foram detectadas nos grupos testados, comprovando que existe liberação de íons metálicos por mini-implantes ortodônticos de Ti-6Al-4V. Apesar da tendência de liberação de íons pela liga de titânio, as quantidades de metais detectadas foram extremamente baixas. Os autores concluíram que os miniimplantes ortodônticos de Ti-6Al-4V podem ser usados com segurança como dispositivos auxiliares de ancoragem ortodôntica.

\subsubsection{Aplicações biomédicas do titânio e suas ligas}

A resistência a corrosão do titânio e suas ligas é obtida em função da formação de óxidos estáveis em sua superfície, porém esta resistência pode ser afetada se estiver em meio nos quais existam fluídos fisiológicos à temperatura do corpo humano. Por outro lado, apenas a liga Ti-6Al-4V e quatro tipos de titânio puro estão disponíveis comercialmente e são habitualmente utilizadas no corpo humano. O titânio puro é utilizado nos casos onde há baixa exigência de carga mecânica no implante, enquanto a liga Ti-6Al-4V é utilizada quando há a solicitação de maiores cargas mecânicas no implante (Gurappa, 2002).

Atualmente, a liga de Ti-6Al-4V apresenta a melhor combinação de propriedades para materiais de implante estrutural, como é evidenciado pelo seu potencial máximo a degradação, mínima taxa de corrosão, alta resistência a microfissuras e ranhuras (Gurappa, 2002).

Nan et al. (1996) estudaram ligas de titânio Ti-6Al-4V recobertas com uma camada de nitreto de titânio (TiN), testadas em solução de Ringer. A solução de Ringer é utilizada para simular os fluídos fisiológicos humanos. Em sua 
composição típica temos: $8,5 \mathrm{~g} / \mathrm{L}$ de $\mathrm{NaCl}, 0,25 \mathrm{~g} / \mathrm{L}$ de $\mathrm{KCl}, 0,22 \mathrm{~g} / \mathrm{L}$ de $\mathrm{CaCl}_{2}$, $0,15 \mathrm{~g} / \mathrm{L}$ de $\mathrm{NaHCO}_{3}$, em meio aquoso (Duisabeau et al. ,2004).

Nas amostras recobertas e não recobertas foram realizados estudos comparativos por Microscopia Eletrônica de Varredura (MEV), associando-se à Espectroscopia de Energia Dispersiva (EDS) e Microscopia Eletrônica de Transmissão (MET) para se avaliar os diferentes mecanismos de fadiga das amostras. Por Difração de Raios X (DRX) observaram a migração do elemento alumínio da matriz para a camada de TiN. Concluíram que o recobrimento da liga com filme de TiN melhorou as propriedades de fadiga sob baixa tensão.

Os mecanismos de deformação da liga de titânio Ti-6Al-4V com microestrutura martensítica submetida a uma fadiga de baixo ciclo foram estudadas por Manero et al. (2000), os quais utilizando-se das técnicas de microdifração eletrônica e raios $X$ mostraram que quando uma liga de titânio Ti6Al-4V com uma estrutura martensítica $\alpha$ é deformada ciclicamente, diversos modos de deformação plástica podem ser observados. Um grande número de maclas de deformação foi formado com um plano de hábito $\mathrm{K} 1=\{1011\} \mathrm{e}$ ocorrendo também a formação de discordâncias do tipo (a) e (c+a) no interior das maclas.

Os mecanismos de deformação em amostras policristalinas de diferentes ligas de titânio (T40, T60 e Ti-6Al-4V) foram estudados por Zaefferer (2003) via MET. O objetivo neste estudo foi o de se entender em detalhes quais os sistemas de escorregamento que são ativados nestas ligas e como as texturas de deformação estão relacionadas a elas. Foram colhidas informações sobre os valores críticos da tensão de cisalhamento $\quad\left(\tau^{\prime}\right.$ c relativo ao sistema <a> do plano prismático) de diferentes sistemas de deformação. Em amostras da liga de titânio Ti-6Al-4V observou-se que a $\tau_{c}$ para os planos basal e piramidal <a> não é, significantemente, maior que para o plano prismático <a>. O alto teor de oxigênio presente nesta liga pode ser responsável pela redução do plano $\tau_{c}^{\prime}$ basal comparado ao titânio puro.

Duisabeau et al. (2004) utilizaram as técnicas de MEV e DRX no estudo de dois diferentes biomateriais, liga de titânio Ti-6Al-4V e o aço inoxidável 316L SS. Observaram o comportamento do desgaste destes materiais quando submetidos a um meio fisiológico artificial. Testes realizados no ambiente 
proposto foram tomados como referência para os estudos dos danos pelo desgaste por corrosão. No início dos experimentos em ambas as atmosferas, o regime de desgaste correspondeu às condições utilizadas. A introdução da solução de Ringer reduziu a interação entre as duas superfícies em função da dissipação da energia e a transformação da fase martensítica induzida por atrito na amostra de aço inoxidável. 


\section{METALURGIA FÍSICA DA LIGA Ti-6Al-4V}

A metalurgia física trata das questões relacionadas ao comportamento das propriedades físicas nos metais e a forma como estes são afetados em sua composição, quando submetidos a fatores como trabalho mecânico e tratamento térmico.

\subsection{Aspectos básicos da metalurgia do titânio}

As diferentes microestruturas que apresentam as ligas de titânio é um resultado do fenômeno de alotropia. O titânio sofre uma transformação alotrópica a $882^{\circ} \mathrm{C}$. Abaixo desta temperatura o titânio exibe uma estrutura cristalina hexagonal compacta ( $\mathrm{hc}$ ), conhecida como fase $\alpha$, enquanto que em temperatura mais elevada, tem uma estrutura cúbica de corpo centrado (ccc), a fase Esta última permanece estável até o ponto de fusão a $1670^{\circ} \mathrm{C}$. Como o titânio é um metal de transição, com uma camada incompleta, pode formar soluções sólidas com vários elementos e ter o equilíbrio das fases $\alpha$ e $\beta$ modificados a diferentes temperaturas (Balazic et al., 2007).

Os elementos presentes em ligas de titânio dividem-se em três classes: estabilizadores- $\alpha$, estabilizadores- $\beta$ e neutros. Enquanto os elementos definidos como estabilizadores- $\alpha$ conduzem a um aumento da temperatura de transformação alotrópica, outros elementos, descritos como estabilizadores- $\beta$ provocam uma diminuição em tal temperatura. Quando uma transformação eutectóide ocorre, este estabilizador- $\beta$ é denominado estabilizador- $\beta$ eutectóide, caso contrário, ele é chamado de estabilizador- $\beta$ isomorfo. Se não for observada uma mudança significativa na temperatura de transformação alotrópica, o elemento ligante é classificado como elemento neutro (Lütjering \& Williams, 2003; Peters et al., 2003). A Figura 4 mostra um esquema representativo dos tipos de diagrama de fases entre titânio e seus elementos de ligas.

Como resultado obteve-se uma enorme gama de composição possível para as ligas de titânio. Entre os elementos estabilizadores- $\alpha$ temos os metais dos 
grupos IIIA e IVA (Al e $\mathrm{Ga}$ ) e os elementos intersticiais $\mathrm{C}, \mathrm{N}$ e O. Como elementos estabilizadores- $\beta$ têm-se os elementos de transição ( $\mathrm{V}, \mathrm{Ta}, \mathrm{Nb}, \mathrm{Mo}, \mathrm{Mg}, \mathrm{Cu}, \mathrm{Cr}$ e $\mathrm{Fe}$ ) e os metais nobres.

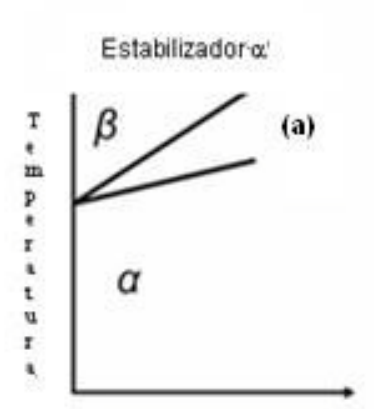

Гi

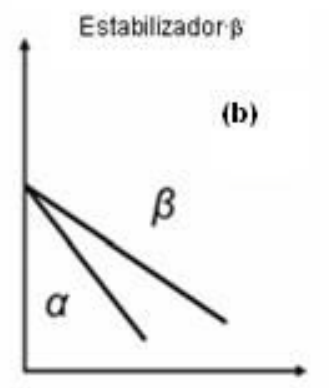

$\mathrm{Ti}$

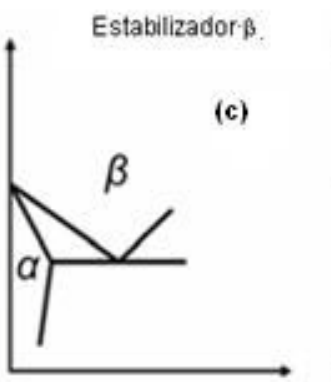

$\mathrm{Ti}$

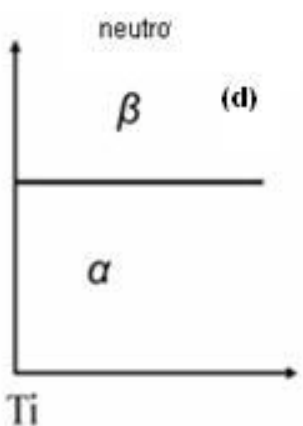

$\mathrm{Ti}$

Quantidade·do·elemento·titânio

FIGURA 4: Representação esquemática dos diagramas de fase entre o titânio e seus elementos de liga: (a) estabilizador $\alpha$, (b) estabilizador $\beta$ tipo isomorfo, (c) estabilizador $\beta$ tipo eutetóide e (d) neutro (Balazic et al., 2007).

A adição de elementos estabilizadores $\alpha$ e $\beta$ ao titânio dá origem a um campo no diagrama fase em que ambas as fases $\alpha$ e $\beta$ podem coexistir. Ligas de titânio exibem uma variedade de propriedades, que estão ligadas a sua composição química e ao processamento metalúrgico. De acordo com a natureza da sua microestrutura, ligas de titânio podem ser divididas como ligas $\alpha, \beta$ e ligas $\alpha+\beta$. As ligas do tipo beta podem ser classificadas como liga $\beta$ e liga $\beta$ metaestável (Balazic et al, 2007).

As ligas de titânio alfa são especialmente formadas por titânio puro e ligas com elementos estabilizadores- $\alpha$, que apresentam apenas fase $\alpha$ à temperatura ambiente. Essas ligas apresentam alta resistência à fluência e são, portanto, adequadas para se trabalhar em altas temperaturas, uma vez que as fases metaestáveis não se mantêm após o resfriamento a partir de altas temperaturas, não sendo possíveis grandes modificações na microestrutura e nas propriedades mecânicas, quando tratamentos térmicos a altas temperaturas são realizados. Como a fase a não está sujeita a transição dúctil-frágil, estas ligas são adequadas para tratamentos a temperaturas muito baixas. Em relação às 
propriedades mecânicas e metalúrgicas, as ligas $\alpha$ apresentam um razoável nível de resistência mecânica, alto módulo de elasticidade, boa tenacidade à fratura e baixa forjabilidade, o que é devido à estrutura cristalina do tipo hexagonal compacta.

As ligas de titânio Beta são obtidas quando uma grande quantidade de elemento estabilizador- $\beta$ é adicionada ao titânio, o qual diminui a temperatura de transformação alotrópica (transição $\alpha / \beta$ ) do titânio. Se a quantidade de estabilizador- $\beta$ é elevada o suficiente para reduzir a temperatura de início da transformação martensítica (MS), para uma temperatura inferior à temperatura ambiente, a nucleação e o crescimento da fase a será muito restrita e, portanto, a fase $\beta$ metaestável será mantida à temperatura ambiente sob resfriamento rápido como demonstrado na Figura 5. Este tipo de liga de titânio pode ser endurecido utilizando tratamento térmico. Ligas de titânio $\beta$ são muito frágeis em temperaturas criogênicas e não são adequadas para aplicação em altas temperaturas, por possuírem baixa resistência à fluência (Balazic et al., 2007).

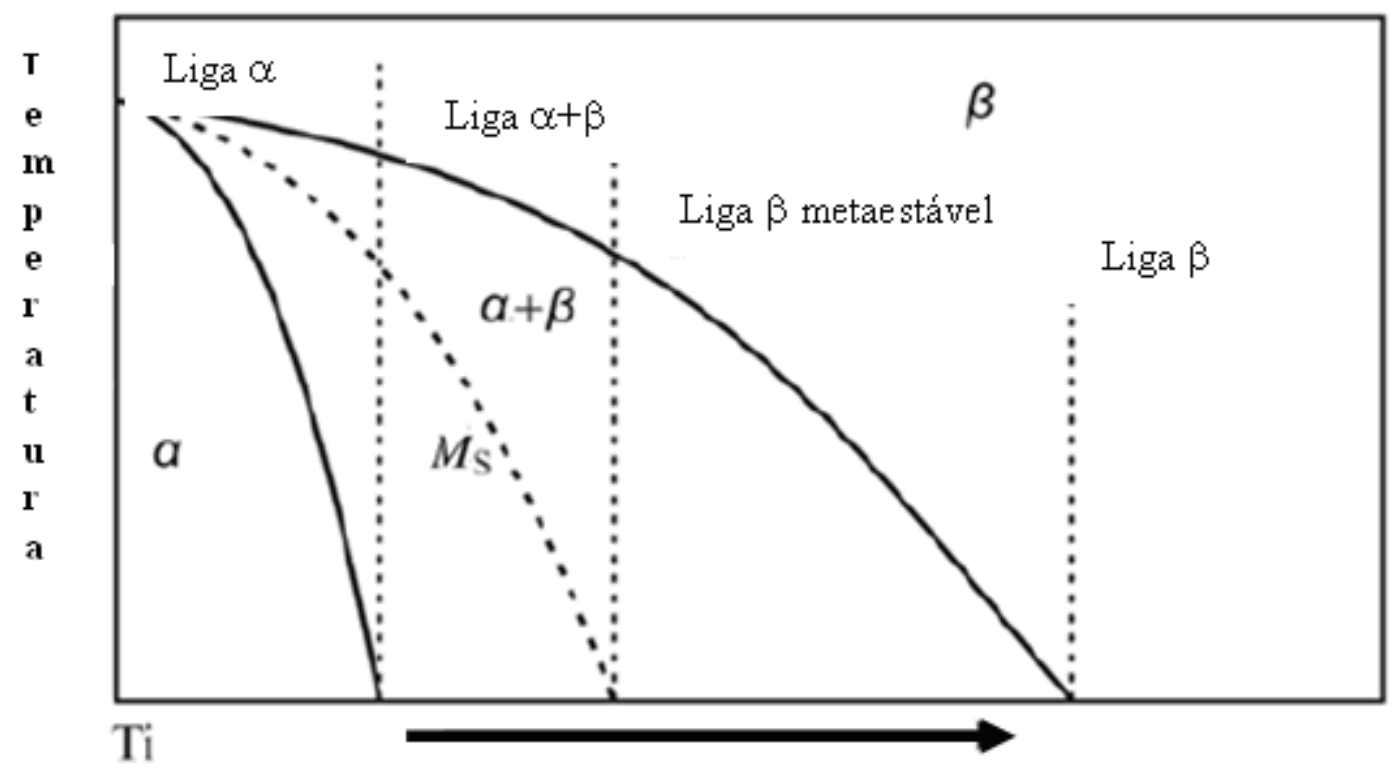

Quantidade de $\beta$-estabilizador

FIGURA 5: Diagrama parcial das fases do titânio e elementos $\beta$-estabilizadores (Balazic et al., 2007) 
As ligas $\alpha+\beta$ incluem ligas com quantidade suficiente de estabilizadores $\alpha$ e $\beta$ para expandir o campo $\alpha+\beta$ a temperatura ambiente (Peters et al., 2003). A combinação das fases $\alpha$ e $\beta$ permitem obter um balanço ótimo de propriedades. As características de ambas as fasesa e $\beta$ pode $\mathrm{m}$ ser adaptadas pela aplicação correta de tratamentos térmicos e termo-mecânicos. Uma significativa variedade de microestruturas pode ser obtida quando comparadas às ligas do tipœ. A liga de Ti-6Al-4V é um exemplo de liga do+\$ipdDevidoà sua grande disponibilidade, boa usinagem e elevado comportamento mecânico a baixas temperaturas, essa liga é a composição mais comum entre as ligas de titânio e é utilizada amplamente como um biomaterial, principalmente em implantes ortopédicos.

\subsection{A liga de titânio Ti-6Al-4V}

Dentre as ligas de titânio, a liga Ti-6Al-4V é a mais utilizada comercialmente, possuindo densidade $4,43 \mathrm{~g} / \mathrm{cm}^{3}$, com excelente resistência à propagação de trincas, podendo ser submetida a diferentes processos de deformação para fabricação de peças. As propriedades mecânicas da liga Ti-6Al$4 \mathrm{~V}$ dependem da direção que se está analisando, uma vez que tanto a fase como a fase $\beta$ ão cristalinas e ambas possuem tendência em recristalizar com microestrutura texturada.

A crescente utilização dos biomateriais em sistemas biológicos tem levado ao estudo e desenvolvimento de materiais que atendam de forma mais eficiente este mercado.

A FIGURA 6 mostra o diagrama pseudobinário de fases para a liga Ti$6 \mathrm{Al}-4 \mathrm{~V}$, onde podemos observar as regiões da formação da fase beta $(\beta)$, da fase alfa $(\alpha)$, da bifásica $(\alpha+\beta)$, da trifásica $(\alpha+\beta+\gamma)$ e da bifásica $(\beta+\gamma)$.

As ligas de titânio são materiais extremamente utilizados para aplicações ortopédicas, devido ao seu baixo módulo de elasticidade comparado com ligas de Co-Cr-Mo, superior biocompatibilidade e resistência à corrosão (Long \& Rach, 1998). Recentemente foram obtidas ligas biomédicas, com melhor biocompatibilidade e um módulo reduzido em ligas de titânio baseadas em 
microestruturas metaestáveis $\beta$ ou martenśtica $\alpha+\beta$. A resistência das ligas de titânio $\beta$ mostram uma melhoria quando comparada às ligas $\alpha+\beta$.

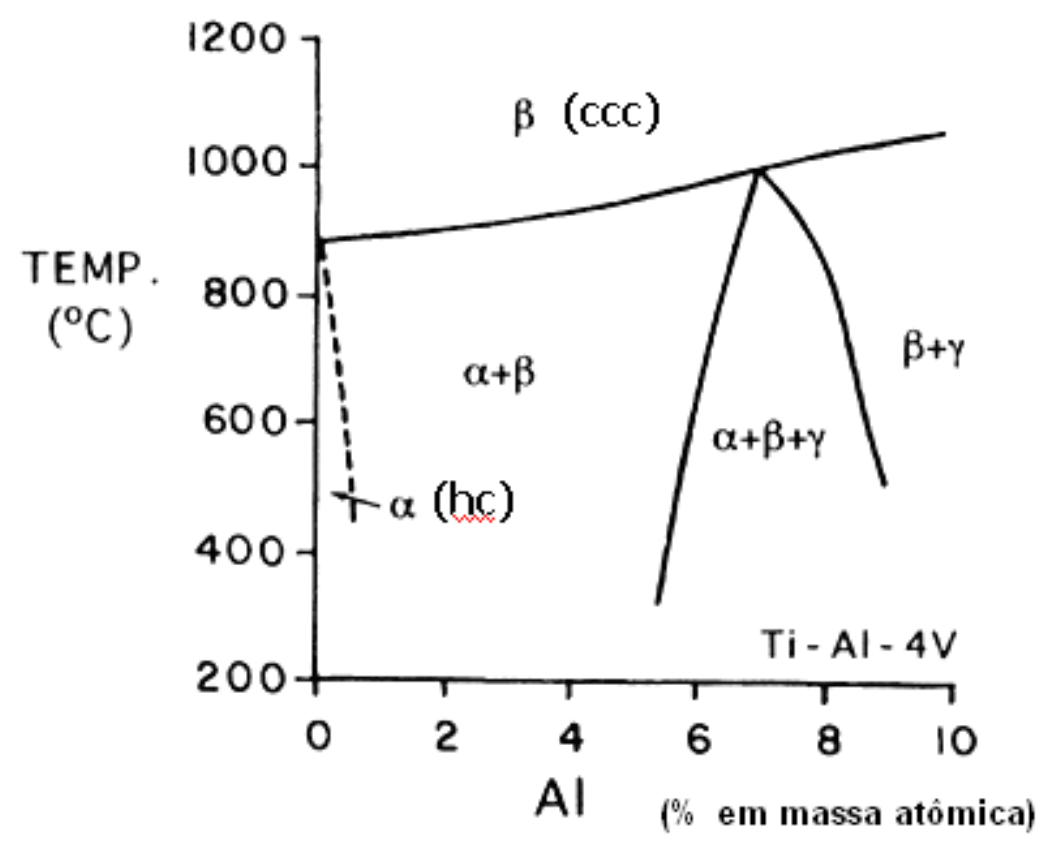

FIGURA 6: Diagrama de fases pseudobinário para a liga Ti-6Al-4V.

Eisenbarth et al.(2004) estudaram comparativamente ligas de titânio $\alpha+\beta$ e $\beta$ para apliçães biomé dicas e observaram que as ligas de titâpio apresentaram melhores propriedades mecânicas como resistência a abrasão, elasticidade elevada e uma excelente plasticidade a quente e a frio, o que implica em aplicações promissoras em implantes de juntas ortopédicas.

As ligas de titâniß formam uma das mais classes de materiais com respeito ao processamento, microestrutura e propriedades mecânicas. Estas ligas incluem ligaß estável, $\beta$ metaestável, $\alpha \quad+\beta$ rica em $\beta$. Estas ligas oferecem uma alternativa atraente para ligas $\alpha+\beta$, devido à melhor manipulação térmica e maior ductilidade, em função da sua estrutura cúbica de corpo centrado. Além disso, possuem superior resistência à fadiga, quando comparadas as ligas $\alpha+\beta$. Estas ligas podem ser encontradas em aplicações aeroespaciais, metalurgia do pó, automotivas, implantes ortopédicos, entre outros (Weiss \& Semiatin, 1998). 
Ligas de titânio $\beta$ metaestáveis são obtidas tipicamente em tratamento térmico para precipitar fases adicionais. Os tratamentos aplicados à fase alfa e/ou intermetálicos melhoram a resistência à fratura. A morfologia, tamanho e distribuição desses precipitados determinam, em grande parte, as propriedades mecânicas da liga. A precipitação homogênea de fase alfa fina em ligas de titânio beta metaestáveis leva ao aumento da tensão de escoamento e ductilidade. Recentemente, os efeitos do envelhecimento duplex com ou sem trabalho a frio tem sido investigados. Esses tratamentos termomecânicos mostram-se promissores no controle da microestrutura final da liga de titânio beta com melhoria das propriedades mecânicas (Long \& Rach, 1998; Martin, 1998).

Nas ligas de titânio $(\alpha+\beta)$, o parâmetro microestrutural mais importante para a determinação das propriedades mecânicas é a fração volumétrica da fase alfa. Com a diminuição da fração volumétrica da fase alfa, ocorre um aumento na ductilidade, na tensão de escoamento, na resistência à nucleação e propagação de microtrincas, enquanto que para aumentar a tenacidade à fratura e a propagação de macrotrincas, é desejável um aumento na referida fração. O tamanho da distribuição da fase alfa depende da razão de aquecimento e do tamanho de grão da fase beta limitando as dimensões máximas da distribuição da fase alfa. Microestruturas lamelares têm maior tamanho de grão beta que a microestrutura bi-modal para a mesma velocidade de resfriamento. A microestrutura bi-modal tem uma maior fração volumétrica da fase alfa. O efeito negativo nas propriedades mecânicas da fase alfa contínua em contorno de grão beta (que é proporcional ao tamanho de grão beta) é eliminado por estruturas bimodais (Lütjering, 1999).

O processamento termomecânico dessas ligas está associado a dois aspectos: para produzir formas utilizáveis através de trabalho primário como a obtenção do lingote, por meio de operações secundárias, laminação a quente e para otimizar propriedades mecânicas através do controle da microestrutura durante diferentes estágios do processamento termomecânico (Weiss \& Semiatin, 1998).

Seshacharyulu et. al (2002) caracterizaram o comportamento da liga Ti-6Al-4V, quando deformada a quente para várias temperaturas e velocidades de deformação modelando os mecanismos microestruturais da liga deformada a quente nos campos $\alpha+\beta$ e $\beta$. Observaram que, para uma faixa de temperatura de 
$800{ }^{\circ} \mathrm{C}$ a $975^{\circ} \mathrm{C}$ e velocidades de deformação variando de $3 \times 10^{-4}$ a $1 \times 10^{-2} \mathrm{~s}^{-1}$, as microestruturas das amostras deformadas tiveram uma mudança significativa na morfologia da fase $\alpha$.

Semiantin et. al. (1999) estudaram o comportamento das ligas de titânio com uma microestrutura lamelar em termos de curvas de escoamento e mecanismos de deformação estudando amostras com diferentes tamanhos iniciais de grãos. Para a liga Ti-6Al-4V, as curvas de escoamento, mostrados na FIGURA 7 exibem um pico de resistência ao escoamento em deformações relativamente baixas (menos que 0,03 ) seguida de moderada a intensa diminuição da resistência ao escoamento. O grau de diminuição da resistência ao escoamento é semelhante a $815^{\circ} \mathrm{C}$ e $900^{\circ} \mathrm{C}$, mas é levemente menor a $955^{\circ} \mathrm{C}$. Além disso, todas as curvas de escoamento tendem a exibir uma menor taxa de diminuição da resistência ao escoamento para deformações na ordem de 0,7.

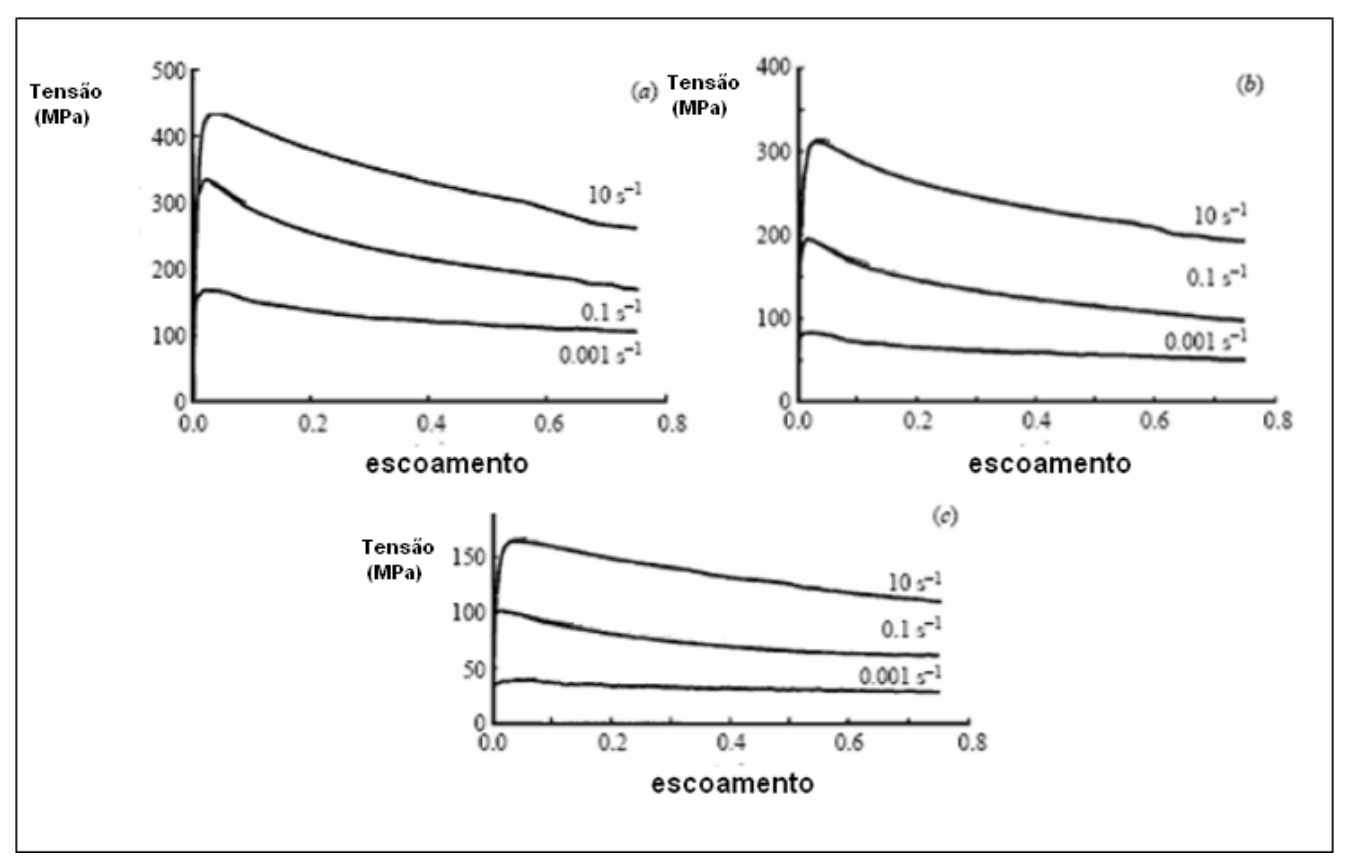

FIGURA 7: Curvas de escoamento obtidas em testes de compressão a quente para velocidades de deformação de 0,001; 0,1 e $10 \mathrm{~s}^{-1}$ (a) $815^{\circ} \mathrm{C}$, (b) $900{ }^{\circ} \mathrm{C}$ e (c) $955^{\circ} \mathrm{C}$ (Semiatin et. al., 1999). 
A não dependência da resistência ao escoamento e tamanho de grão sugere que o escoamento plástico é controlado pelo deslizamento das discordâncias. A diminuição da resistência ao escoamento observada nas curvas de escoamento, na FIGURA 7, pode ser proveniente de vários fatores, dentre eles o aquecimento por deformação (para grandes velocidades de deformação) ou mudanças na morfologia da microestrutura.

Ding et al. (2002) relatam que o processamento termomecânico de uma liga de titânio acima da temperatura de transição $\beta$ leva a uma morfologia da microestrutura lamelar, consistindo de plaquetas de fase $\alpha$ com plaquetas internas de fase $\beta$. Quando processada abaixo da temperatura de transição $\beta$, a liga Ti-6Al-4V mostra uma estrutura $(\alpha+\beta)$ com fase $\alpha$ anterior retida à temperatura ambiente e parte da fase $\beta$ transformada. Em adição a temperatura de processamento, outros parâmetros de trabalho a quente, como deformação e razão de deformação afetam a microestrutura, por exemplo, frações volumétricas das fases $\alpha$ e $\beta$, o tamanho da fase e as dimensões lamelares da fase $\alpha$.

O comportamento microestrutural da liga Ti-6Al-4V foi analisado por Knoll \& Schaeffaer (2006), a peça estudada apresentava regiões distintas em relação à deformação, o que possibilitou a comparação da microestrutura em regiões de diferentes deformações. A matéria-prima utilizada apresentava uma microestrutura com fase $\alpha$ lamelar com grãos grosseiros e fase $\beta$ intergranular. Através das micrografias obtidas pode-se observar que para a faixa de temperatura utilizada no forjamento $\left(980{ }^{\circ} \mathrm{C}-930{ }^{\circ} \mathrm{C}\right)$, combinada com as altas velocidades de deformação obtidas $\left(0,3 \mathrm{~s}^{-1}\right.$ e $\left.0,7 \mathrm{~s}^{-1}\right)$, as lamelas de fase $\alpha$ não sofreram o fenômeno de globularização e ocorreu um refinamento dos grãos. Para a região com maior deformação, as lamelas sofreram, em alguns pontos, um encurvamento e, em outros, uma orientação perpendicular ao eixo de compressão. Na região com menor deformação ocorreu o refinamento dos grãos, porém os grãos não apresentam uma orientação definida.

Um melhor controle microestrutural deve ser feito para encontrar 0 equilíbrio entre a dureza e a resistência; para isso, são feitos estudos da relação da microestrutura e as características de fratura, principalmente, para ligas de titânio compostas por intermetálicos. A resistência à fadiga é uma das mais importantes propriedades das ligas de titânio e também é objeto de trabalhos de 
pesquisas. Estudos revelam um número de fatores responsáveis para 0 comportamento de fadiga das ligas de titânio. Entre eles está o tamanho de grão e é considerado que o refinamento de grão aumenta a resistência à fadiga em ligas de titânio $\alpha+\beta$. O esłagio inicial de crescimento da trinca de fadiga é uma pesquisa de grande interesse, devido à natureza anômala do comportamento de crescimento de trincas. O comportamento de crescimento de trinca em ligas de titânio com alta resistência à fadiga com finos grãos não é muito explorado devido a dificuldades experimentais associadas à microestrutura fina (Nakajima et al.,1998).

Alguns resultados do estudo das relações entre o comportamento à fadiga da liga Ti-6Al-4V com estrutura equiaxial alfa, mostram que a resistência a tração residual da amostra fatigada a vários números de ciclos, aumenta rapidamente durante os primeiros estágios de baixo ciclo de fadiga. Quando o alongamento residual diminui rapidamente a dureza da amostra fatigada apresenta um gradiente da superfície para dentro; durante os primeiros estágios de fadiga de baixo ciclo e durante os estágios finais, a dureza da amostra é aproximadamente igual à superficial. A energia absorvida durante o impacto diminui durante os últimos estágios da fadiga de baixo ciclo e as propriedades mecânicas residuais mudam pouco, comparativamente, depois de fadiga de alto ciclo (Akahori \& Niinomi,1998).

\subsubsection{Processamento termomecânico, microestrutura e comportamento mecânico da liga Ti-6Al-4V forjada e fundida}

No processo de fabricação das ligas de Ti, processos como fundição, forjamento e metalurgia do pó, são muito comuns.

No forjamento as ligas de Ti são submetidas a vários ciclos de fusão, a fim de remover impurezas tais como hidrogênio e substâncias voláteis, para atingir um alto grau de pureza. Fatores críticos, associados ao forjamento das ligas de $\mathrm{Ti}$; incluem a formação das ligas, o processo de fusão utilizado no tratamento do lingote; questões relacionadas ao trabalho mecânico; ao tratamento térmico e às taxas de resfriamento e envelhecimento. As peças fundidas de ligas de $\mathrm{Ti}$ podem ser produzidas com propriedades similares ou superiores aos 
produtos forjados, com incremento na propagação de trincas e propriedades de resistência à fluência (Murr et al., 2009).

A vantagem da liga forjada com relação à liga fundida reside no fato de que a primeira pode ser tratada termicamente (a frio ou a quente) permitindo obter as propriedades mecânicas desejadas no produto final. A densidade é crítica para as ligas de Ti, uma vez que a porosidade tem efeitos negativos sobre a fadiga $\mathrm{e}$ propriedades de fratura. Por esta razão, os diferentes parâmetros devem ser testados para esta liga, a fim de determinar a gama de propriedades mecânicas que podem ser adaptadas através desta técnica. Com a deformação extensiva, as plaquetas $\alpha$ se rompem e uma estrutura coalescida. Assim, existe a possibilidade de se produzir Ti-6Al-4V com uma variedade de microestruturas e propriedades associadas, variando-se o processamento mecânico e térmico, e as taxa de exposição de resfriamento lento (Murr et al., 2009).

\subsubsection{Mecanismos de deformação no titânio e suas ligas}

A caracterização da deformação sob um carregamento mecânico em uma escala microscópica, para a liga de titânio Ti-6Al-4V, utilizando-se 0 Microscópio Eletrônico de Varredura com Difração de Elétrons Retroespalhados (MEV/EBSD) e módulo de tração in situ, foi realizado por Bridier et al. (2005). Nestes ensaios, conforme mostra a FIGURA 8, observou-se a deformação macroscópica plástica a 3\%, com nove patamares regulares distribuídos nas partes elástica e plástica da amostra. Nestas condições a taxa de deslocamento, variando-se de 0,02 $\mathrm{mm} / \mathrm{min}$ até $1,5 \mathrm{~mm} / \mathrm{min}$, o módulo de Young apresentado pela liga Ti-6Al-4V foi de $119 \mathrm{GPa}$. 


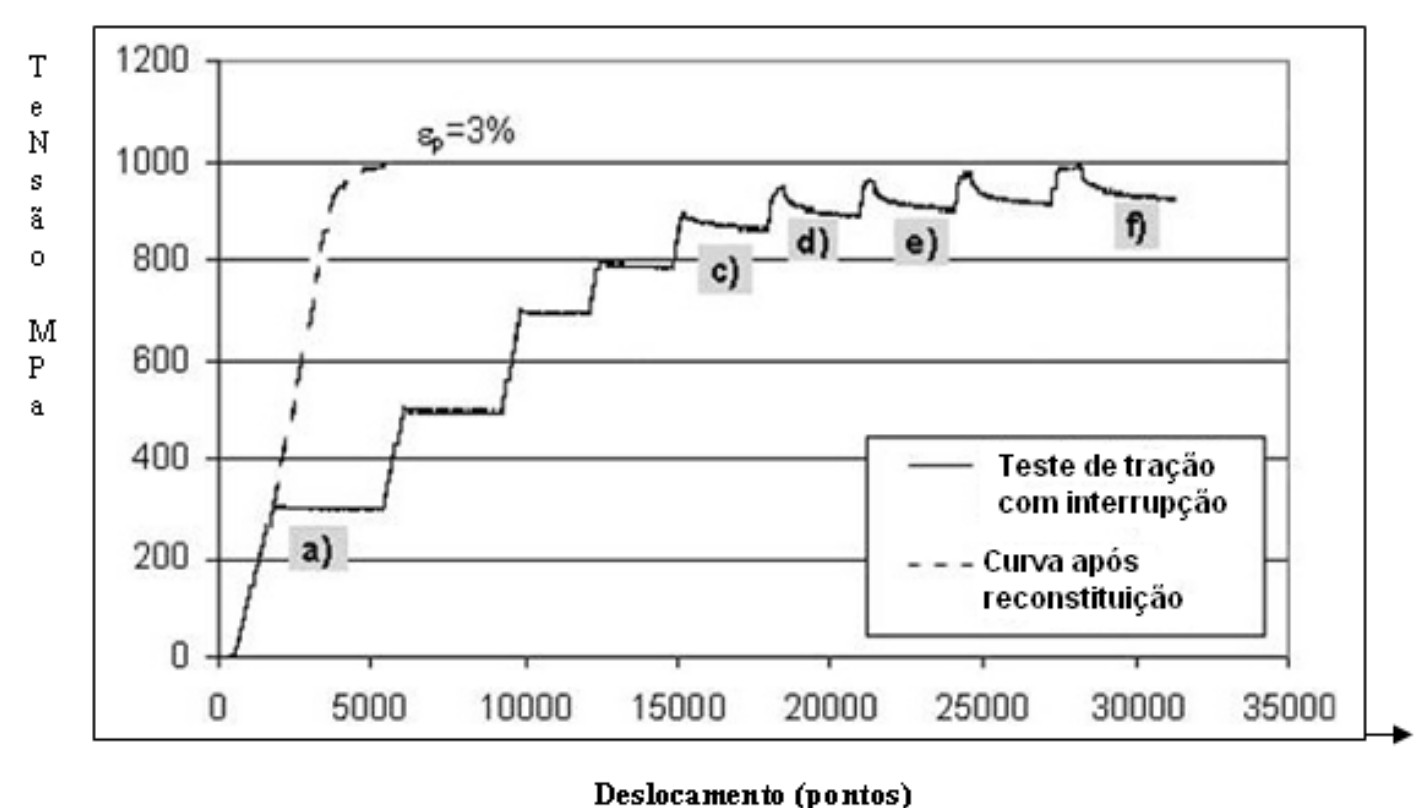

FIGURA 8: Curva Tensão x Deformação da liga Ti-6Al-4V em ensaio de tração in situ (Bridier et al.,2005)

A possibilidade do escorregamento ocorrer nos planos prismático, piramidal ou basal está geralmente associada com a tensão crítica de cisalhamento. A relativa facilidade de deslizamento do plano prismático e basal é explicada pela sua baixa tensão crítica de cisalhamento, geralmente com valores mais baixos para o deslizamento prismático (Bridier et al., 2005).

Uma das dificuldades para entender os mecanismos de deformação no titânio puro e suas ligas deriva da complexa competição entre os diferentes sistemas de escorregamento e sua forte dependência em diversos fatores como temperatura, composição química e morfologia microestrutural ou orientação cristalográfica (Serra et al.,2002).

Os mecanismos de deformação plástica nos metais de estrutura hexagonal compacta apresentam baixo número de discordâncias em sistemas de escorregamento. Além disso, a tensão crítica de cisalhamento requerida para ativar estes sistemas aumenta fortemente com o decréscimo da temperatura. Somente dois sistemas de escorregamento, o basal e o prismático são ativados na liga de Ti-6Al-4V a $20 \mathrm{~K}$. Por outro lado a tensão necessária para a formação de maclas praticamente independe da temperatura. Isto explica porque a 
maclação está presente na liga Ti-6Al-4V em temperaturas abaixo de $20 \mathrm{~K}$ (lorio et al., 2007).

Os possíveis sistemas de escorregamento em metais que apresentam uma estrutura hexagonal compacta (hc) são mostrados na TABELA 2.

TABELA 2 Modos independentes de deformação em metais com estrutura hexagonal compacta (hc)

\begin{tabular}{|c|c|c|c|}
\hline Direção & $\begin{array}{c}\text { Plano de } \\
\text { Deslizamento }\end{array}$ & $\begin{array}{c}\text { Elementos } \\
\text { cristalográficos }\end{array}$ & $\begin{array}{c}\text { Número de modos } \\
\text { independentes }\end{array}$ \\
\hline A & Basal & (0002) $\langle 11 \overline{2} 0\rangle$ & 2 \\
& Prismático & $\{1 \overline{1} 00\}\langle 11 \overline{2} 0\rangle$ & 2 \\
\hline C & Piramidal & $\{1 \overline{1} 0 l\}\langle 11 \overline{2} 0\rangle$ & 4 \\
\hline c+a & Piramidal & $\{h k i l\} *\langle 11 \overline{2} \overline{3}\rangle$ & 5 \\
\hline Maclação & & $\left\{K_{l}\right\}\left\langle\overline{\eta_{l}}\right\rangle$ & $0-5$ \\
\hline
\end{tabular}

Fonte: Smith C., 2008

A FIGURA 9 mostra em detalhes os planos prismático, piramidal e basal para uma estrutura cristalina do tipo hexagonal compacta. São representados os diferentes planos e direções de escorregamento possíveis. 

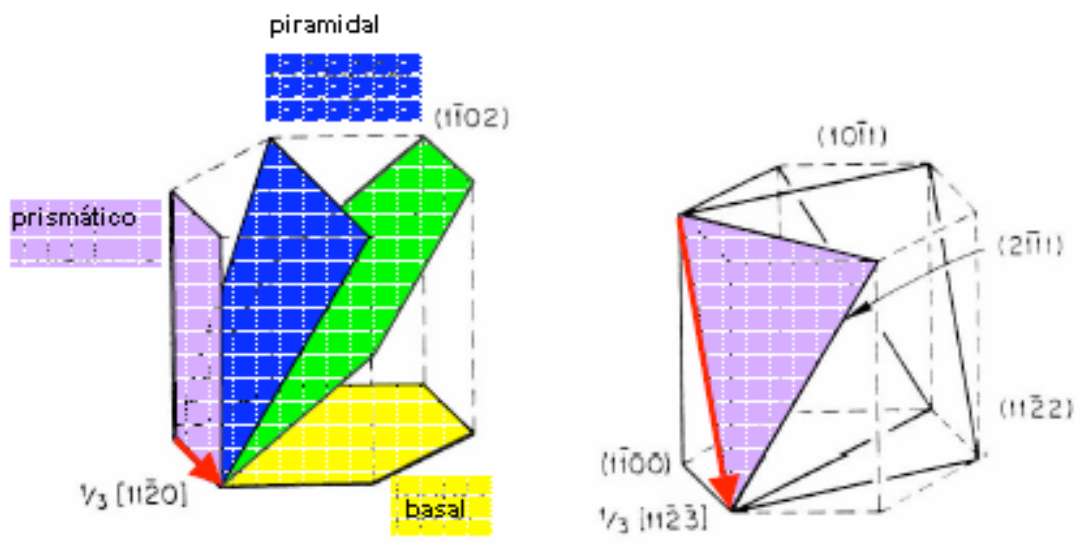

$\overrightarrow{0}$ escorregamento

$$
\hat{\mathrm{C}}+\overline{\mathrm{o}} \text { escorregamento }
$$

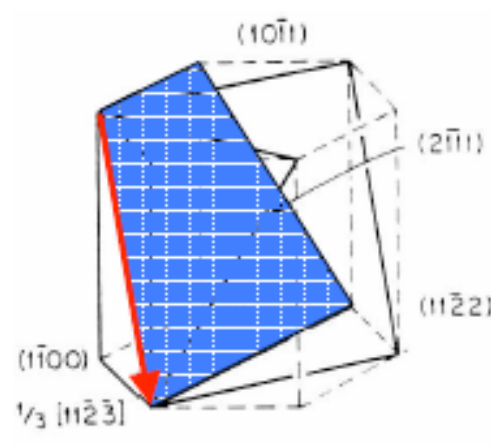

$\widehat{c}+\overrightarrow{0}$ escorregamento

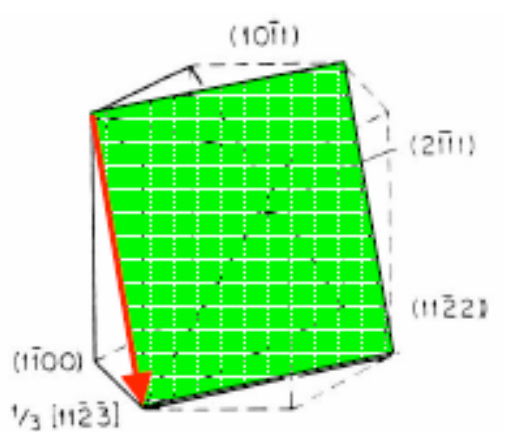

$\widehat{c}+\vec{o}$ escorregamento

FIGURA 9: Sistemas possíveis de escorregamento para cristais com estrutura hc (Smith C., 2008)

As interações entre os deslizamentos de discordâncias e contornos de macla são de interesse prático, porque a deformação induzida de maclas pode atuar como uma barreira para posteriores escorregamentos.

A FIGURA 10 ilustra esquematicamente o processo de maclação em um cristal com estrutura do tipo hexagonal compacta.

De acordo com a notação apresentada na FIGURA 10 temos que:

$\mathrm{K}_{1}=$ plano de maclação;

$\mathrm{K}_{2}=$ plano de maclação conjugado;

$\eta_{1}=$ direção de maclação;

$\eta_{2}=$ direção de maclação conjugada; e 


$$
\mathrm{S}=\text { maclação com cisalhamento. }
$$

A FIGURA 10 (A) mostra os elementos de maclação $K_{1}, \eta_{1}, K_{2}$, e $\eta_{2}$ e o desnível interfacial associado com uma discordância de maclação, em (B) ilustra-se os mesmos elementos de forma tridimensional e em (C) os elementos cristalográficos da maclação, em uma célula unitária definida pelos vetores $\eta_{1} \mathrm{e}$ $\eta_{2}$ sendo $S$ o plano homogeneamente cisalhado na macla definida por $\eta_{1}, \eta_{2}$ e $S$.

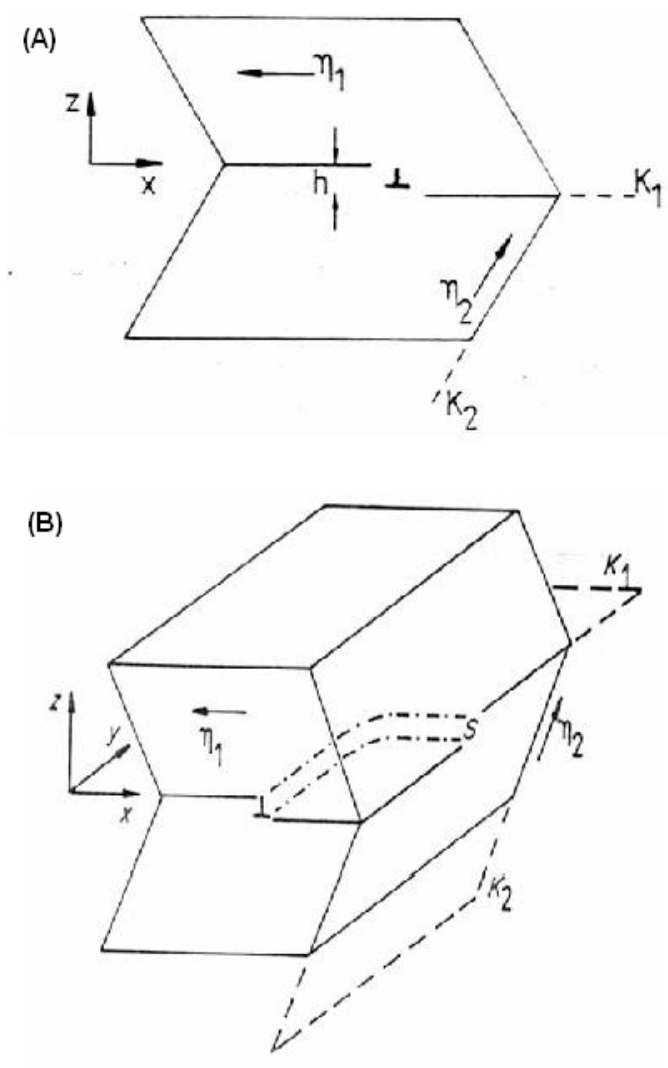

(C)

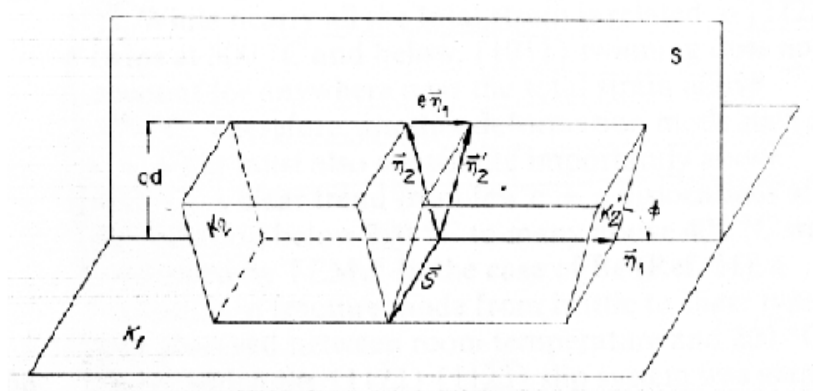

FIGURA 10: Ilustração esquemática da maclação para um cristal hc: (A) ilustração planos $x, z$; (B) ilustração planos $x, y, z$ e (C) célula unitária definida nos planos $\mathrm{K}_{1}$ e S (Smith C., 2008).

Na FIGURA 11 observa-se uma relação entre o sistema de maclação e escorregamento normalizados para o módulo de cisalhamento do titânio, onde foi considerado diferentes valores de tensão crítica de cisalhamento em função da temperatura, sendo que a curva obtida é uma média aproximada dos dados. O valor de $T / T_{\text {fusão }}$ igual a 0.3 está relacionado com as famílias de planos de maclação $\{1122\}$ e acima está o escorregamento da família de direção <c+a> em 
combinação com a família de planos de maclação $\{1011\}$, resultado similares tem sido obtidos por diversos pesquisadores (Yoo et al., 2002).

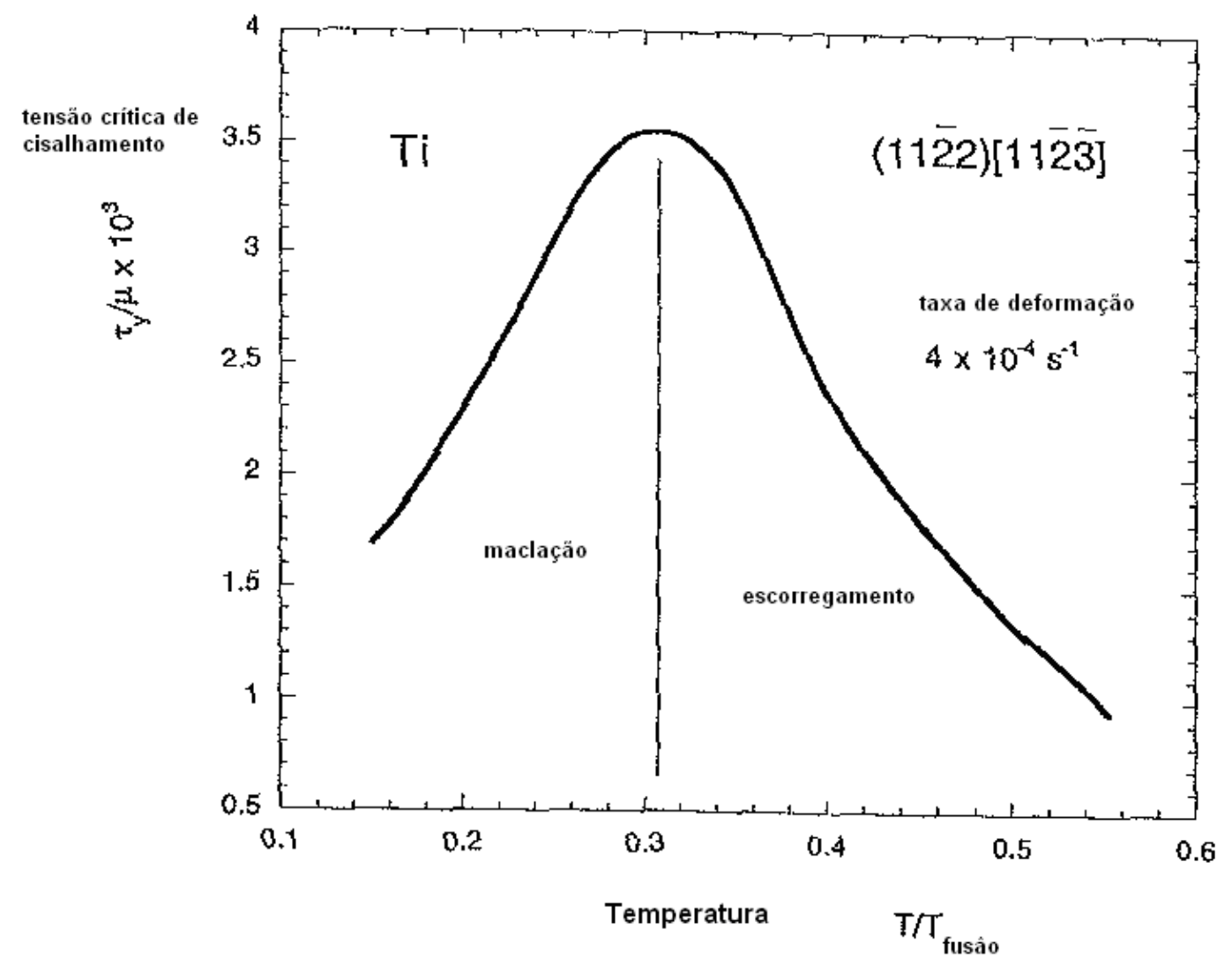

FIGURA 11: Dependência da tensão crítica de cisalhamento em relação à temperatura para $(11 \overline{2} 2)$ [11 $\overline{2} \overline{3}]$ macla/sistema de escorregamento, normalizado para um módulo de cisalhamento para cristais de Ti (Yoo et al., 2002).

A Figura 12 mostra a descrição esquemática da nucleação de maclas heterogêneas. Yoo et al. (2002) ao analisarem as interações das discordâncias em , <a $>,<c>$ e $<c+a>$ com os quatro sistemas primários de maclação identificaram 26 processos de discordâncias distintos na interface matriz-macla. Pelo menos 5 desses casos envolvem discordâncias adicionais de maclação indicando que o processo de espessura/afinamento dependem da tensão de cisalhamento a que são submetidos. 


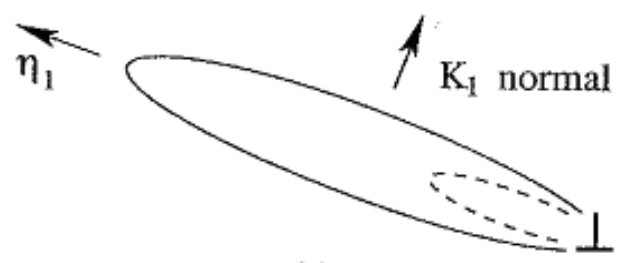

(a)

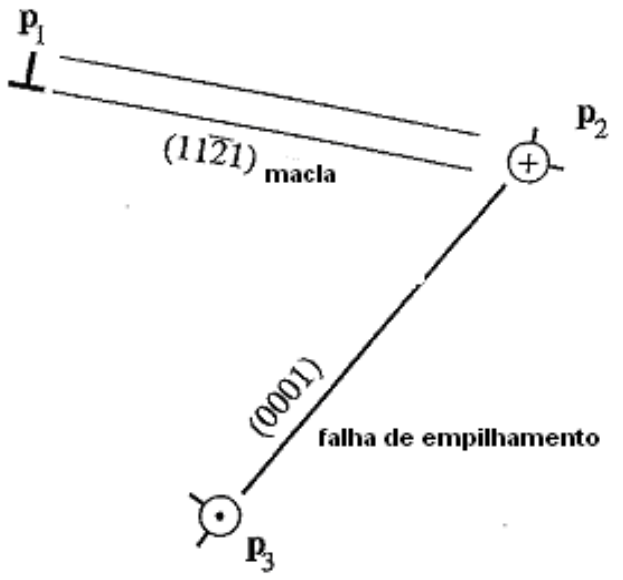

(b)

FIGURA 12: Descrição esquemática da nucleação de maclas heterogêneas: (a) macla de formação inicial associada com o local da concentração de tensão representada por uma super discordância, e (b) geração das discordâncias de maclas como resultado da dissociação não-planar de uma discordância (Yoo et al., 2002).

Os contornos de grão são locais potenciais para o início do escorregamento piramidal, $\langle\mathrm{C}+\mathrm{a}\rangle$, em materiais policristalinos. Um possível mecanismo de formação para as discordâncias $<c+a>$ está baseado na junção atrativa entre a discordância $<\mathrm{c}>\mathrm{e}$ as discordâncias de escorregamento $<\mathrm{a}>\mathrm{Na}$ interação elástica isotrópica a força de direção principal na reação de junção está entre duas discordâncias com os vetores de Burgers, mutuamente perpendiculares, mostrado na FIGURA 13(a). A força de atração entre uma discordância $<c>$ no plano prismático e a discordância $<$ a $>$ no plano basal pode ser suficientemente alta para puxar a discordância <a> para fora do plano basal, conforme se pode observar na FIGURA 13 (b). Para o caso do titânio e outros metais hexagonais compacto que deformaram primeiramente no plano prismático, o modelo proposto somente depende do último estágio, mostrado na FIGURA 13(c), desde que a formação de uma junção atrativa no plano prismático seja energeticamente favorável para todos os metais hc (Yoo et al., 2002). 


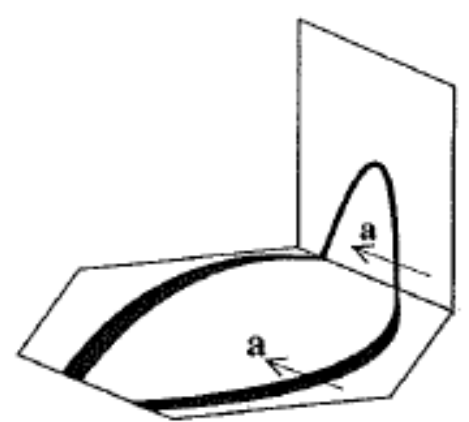

(a)

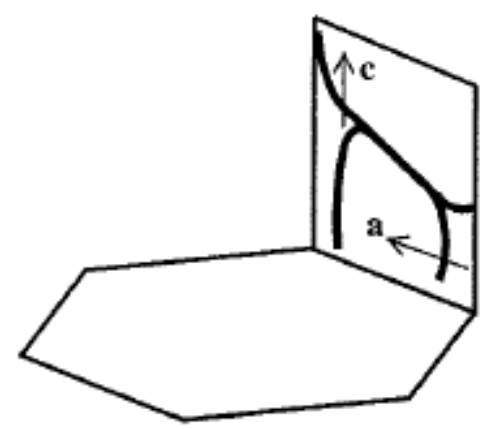

(b)

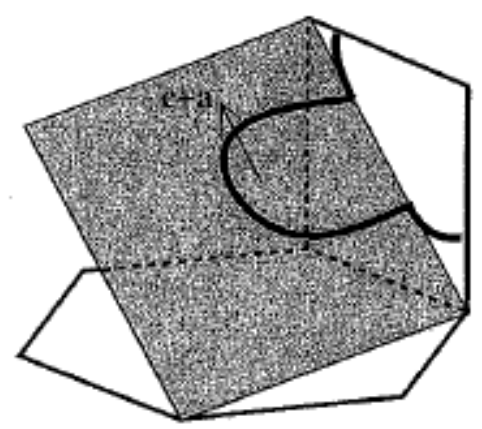

(c)

FIGURA 13: Mecanismos de origem das discordâncias para o sistema de escorregamento piramidal $<c+a>$ : (a) discordância, (b) formação da junção $<c+a>$ e (c) escorregamento transversal da discordância $<c+a>$ (Yoo et al., 2002).

A FIGURA 14 mostra a forma do retículo cristalino de uma macla em formação. Esta dissociação não-planar não foi observada em simulações anteriores devido às condições geométricas de simulação. A formação deste tipo de estrutura depende sensivelmente da posição inicial de geração deste tipo de estrutura, do potencial interatômico e das técnicas de alívio de tensões mediante fluência. Isto indica que a estrutura final não foi determinada pelas considerações energéticas, mas sim pela configuração inicial e dinâmica subseqüente (Yoo et al.,2002). 

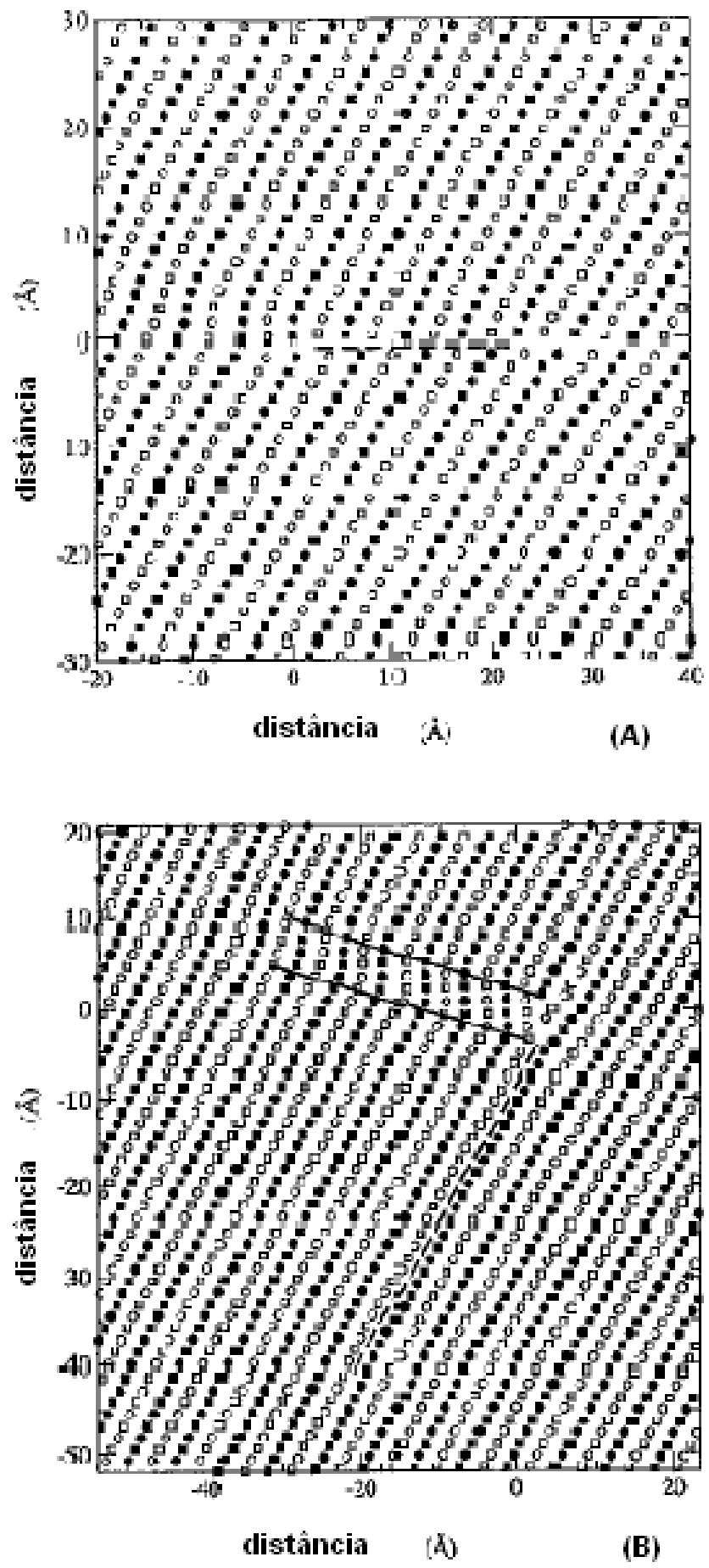

FIGURA 14: Dois tipos de dissociação <c+a> discordância em cunha, obtidas a partir de simulação atomística: (a) tipo planar e (b) tipo não - planar (Yoo et al., 2002). 
A FIGURA 15 mostra o crescimento de maclas sob tração e neste caso a direção $p_{3}=[1010] / 3$ é parcialmente relacionada à tensão e se estende ou contrai o plano basal provocando uma falha na seqüência de empilhamento.

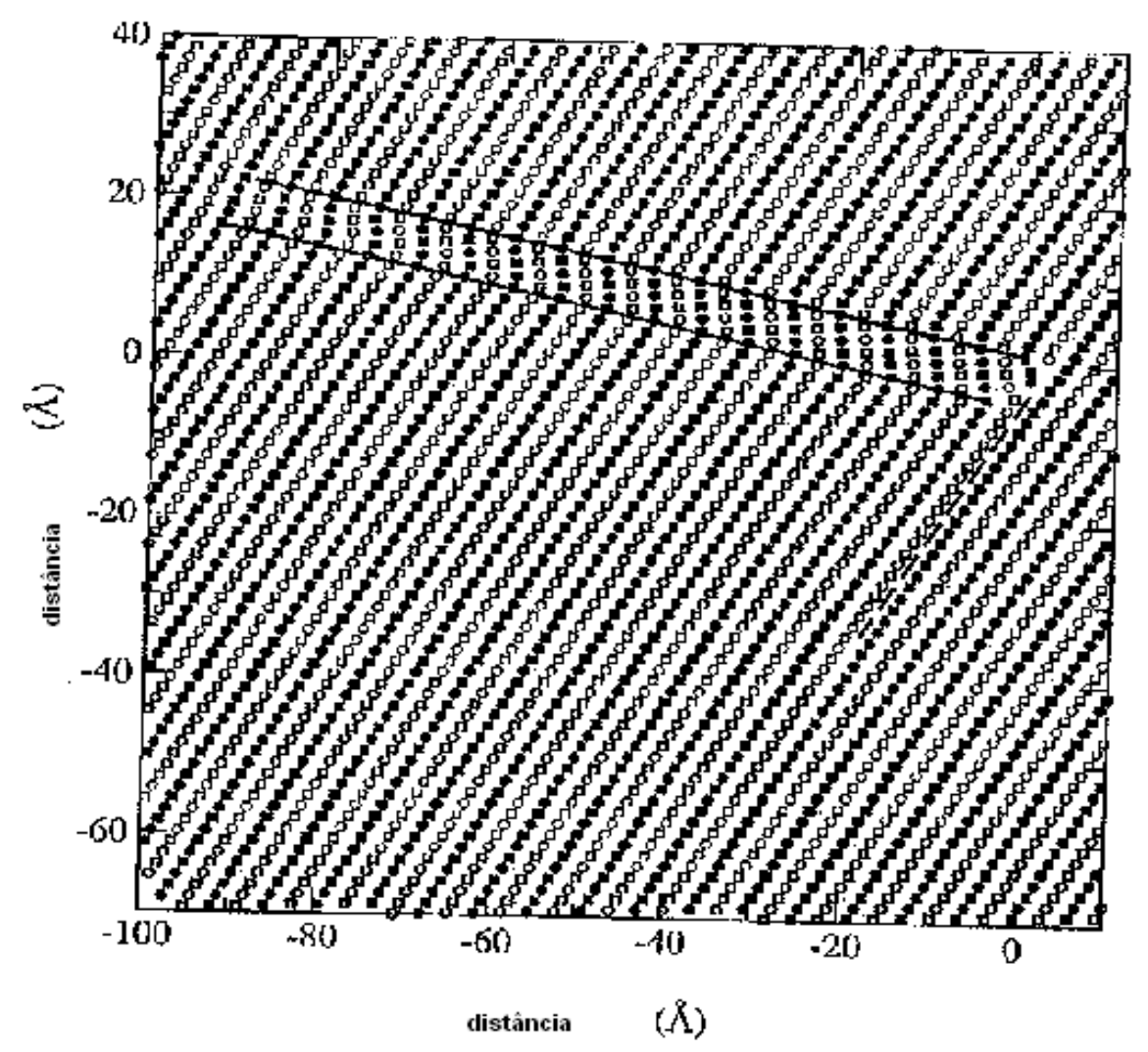

FIGURA 15: Crescimento de uma macla, "embryo", no plano (11̄1) e direção [ $\overline{1}$ 1 26] sob deformação de tração (Yoo et al., 2002). 


\section{MATERIAIS E MÉTODOS EXPERIMENTAIS}

Neste capítulo estão relacionados os métodos e equipamentos necessários à realização da parte prática do trabalho, bem como a descrição das amostras utilizadas.

O material utilizado no presente trabalho foi a liga de Ti-6Al-4V. O material foi adquirido na forma de barras de $6 \mathrm{~mm}$ de diâmetro. O estado do material na condição como recebido encontrava-se recozido a $800^{\circ} \mathrm{C}$ por duas horas.

Inicialmente foram realizadas as análises na liga de titânio Ti-6Al-4V como recebida. Para uma melhor compreensão da formação das fases $\alpha$ e $\beta$ que estão presentes na amostra realizou-se um tratamento térmico na mesma.

Para cada uma das técnicas experimentais empregadas foram realizadas preparações de amostras diferenciadas, apresentadas em 4.1.1., 4.2.1., 4.2.2. e 4.3.1.

\subsection{Procedimento para análise microestrutural por Microscopia Óptica - MO e Microscopia Eletrônica de Varredura - MEV (EDS e EBSD)}

\subsubsection{Procedimento utilizado no preparo das amostras para análise microestrutural por MO e MEV (EDS e EBSD)}

O preparo das amostras foi realizado seguindo-se a etapa de corte das mesmas, com disco adiamantado, onde a superfície plana foi posteriormente lixada, utilizando lixa de carbeto de silício (SiC) com granulometria de $600 \mu \mathrm{m}$, passando-se posteriormente para SiC com granulometrias de $1.000 \mu \mathrm{m}$ e de 1500 $\mu \mathrm{m}$. Após o lixamento, as amostras foram submetidas ao polimento com pasta de diamante (na seqüência: $9 \mu \mathrm{m}, 6 \mu \mathrm{m}, 3 \mu \mathrm{m}, 1 \mu \mathrm{m}, 1 / 4 \mu \mathrm{m}$ ), sendo que antes desta etapa, as mesmas foram limpas num banho ultrassônico por 5 minutos. A cada 
mudança de estágio da granulometria, as amostras foram lavadas e secas para que não houvesse contaminação no pano de polimento:

- Os cortes longitudinais e transversais das amostraa foram realizados com equipamento ISOMET 1000 (dotado de disco adiamantado), obtendo-se placas de espessura e altura aproximadas de 1,0 mm;

- As amostras foram embutidas a quente em baquelite;

- O lixamento das amostras foi realizado conforme descrito em 4.1.1.;

- Na revelação da estrutura das amostras de Ti-6Al-4V foi realizado ataque químico, utilizando-se a mistura de $10 \mathrm{~mL}$ de ácido fluorídrico $(\mathrm{HF}), 10 \mathrm{~mL}$ de ácido nítrico $\left(\mathrm{HNO}_{3}\right)$ e $30 \mathrm{~mL}$ de ácido lático $\left(\mathrm{C}_{3} \mathrm{H}_{6} \mathrm{O}_{3}\right)$;

- $\mathrm{Na}$ revelação da estrutura das amostras Ti-6Al-4V, tratadas termicamente, foi realizado ataque químico utilizando-se a mistura de $10 \mathrm{~mL}$ de ácido fluorídrico (HF), $10 \mathrm{~mL}$ de ácido nítrico $\left(\mathrm{HNO}_{3}\right)$ e $85 \mathrm{~mL}$ de água.

Após o preparo para a análise no MEV as amostras foram recobertas com carbono amorfo, para observação das principais fases presentes.

\subsubsection{Equipamentos utilizados na análise microestrutural por Microscopia Óptica- MO e Microscopia Eletrônica de Varredura - MEV (EDS e EBSD)}

Para a realização destas análises foram utilizados os equipamentos do:

- Microscópio Óptico da marca Olympus (modelo BX 60), com sistema de captura de imagem digital, CCTM/IPEN;

- Microscópio Eletrônico de Varredura (MEV) da marca Philips (modelo XL-30), com sistema EDS da marca Edax, CCTM/IPEN;

- Microscópio Eletrônico de Varredura (MEV) da marca CamScan (série 4), instalado no núcleo de física do Instituto de Criminalística de São Paulo; e

- Microscópio Eletrônico de Varredura (MEV) da marca Philips (modelo XL-30), no qual estava acoplada uma câmera CCD de alta resolução, com uma tela fosforescente interligada por meio de uma interface mecânica ao MEV. O sistema para interpretação, controle 
e aquisição dos dados da difração de elétrons retroespalhados (EBSD) é da marca TSL (TexSEM Laboratories Inc.), instalados no laboratório de microscopia eletrônica do Departamento de Engenharia Metalúrgica e de Materiais, da Escola Politécnica da Universidade de São Paulo.

\subsection{Procedimento para análise microestrutural pela técnica analítica de Microscopia Eletrônica de Transmissão (MET)}

\subsubsection{Procedimento utilizado no preparo das amostras na análise microestrutural (MET)}

- Foi realizado corte longitudinal da amostra com equipamento ISOMET 1000 (dotado de disco adiamantado), obtendo-se placas de espessura de 0,5 mm, conforme FIGURA 16(A).

- Parte das amostras foram cortadas por meio de eletroerosão formando discos com diâmetro de 3 mm, FIGURA 16 (B).

- Foi realizado afinamento mecânico com a utilização de um suporte, lixando a amostra com lixa de $600 \mu \mathrm{m}$, até atingir a espessura de 0,2 mm, FIGURAS 16 (C) e (D).

- Após redução da espessura da amostra, a mesma foi submetida ao afinamento final e perfuração no equipamento TENUPOL, FIGURAS 16 (E) e (F).

- As amostras com espessura correta foram recobertas com carbono amorfo, através do sistema de "sputtering", colocadas no porta amostras e analisadas no MET-AR conforme FIGURA 17. 


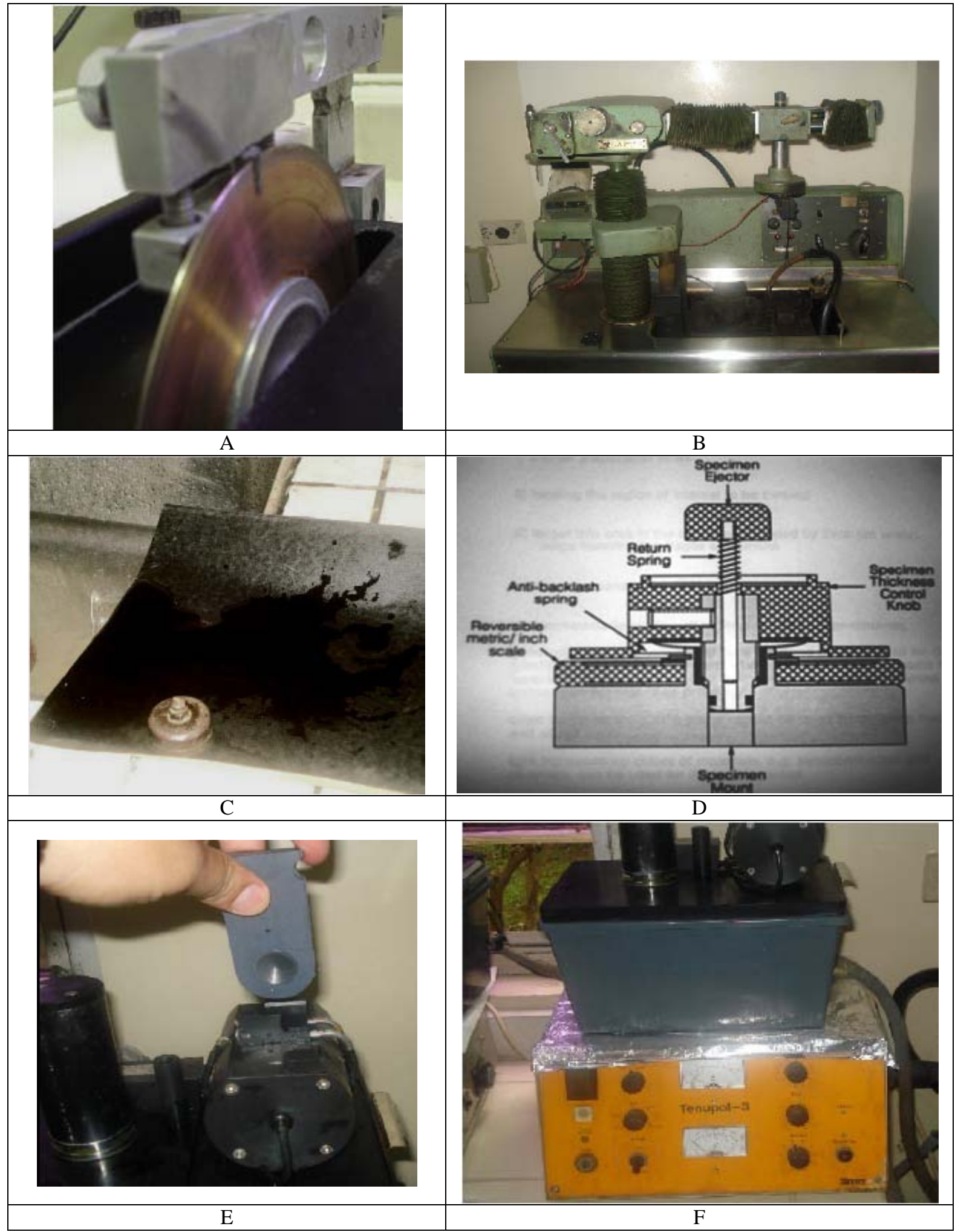

FIGURA 16: Equipamentos utilizados na preparação das amostras de titânio Ti-6Al4V: (A) Equipamento ISOMET 1000 para corte longitudinal; (B) Equipamento para efetuar cortes dos discos por eletroerosão; (C) Lixamento para reduzir a espessura das amostras; (D) Esquema do dispositivo de afinamento manual das amostras; (E) Detalhe do portaamostra para a redução da espessura e afinamento eletrolítico e (F) Equipamento TENUPOL utilizado para afinamento no preparo das amostras para análise microestrutural no MET. 


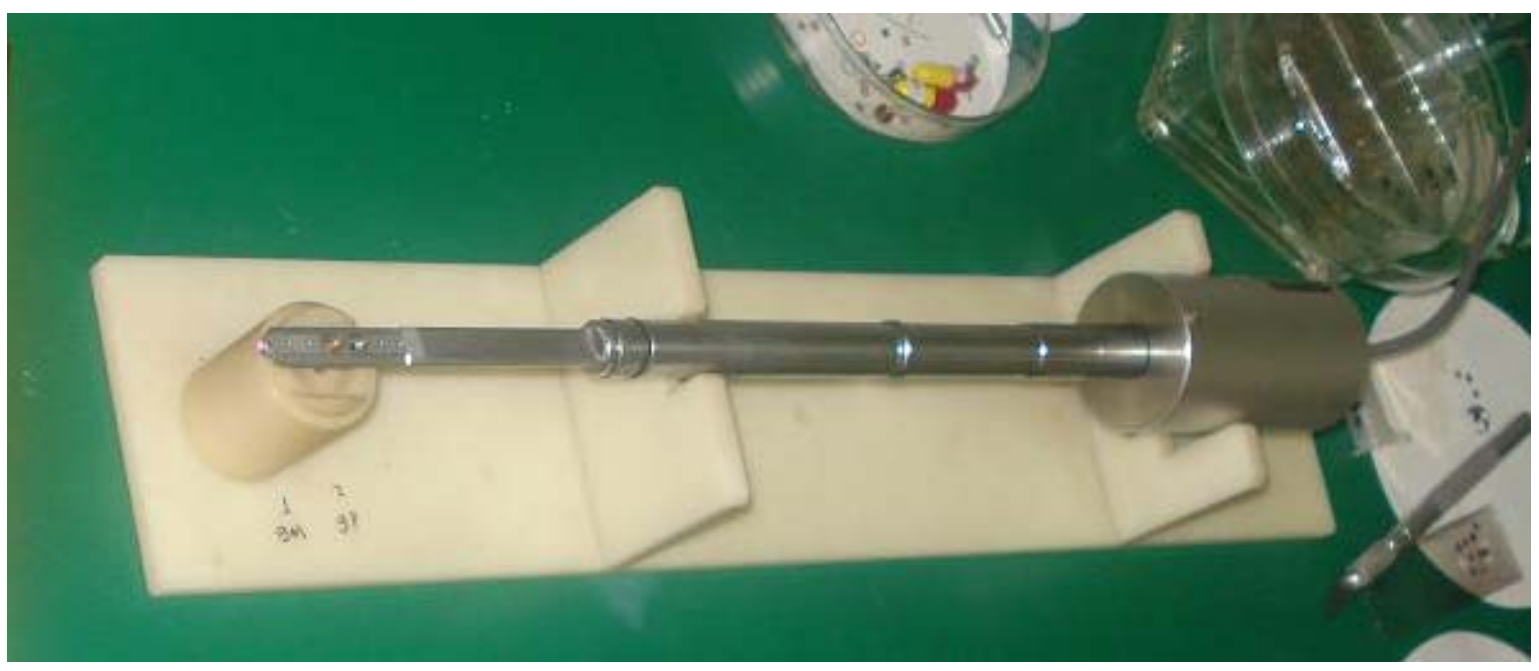

FIGURA 17: Porta amostra do Microscópio Eletrônico de Transmissão analítico (MET-AR) da marca JEOL utilizado para análise das amostras de Ti6Al-4V.

4.2.2. Procedimento utilizado no preparo das amostras para análise microestrutural por Microscopia Eletrônica de Transmissão (MET) e ensaios de tração in situ

Na FIGURA 18, a seguir, é apresentado o esquema da amostra preparada para análise de tração in situ no MET.

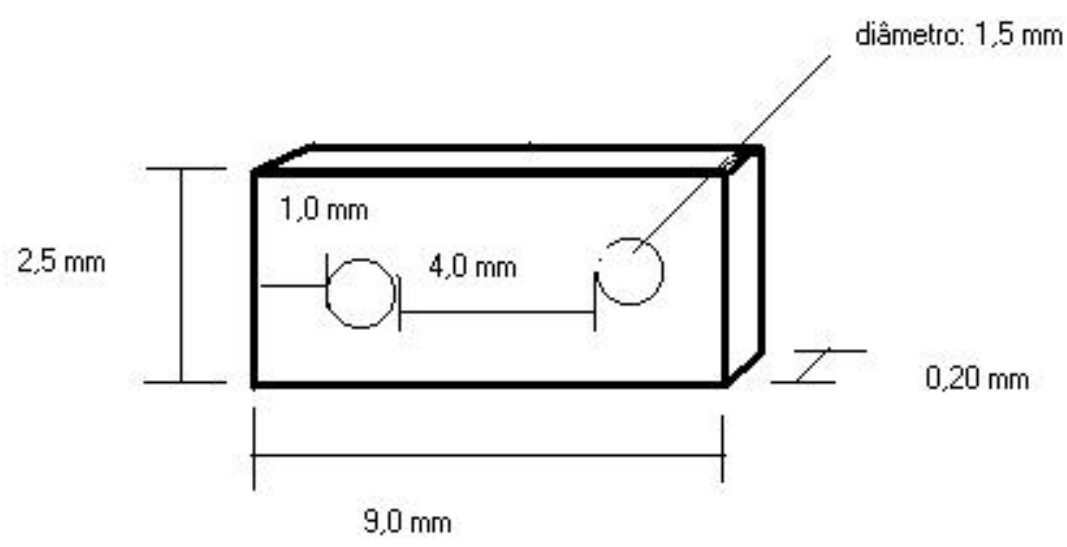

FIGURA 18: Esquema da amostra de Ti-6AI-4V para ensaio de tração in situ no MET. 
Após o preparo das amostras, como ilustrado na FIGURA 19, as mesmas passam pelas etapas a seguir:

- Afinamento mecânico com a utilização de um suporte, lixando a amostra com lixa de $600 \mu \mathrm{m}$, até atingir a espessura de 0,2 mm, e

- Afinamento final e perfuração no equipamento TENUPOL.

As amostras com espessura de $0,2 \mathrm{~mm}$ são recobertas com carbono amorfo, através do sistema de "sputtering" e as analises realizadas no MET JEOL 200C. A FIGURA 19 mostra em detalhe a seqüencia das amostras preparadas para o ensaio de tração in situ , no MET.

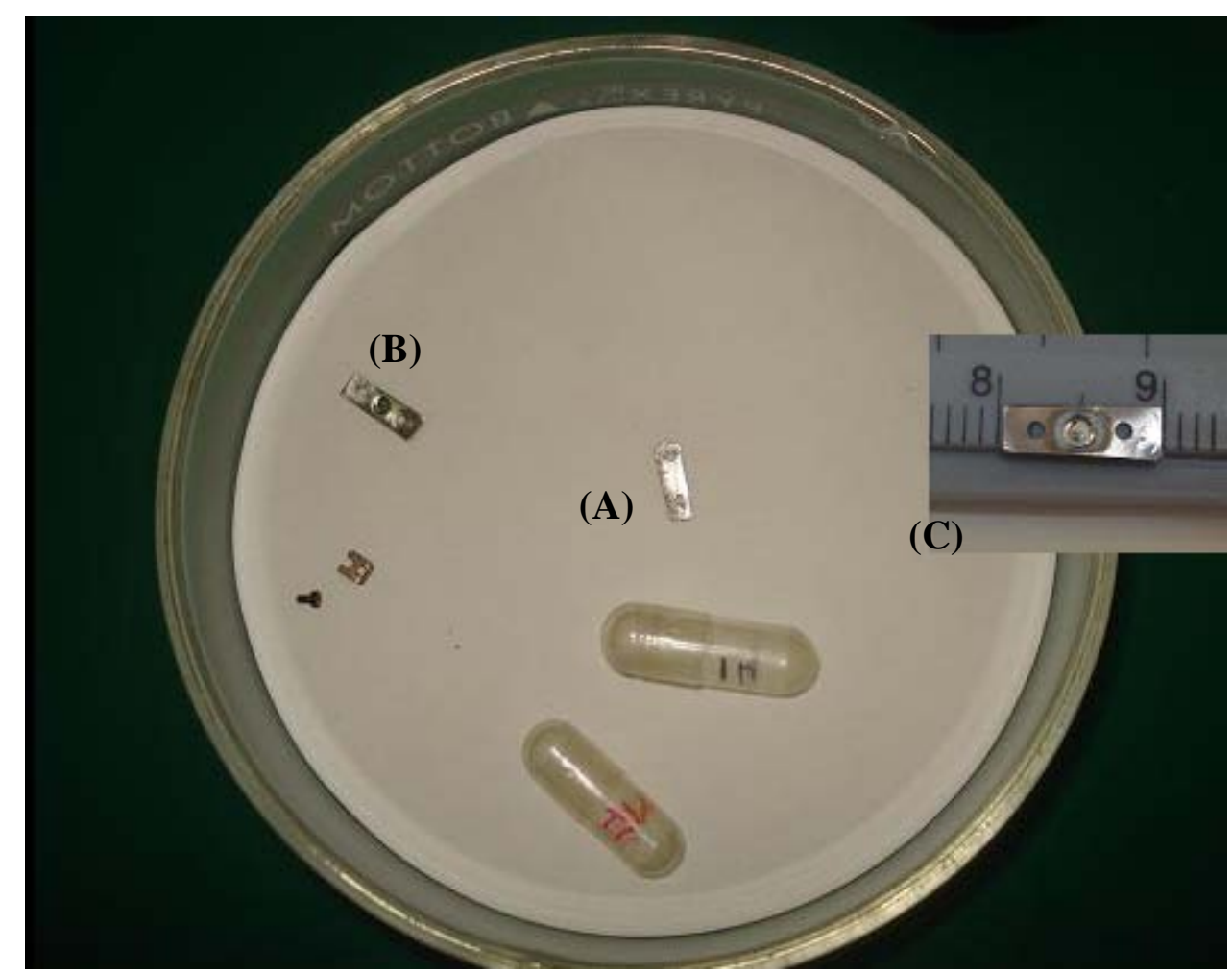

FIGURA 19: Detalhes das amostras de Ti-6Al-4V preparadas para ensaio de tração in situ onde se pode observar: (A) amostra perfurada, (B) amostra após afinamento eletrolítico e (C) detalhe da dimensão da amostra preparada 


\subsubsection{Equipamentos utilizados na análise microestrutural (MET)}

Para a realização destes ensaios foram utilizados os seguintes equipamentos:

- Microscópio Eletrônico de Transmissão de alta resolução (MET-AR), marca JEOL JEM 2100 tensão 200 kV, conforme mostra a FIGURA 20.

- Microscópio Eletrônico de Transmissão (TEM), marca JEOL 200C.

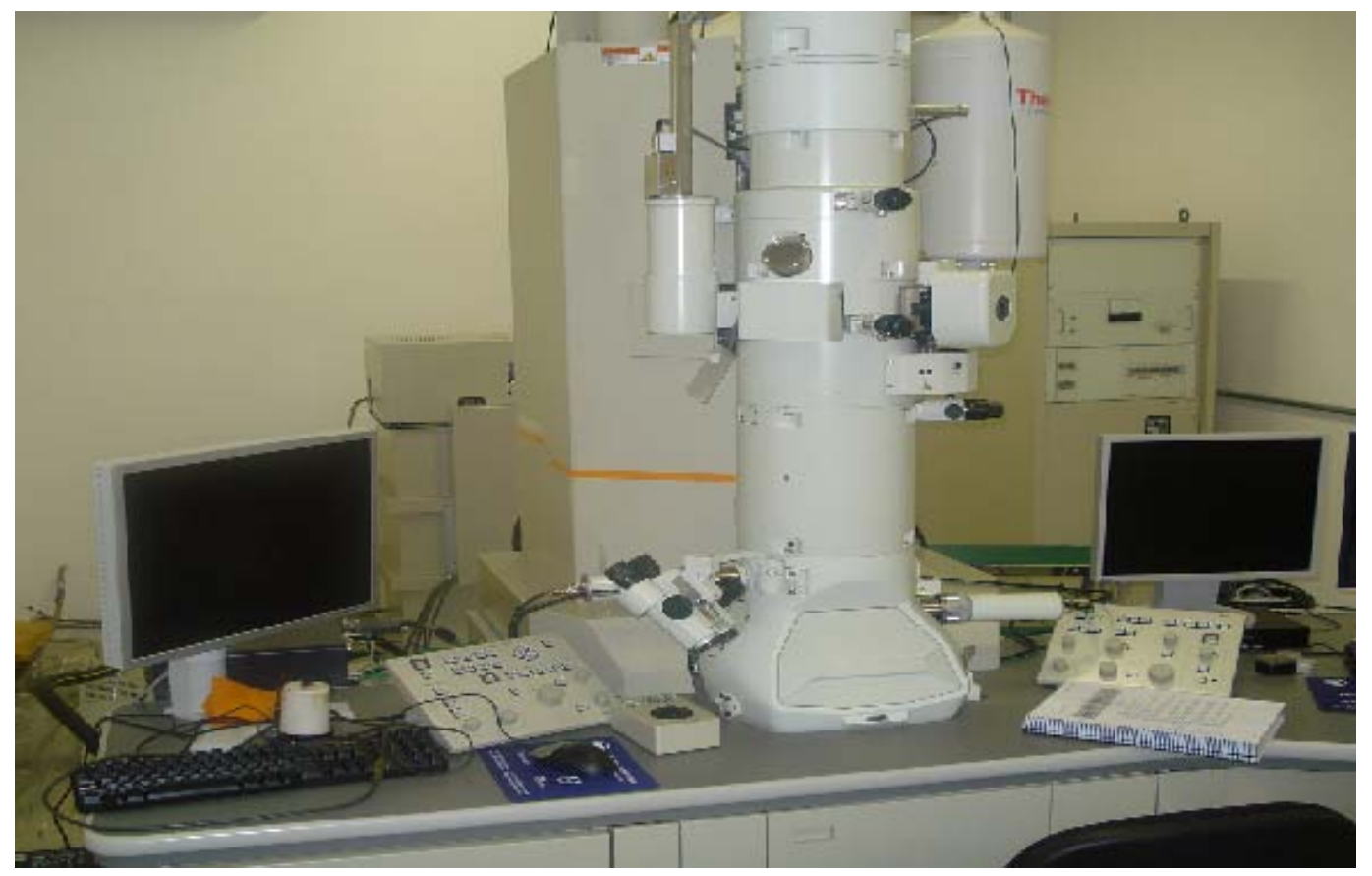

FIGURA 20: Microscópio eletrônico de transmissão analítico marca JEOL utilizado para análise das amostras de Ti-6Al-4V.

A Figura 21 mostra em detalhe o módulo de tração acoplado ao MET. A seta indica o visor para obtenção do valor do deslocamento aplicado à amostra. 


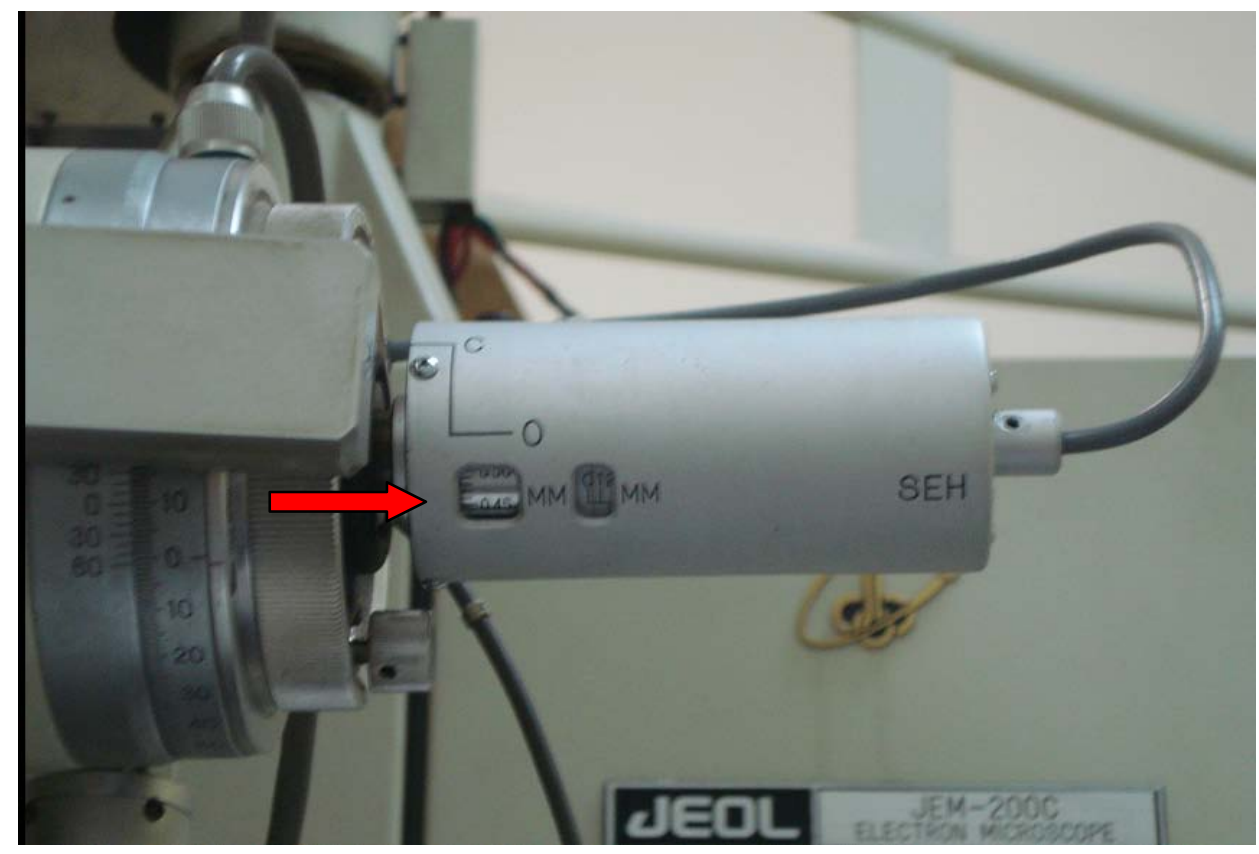

FIGURA 21: Detalhe do sistema de tração e obtenção de medidas utilizado para análise de tração in situ das amostras de Ti-6Al-4V.

A FIGURA 22 mostra em detalhe o sistema para fixação da amostra, na realização do ensaio de tração in situ.

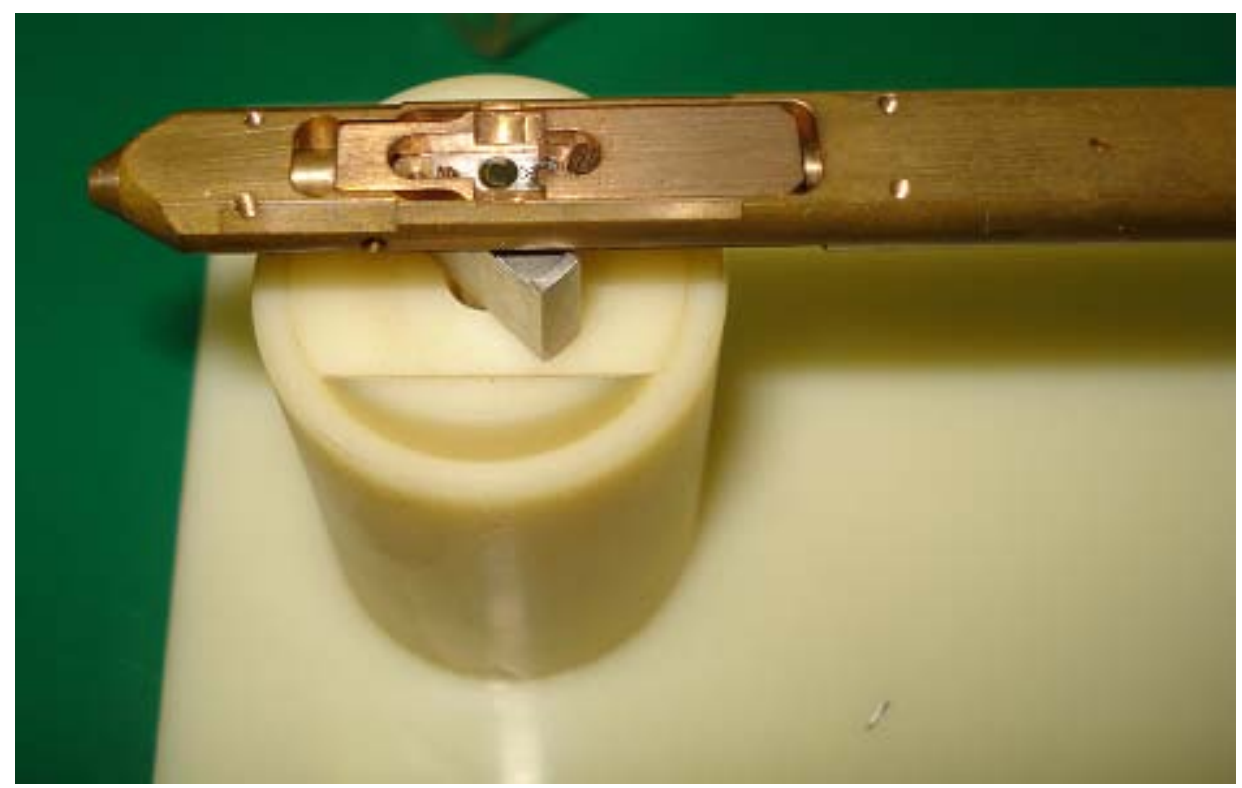

FIGURA 22: Porta-amostra para tração in situ do microscópio eletrônico de transmissão marca JEOL, com detalhe do sistema de tração e obtenção de medidas, utilizado para de análise tração das amostras de Ti-6Al-4V. 
A FIGURA 23 mostra em detalhe a amostra de Ti-6Al-4V, após o afinamento eletrolítico e conferência das medidas.

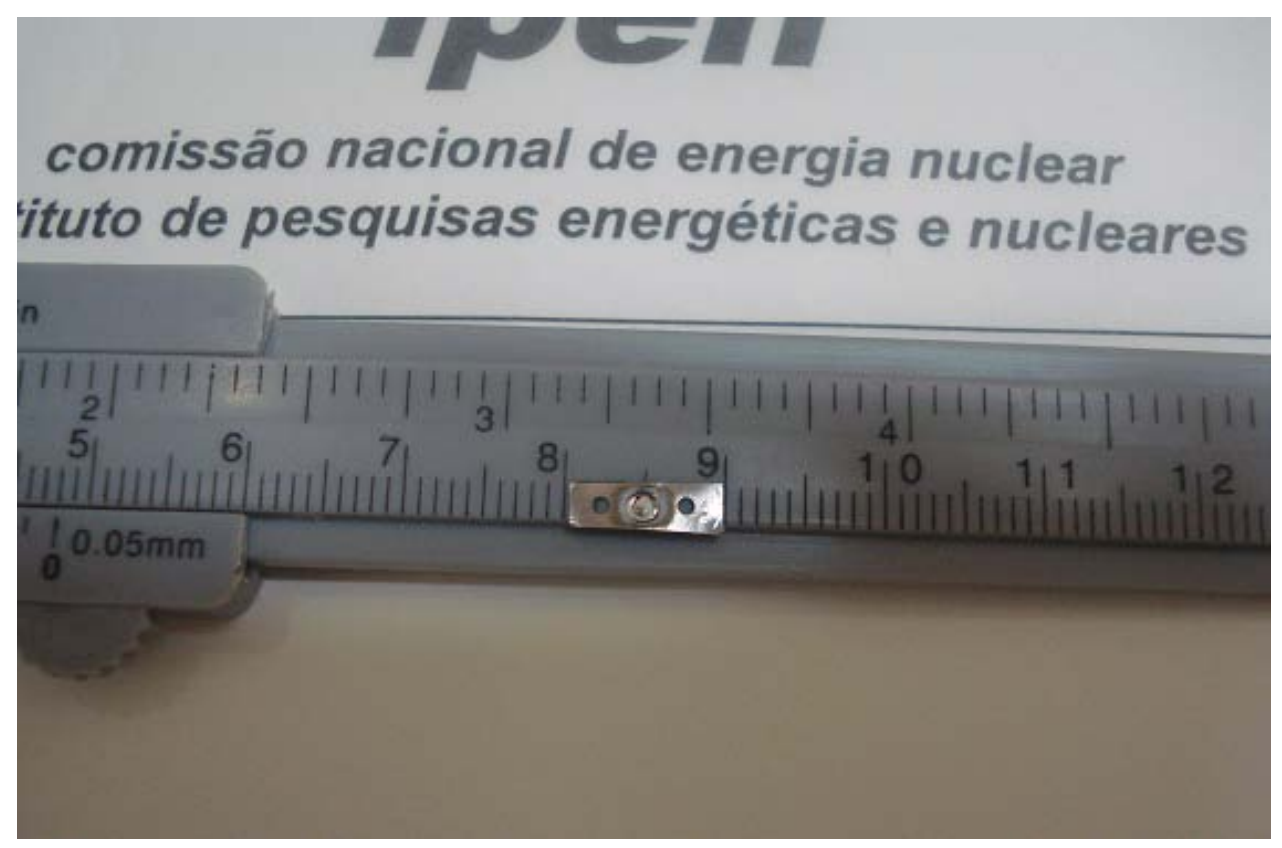

FIGURA 23: Detalhe da amostra de Ti-6Al-4V preparada para ensaio de tração in situ no microscópio eletrônico de transmissão marca JEOL.

4.3. Procedimento para análise microestrutural pela técnica analítica de Difração de Raios X (DRX)

4.3.1. Procedimento de preparo das amostras para análise microestrutural pela técnica analítica de Difração de Raios $X$

- Uma folha fina de amostra, com 1,0 mm de espessura e área superficial de $225 \mathrm{~mm}^{2}$, foi preparada cortando-a com a utilização de disco adiamantado acoplado à ISOMET;

- Fixou-se a amostra em uma lâmina de vidro; e

- A amostra foi analisada a partir de um feixe de raios $X$, gerado por meio de um tubo com anteparo de $\mathrm{Cu}$. 


\subsubsection{Equipamento utilizado na análise microestrutural por Difração de Raios X (DRX)}

É utilizado nestas análises um Difratômetro de Raios X (DRX), marca Rigaku, modelo Multiflex, mostrado na FIGURA 24, o qual possui tubo com anteparo de $\mathrm{Cu}$, gerando raios $\mathrm{X}$ de comprimento de onda $\lambda=1.54060 \AA$, variandose a análise da tensão entre 35 e $40 \mathrm{kV}$, e da corrente entre 30 e $35 \mathrm{~mA}$, sendo que os difratogramas obtidos são posteriormente analisados em conjunto com o "software" e acesso ao banco de dados das fichas do JCPDS (Joint Committe on Powder Diffraction Standards).

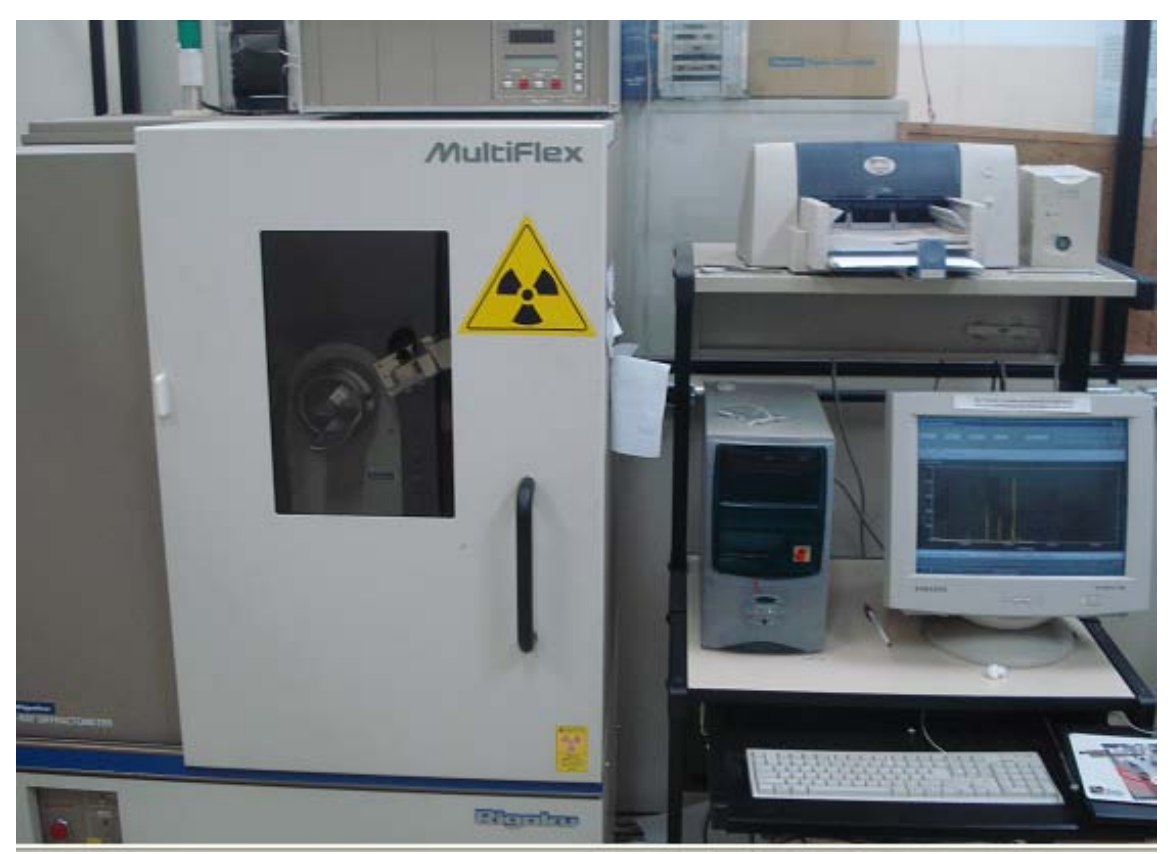

FIGURA 24: Difratômetro de raios $X$ marca RIGAKU utilizado para análise das amostras de Ti-6Al-4V.

\subsection{Tratamento térmico das amostras de titânio Ti-6Al-4V}

O tratamento térmico das amostras de titânio Ti-6Al-4V foi realizado em um forno (Carbolite) com os elementos resistivos de aquecimento de grafite, inseridas em um tubo de alumina que serve de suporte aos materiais a serem aquecidos. Este forno opera com um tubo de $80 \mathrm{~mm}$ de diâmetro e a temperatura pode alcançar $1500^{\circ} \mathrm{C}$. 
Para a liga de titânio Ti-6Al-4V foram realizados os seguintes tratamentos térmicos, partindo-se da amostra como recebida:

a) Tratamento térmico a temperatura de $1000^{\circ} \mathrm{C}$ durante uma hora e posterior resfriamento em água; e

b) Amostra inserida em um tubo de quartzo, retirando-se o ar e selando-a no tubo. Após este procedimento, a mesma foi tratada termicamente, a uma temperatura de $1000^{\circ} \mathrm{C}$ por duas horas e posteriormente resfriada em água.

As FIGURAS 25 (A) e (B) mostram em detalhe o forno utilizado para 0 tratamento térmico das amostras de titânio da liga Ti-6Al-4V.

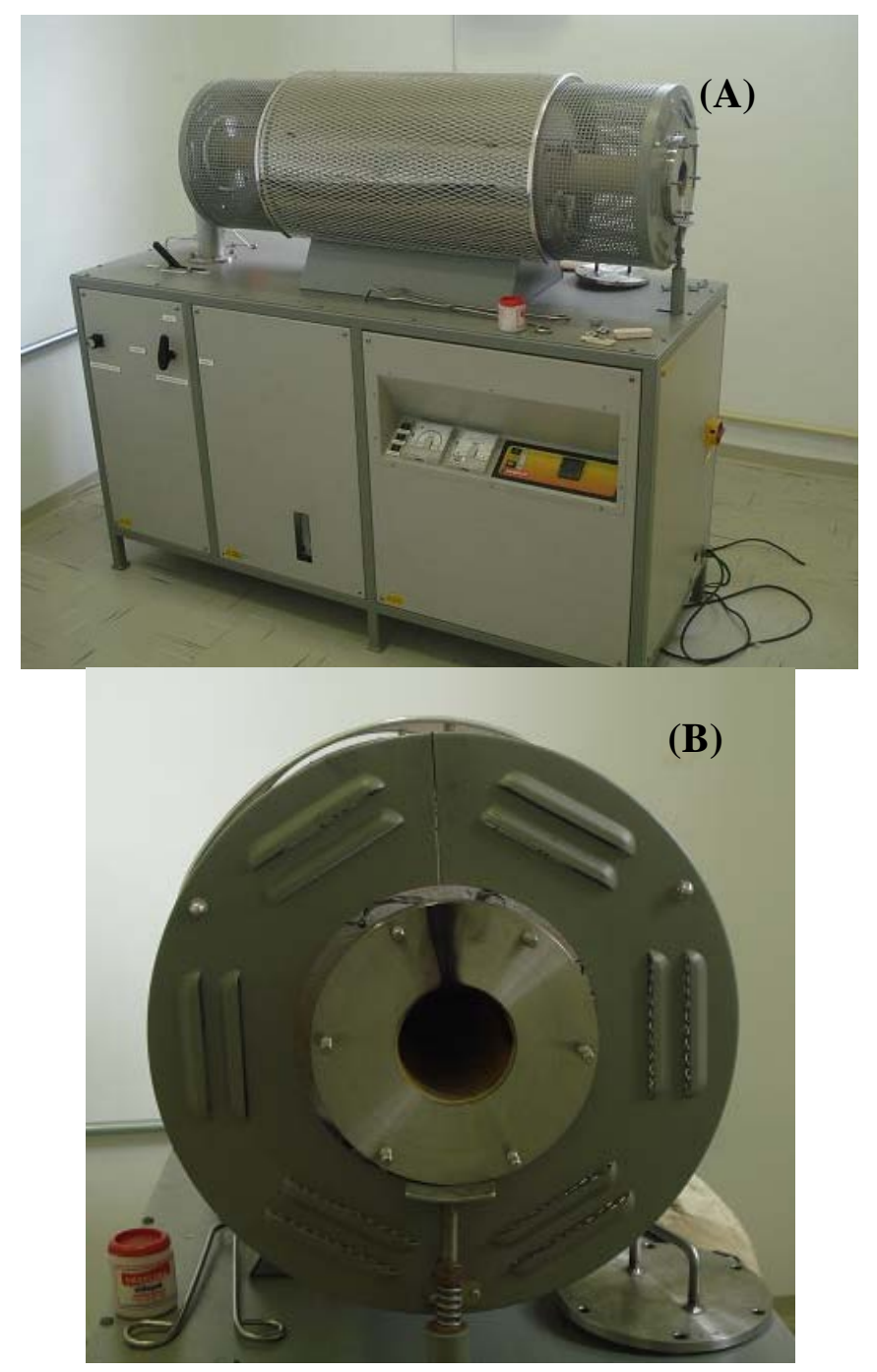

FIGURA 25: Forno resistivo (A) forno da marca Carbolite e (B) detalhe do tubo de alumina para colocação dasamostras. 


\section{RESULTADOS E DISCUSSÃO}

Neste capítulo serão apresentados os resultados obtidos na realização das diversas análises, que tiveram por objetivo, obter a caracterização morfológica e semiquantitativa da liga Ti-6Al-4V (liga comercial recozida a $800^{\circ} \mathrm{C}$ por duas horas).

Para a implementação das análises, realizaram-se tratamentos térmicos na liga de titânio Ti-6Al-4V, para uma melhor compreensão da formação das fases $\alpha$ e $\beta$, que estão presentes na amostra, conforme procedimento descrito anteriormente em 4.4 .

\subsection{Microscopia Óptica (MO)}

As FIGURAS 26 (A) e 26 (B) mostram a superfície da amostra de Ti-6Al-4V, na condição como recebida e após o lixamento, polimento, seguido do ataque químico, respectivamente, utilizando-se a mistura de $10 \mathrm{~mL}$ de ácido fluorídrico (HF), $10 \mathrm{~mL}$ de ácido nítrico $\left(\mathrm{HNO}_{3}\right)$ e $30 \mathrm{~mL}$ de ácido lático $\left(\mathrm{C}_{3} \mathrm{H}_{6} \mathrm{O}_{3}\right)$, conforme descrito em 4.1.1.

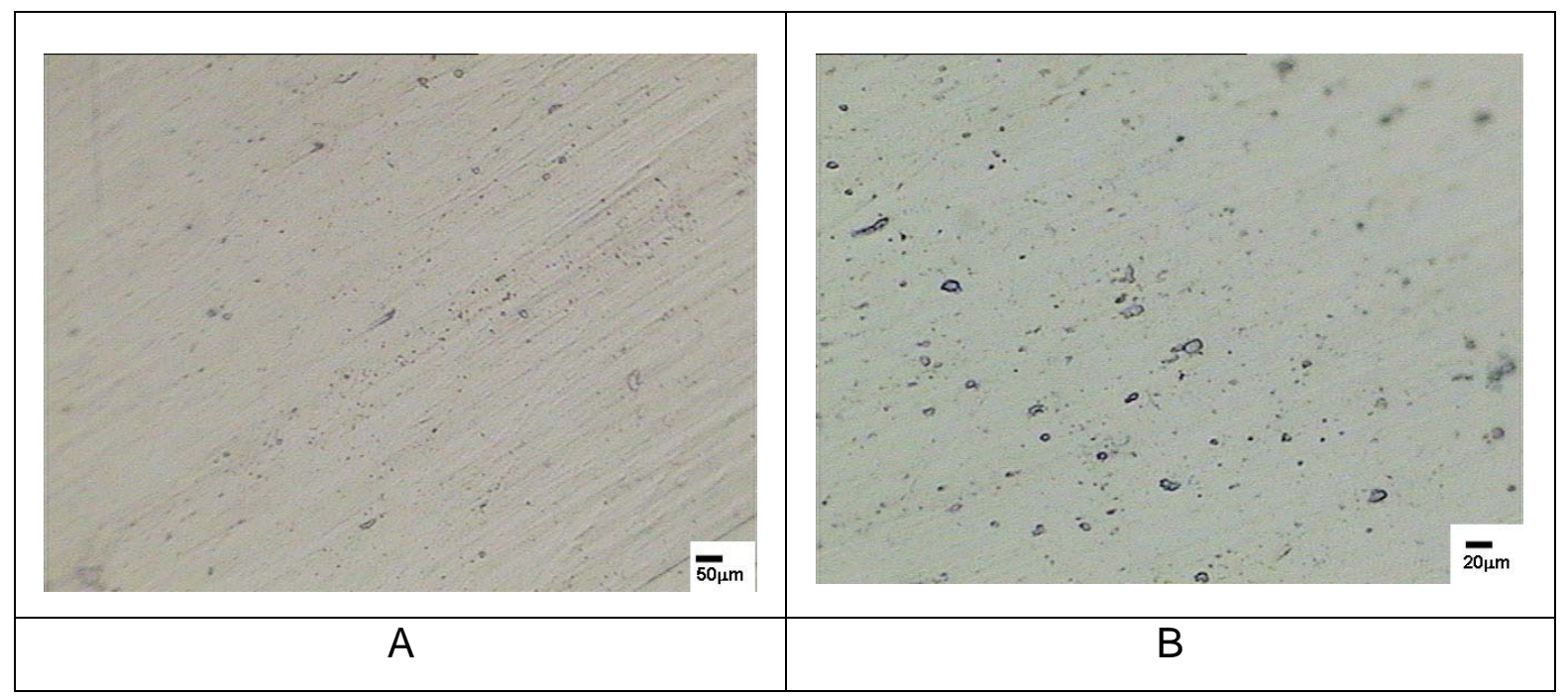

FIGURA 26: Micrografia óptica da amostra de Ti-6Al-4V tratada termicamente a $800^{\circ} \mathrm{C}$ por duas horas: (A) como recebida $r$ (B) após o lixamento, polimento e ataque químico (10 mL HF, $10 \mathrm{~mL} \mathrm{HNO}_{3}$ e $30 \mathrm{~mL} \mathrm{C}{ }_{3} \mathrm{H}_{6} \mathrm{O}_{3}$ ). 
$\mathrm{Na}$ análise da superfície da amostra por M.O., observa-se a presença de duas fases, revelando a microestrutura presente nesta liga sendo uma mistura de $\alpha+\beta$, com a fase $\beta$ distribuída homogeneamente na matriz $\alpha$, conforme descrito na literatura (Couto,2006).

Para uma melhor interpretação das fases $\alpha$ e $\beta$, presentes na liga de titânio Ti-6Al-4V, realizou-se o tratamento térmico da amostra como recebida. O procedimento experimental para o tratamento térmico aplicado à amostra está descrito em 4.4 (b).

Após a obtenção da amostra tratada termicamente, a mesma foi dividida gerando-se duas novas amostras, sendo as mesmas embutidas e preparadas para a análise no M.O., conforme procedimento experimental descrito em 4.1.1. Para a revelação da estrutura, optou-se pelo ataque químico, utilizandose a mistura de $10 \mathrm{~mL} \mathrm{HF}, 10 \mathrm{~mL} \mathrm{HNO}_{3}$ e $85 \mathrm{~mL}$ de água. Os ensaios de exposição da superfície da amostra, para o ataque químico, foram realizados variando-se o tempo de exposição em 15 segundos, 45 segundos e 90 segundos. Obteve-se um resultado adequado para as amostras expostas ao ataque químico nos tempos de $45 \mathrm{~s}$ e $90 \mathrm{~s}$.

Na FIGURA 27 são apresentadas as micrografias da amostra de Ti-6Al-4V após ataque químico. Nas FIGURAS 27 de $(A)$ a $(E)$ observa-se a revelação de uma microestrutura martensítica acicular, ou seja, a estrutura mostra a presença de lamelas em formas extremamente finas, assemelhando-se a agulhas, característica de estrutura alfa.

As estruturas alfa podem desenvolver várias morfologias que são alcançadas por uma combinação de tratamentos térmicos e/ou mecânicos. A estrutura acicular é uma das mais comuns, aparece após um resfriamento, partindo-se de uma temperatura em que predomina a fase beta $(\beta)$ e é produzido por nucleação e crescimento, sendo que o crescimento ocorre no sentido dos planos preferenciais cristalográficos de uma matriz beta primária ou ao longo de vários planos, conforme mostra a FIGURA 27 (B), conferindo ao material uma boa tenacidade à fratura, porém uma baixa resistência à tração e à fadiga (Melo,2007). 


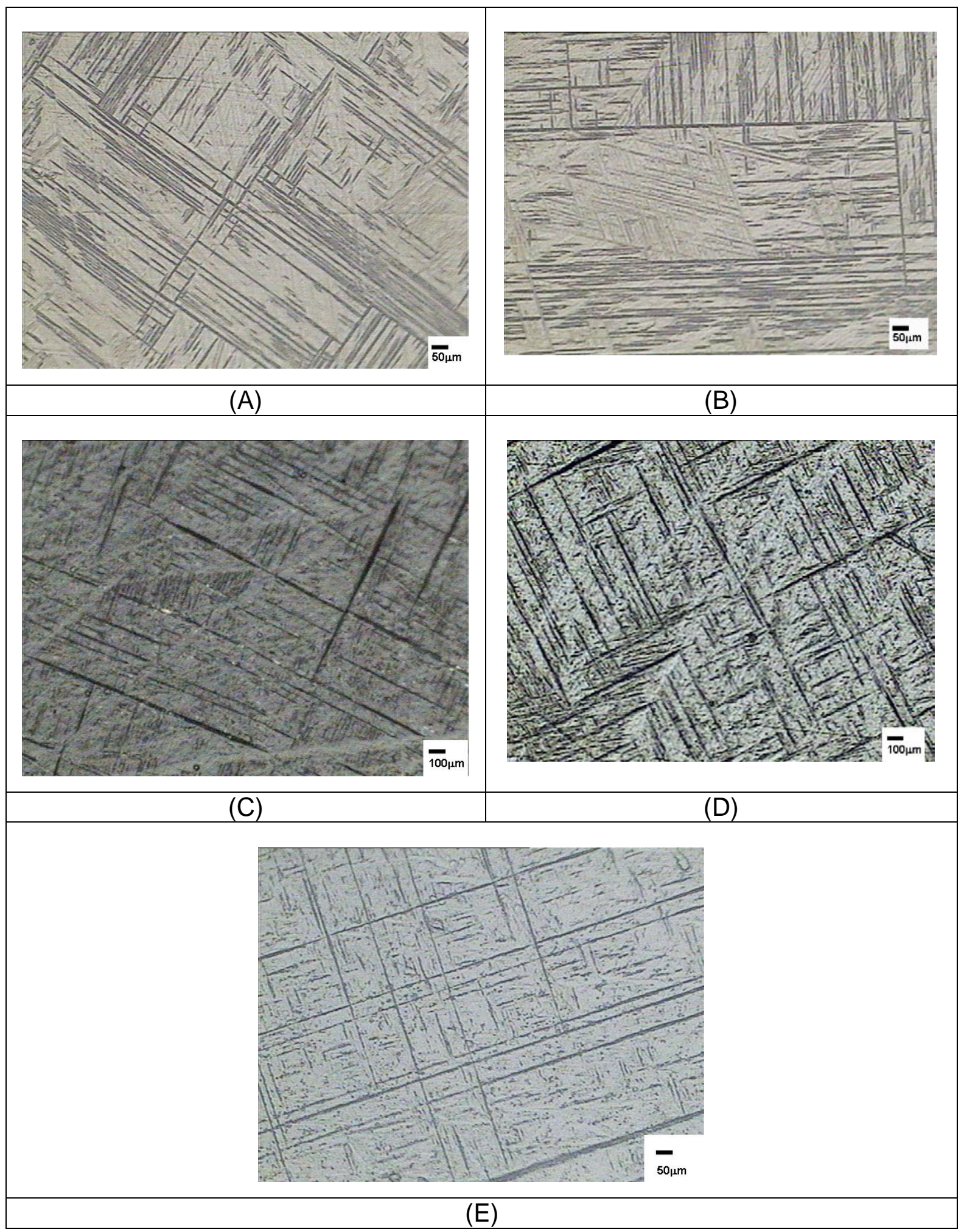

FIGURA 27: Micrografia Óptica da amostra de Ti-6Al-4V tratada termicamente sob tubo de quartzo a $1000^{\circ} \mathrm{C}$ por duas horas e resfriada em água. (A), (B) e (C) amostra submetida ao ataque químico da superfície por 45 segundos e (D) e (E) por 90 segundos. 
A FIGURA 27 (C) mostra uma microestrutura com grãos $\beta$, colônias de lamelas finas dispostas paralelamente, com orientações diversas.

Ao estudarem as propriedades da liga Ti-6Al-4V e, após o tratamento térmico com taxas de aquecimento e resfriamentos rápidos, Jesuíno et al. (2001) observaram que as altas taxas de aquecimento induzem à formação de uma microestrutura fina, totalmente $\beta$, ao contrário de taxas lentas que favorecem o crescimento de grão. Para as condições tratadas a $1000^{\circ} \mathrm{C}$, limite superior do campo $\alpha+\beta$ e resfriamento rápido, a cinética de transformação de $\alpha+\beta$ para $\beta$, pela decomposição da fase $\alpha$ primária, dentro da região $\alpha+\beta$ durante o aquecimento, produz a quebra da estrutura original.

Na FIGURA 28 observa-se a existência de estruturas distintas, delineadas possivelmente por um contorno de grão, onde coexistem estruturas lamelares, indicando a presença da fase alfa lamelar primária (região A) e uma estrutura martensítica (região B). 


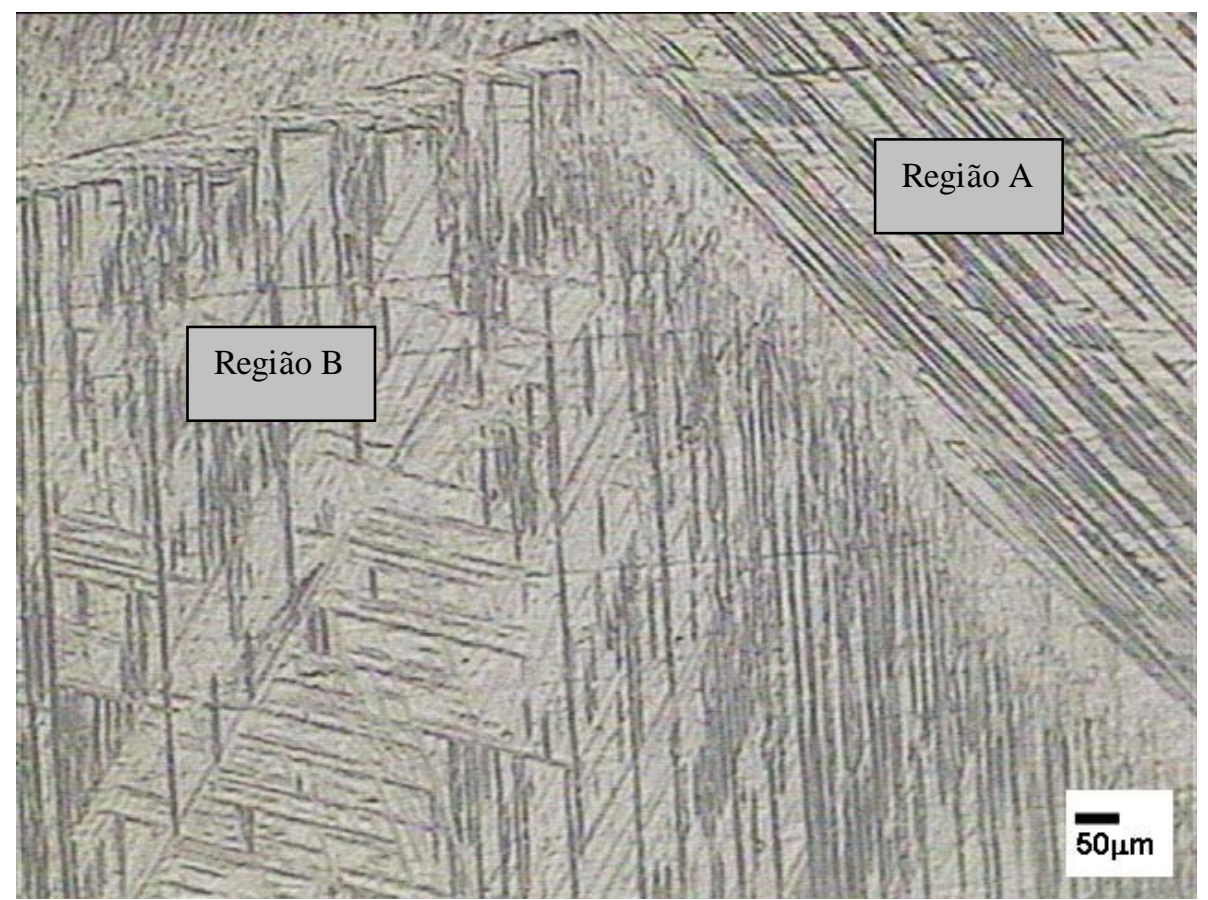

FIGURA 28: Micrografia Óptica da amostra de Ti-6Al-4V tratada termicamente a $1000{ }^{\circ} \mathrm{C}$ por duas horas e resfriada em água. Amostra submetida ao ataque por 90 segundos (10 mL HF, $10 \mathrm{~mL} \mathrm{HNO}_{3}$ e $85 \mathrm{~mL} \mathrm{H} \mathrm{H}_{2} \mathrm{O}$ ).

Estudos sobre a evolução microestrutural na liga Ti-6Al-4V foram realizados por Ding et al. (2002), por processo termomecânico, nas temperaturas de $850^{\circ} \mathrm{C}, 900^{\circ} \mathrm{C}, 950^{\circ} \mathrm{C}$ e $1000^{\circ} \mathrm{C}$. Estes autores relatam que o comportamento de deformação e transformação da fase alfa lamelar primária durante o tratamento térmico é muito complexo. Baseados em Weiss \& Semiatin (1998) relatam que existem dois mecanismos possíveis para a separação das placas do tipo $\alpha$ para segmentos mais curtos. Um destes mecanismos ocorre durante a deformação a quente promovendo o aparecimento de ângulos baixos e altos entre as placas alfa, que variam de alguns graus até cerca de $30^{\circ}$. A fase $\beta$ então pode penetrar nesta fase alfa por esta região ao longo desses contornos. 


\subsection{Microscopia Eletrônica de Varredura (MEV)}

A análise efetuada na liga de titânio Ti-6Al-4V, utilizando-se 0 Microscópio Eletrônico de Varredura (MEV), teve por objetivo a caracterização morfológica da liga e a realização da microanálise nas regiões da microestrutura, apresentadas na superfície da amostra.

\subsubsection{Caracterização morfológica e semiquantitativa da liga Ti-6Al-4V.}

A amostra da liga de titânio Ti-6Al-4V, após ser preparada conforme descrito em 4.1.1, foi submetida ao ataque químico, utilizando-se a mistura de 10 $\mathrm{mL}$ de ácido fluorídrico (HF), $10 \mathrm{~mL}$ de ácido nítrico $\left(\mathrm{HNO}_{3}\right)$ e $30 \mathrm{~mL}$ de ácido lático $\left(\mathrm{C}_{3} \mathrm{H}_{6} \mathrm{O}_{3}\right)$, para a revelação da sua microestrutura. A FIGURA 29 mostra a distribuição da fase $\beta$ presente na matriz $\alpha$ da liga de Ti-6Al-4V, sendo a imagem de elétrons retroespalhados obtida por MEV.

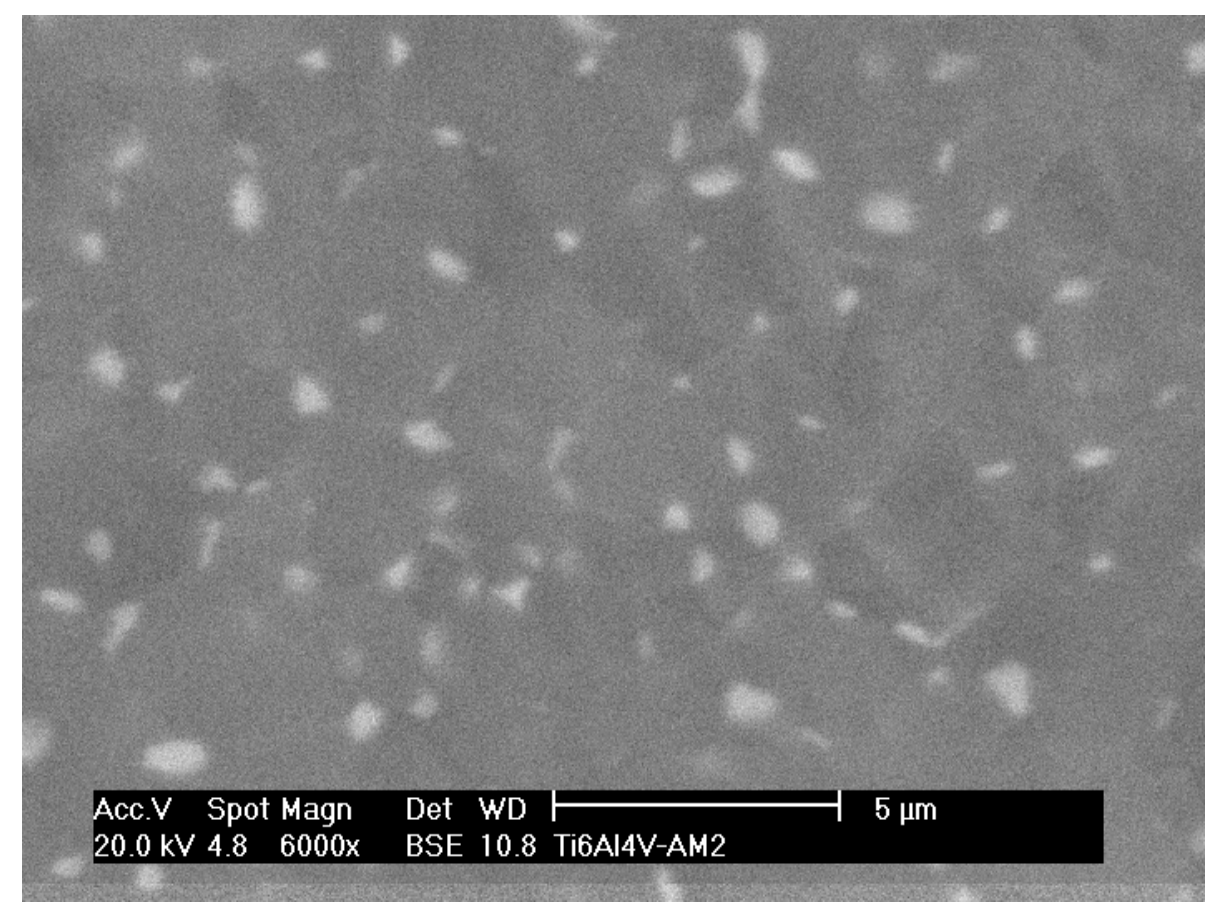

FIGURA 29: Micrografia eletrônica da amostra de Ti-6Al- 4V, atacada quimicamente, revelando regiões contendo a fase Ti $\beta$ (partículas claras) e a matriz Ti $\alpha$ (regiões escuras) obtida por MEV, por meios de imagem de elétrons retroespalhados. 
Na FIGURA 29, pode-se visualizar a presença de partículas claras e regiões escuras. A fase $\beta$ (partículas claras), está distribuída em toda a matriz de fase $\alpha$ (regiões escuras).

Para o estudo das fases presentes, realizou-se a microanálise nas partículas claras (fase $\beta$ ), observada na micrografia da FIGURA 29. Com o intuito de se determinar os elementos químicos presentes na região que apresenta contraste claro (fase beta) da liga de Ti-6Al-4V, foi realizada a microanálise obtendo-se o espectro por energia dispersiva (EDS) da fase analisada, o qual apresenta os elementos químicos: titânio, alumínio e vanádio, conforme mostrado na FIGURA 30.

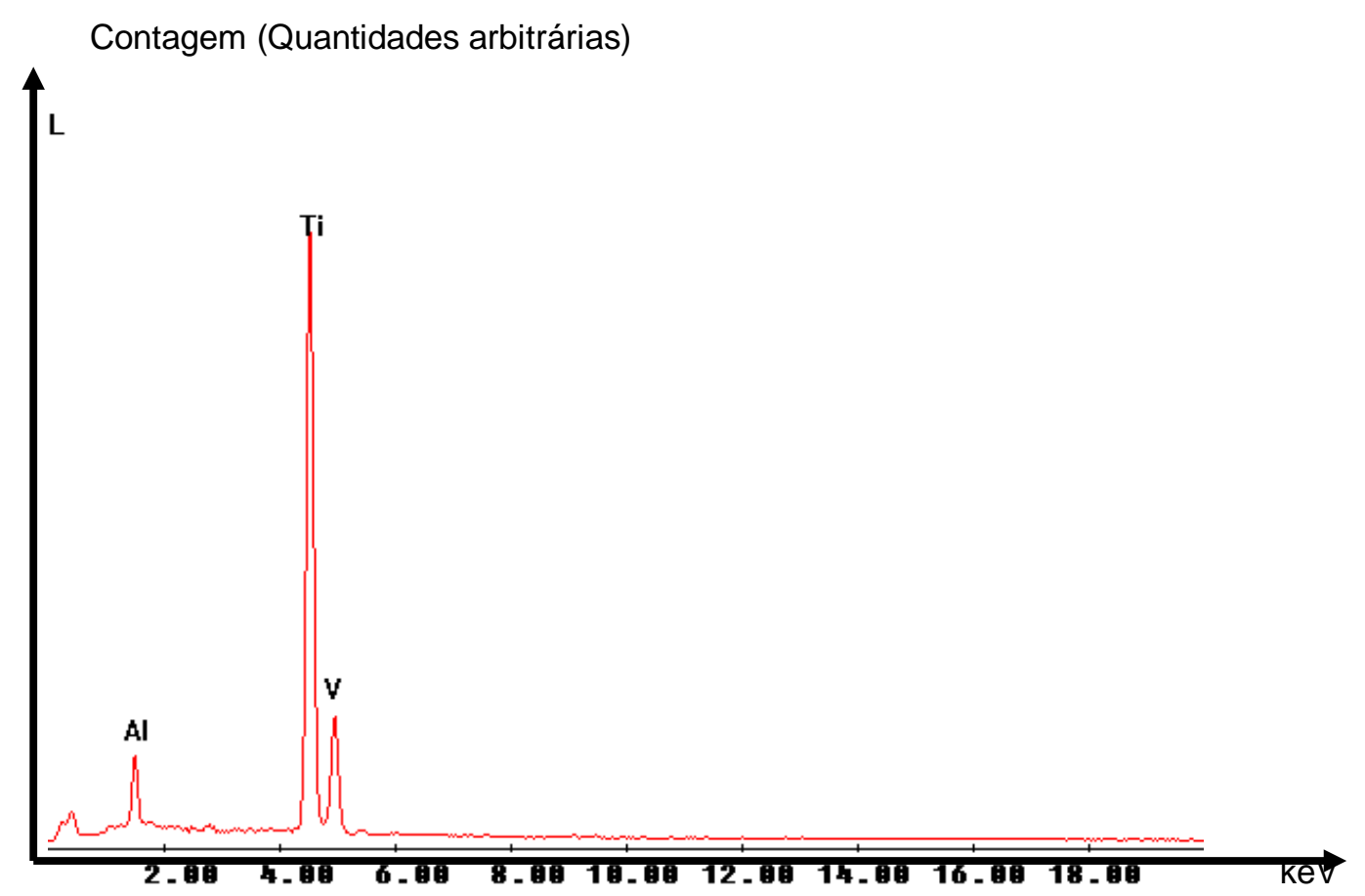

FIGURA 30: Espectro por Energia Dispersiva (EDS) das partículas claras (Fase Tiß), após ataque químico, obtidas por MEV/EDS, com a presença dos elementos Al, Ti e $\mathrm{V}$.

Na TABELA 3 é apresentada a respectiva composição média em porcentagem de massa atômica dos elementos citados na análise semiquantitativa. 
TABELA 3: Resultados das análises semiquantitativas relativas aos EDS da FIGURA 30.

\begin{tabular}{|c|c|}
\hline Elemento químico & Porcentagem em massa atômica (\%) \\
\hline Alumínio (Al) & 6,99 \\
\hline Titânio (Ti) & 86,15 \\
\hline Vanádio (V) & 6,86 \\
\hline
\end{tabular}

Após a microanálise das partículas claras (fase $\beta$ do titânio) foi realizada também a microanálise nas regiões escuras (fase $\alpha$ do âtifo), observadas na micrografia da FIGURA 29. Com o intuito de se determinar os elementos químicos presentes na fase alfa da liga de Ti-6Al-4V, foram obtidos os espectros por energia dispersiva (EDS) da fase analisada, o qual apresenta os seguintes elementos químicos: titânio, alumínio e vanádio, conforme mostra a FIGURA 31.

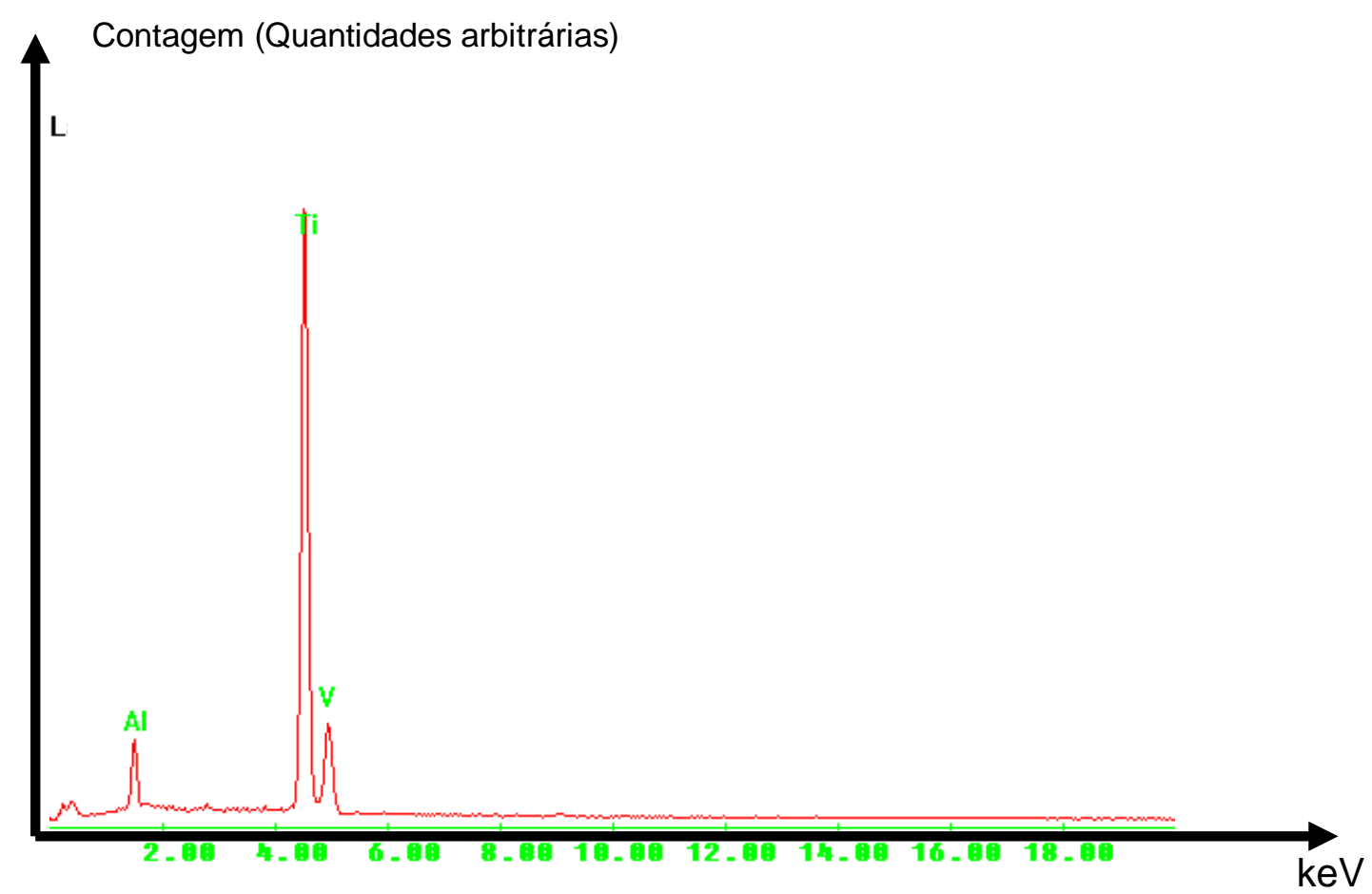

FIGURA 31: Espectro por Energia Dispersiva (EDS) das regiões escuras (Fase Ti $\alpha$ ), após ataque químico, obtidas por MEV/EDS, com a presença dos elementos Al, Ti e V. 
Na Tabela 4 é apresentada a composição média em porcentagem de massa atômica dos elementos químicos encontrados nas análises semiquantitativas.

TABELA 4: Resultados das análises semiquantitativas relativas aos EDS da FIGURA 31.

\begin{tabular}{|c|c|}
\hline Elemento químico & Porcentagem massa atômica (\%) \\
\hline Alumínio (Al) & 5,59 \\
\hline Titânio (Ti) & 89,21 \\
\hline Vanádio (V) & 5,21 \\
\hline
\end{tabular}

Comparando-se os espectros obtidos por EDS, nas FIGURAS 30 e 31, para ambas as fases presentes na amostra, verifica-se que são idênticos, apresentando os elementos químicos: titânio, alumínio e vanádio, cujo resultado é esperado.

Na Tabela 5 é realizada a comparação dos resultados obtidos nas respectivas análises semiquantitativas, efetuadas nas fases alfa e beta, presentes na liga de titânio Ti-6Al-4V, onde se observou uma pequena variação na concentração dos elementos químicos presentes em cada fase.

TABELA 5: Comparação dos resultados obtidos nas análises semiquantitativas realizadas nas fases alfa e beta, presentes na amostra de Ti-6Al-4V.

\begin{tabular}{|c|c|c|}
\hline Elemento químico & $\begin{array}{c}\text { Fase beta } \\
\text { (\% em massa atômica) }\end{array}$ & $\begin{array}{c}\text { Fase alfa } \\
\text { (\% em massa atômica) }\end{array}$ \\
\hline $\mathrm{Al}$ & 6,99 & 5,59 \\
\hline $\mathrm{Ti}$ & 86,15 & 89,21 \\
\hline $\mathrm{V}$ & 6,86 & 5,21 \\
\hline
\end{tabular}

Com o objetivo de revelar a fase beta prešente na matriz de titânio alfa e a sua distribuição na amostra, foi realizado o ataque químico utilizando-se a mistura de $10 \mathrm{~mL}$ de $\mathrm{HF}, 10 \mathrm{~mL} \mathrm{HNO}_{3}$ e $30 \mathrm{~mL} \mathrm{C}_{3} \mathrm{H}_{6} \mathrm{O}_{3}$, em outra amostra de 
Ti-6Al-4V, aumentando-se o tempo de exposição ao ataque químico para cinco minutos. Após a secagem e recobrimento com carbono amorfo a amostra foi analisada no MEV/EDS.

Pode-se observar, na FIGURA 32, que o ataque químico aplicado à superfície da amostra, provocou uma corrosão e alteração da superfície da amostra, atacando a fase escura (Ti $\alpha$ ) e expondo partículas claras (Ti $\beta$ ) com dimensão aproximada de $1 \mu \mathrm{m}$.

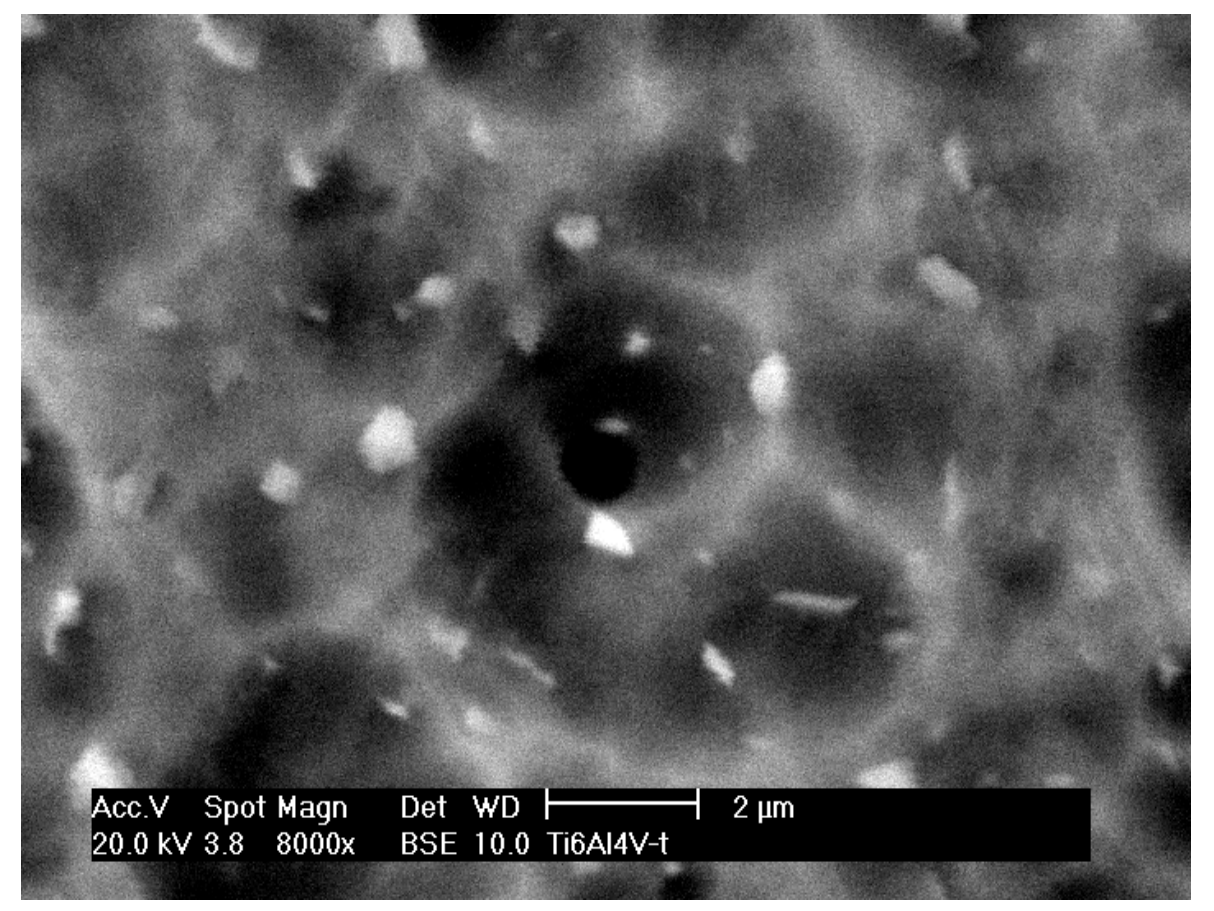

FIGURA 32: Micrografia eletrônica da amostra de Ti-6Al-4V, atacada quimicamente com tempo de exposição de cinco minutos (mistura de $10 \mathrm{~mL} \mathrm{HF,} 10 \mathrm{~mL} \mathrm{HNO}_{3}$ e $30 \mathrm{~mL} \mathrm{C} \mathrm{H}_{6} \mathrm{O}_{3}$ ).

Dada a grande profundidade de foco obtida pelo MEV, as FIGURAS 33 (A), (B), (C) e (D) mostram partículas apresentando contraste de imagem clarA na matriz da liga de Ti-6Al-4V, dispostas aleatoriamente e seguindo as regiões corroídas pelo ataque químico, imposto à superfície da amostra. Observa-se nestas micrografias a presença de duas fases: $\alpha$ (hexagonal compacta), cuja região apresenta contraste escuro e $\beta$ (cúbica de corpo centrado), cujas partículas apresentam contraste claro, dispostas na matriz da liga, indicando que a 
microestrutura presente na liga de Ti-6Al-4V investigada, apresenta uma mistura de $\alpha+\beta$, ou seja, uma estrutura duplex, com a fase beta distribuída uniformemente na matriz alfa.

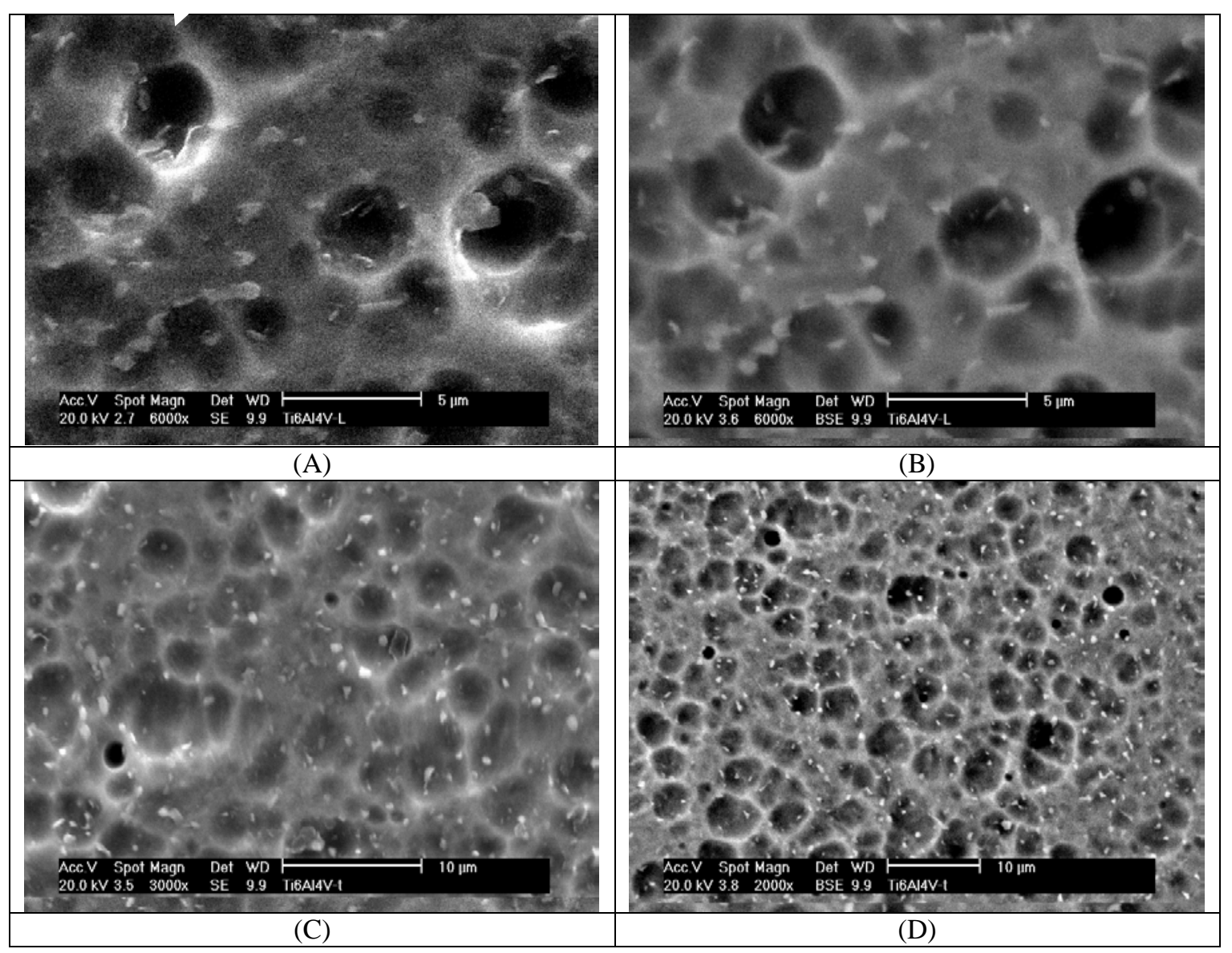

FIGURA 33: Micrografias da superfície da amostra de Ti-6Al-4V, atacada quimicamente, com tempo de exposição de cinco minutos. (A) e (C) imagem de elétrons secundários, (B) e (D) imagem de elétrons retroespalhados (mistura de $10 \mathrm{~mL} \mathrm{HF}, 10 \mathrm{~mL} \mathrm{HNO}_{3}$ e $30 \mathrm{~mL}$ $\mathrm{C}_{3} \mathrm{H}_{6} \mathrm{O}_{3}$ ). 


\subsubsection{Caracterização quantitativa da liga Ti-6Al-4V.}

A análise quantitativa foi realizada utilizando-se um Detector X-Max Silicon da Oxford Instruments, acoplado a um microscópio eletrônico de varredura de emissão de campo, da marca Zeiss, modelo Supra 55 e o programa Inca Energy que permite separar os picos sobrepostos de titânio e vanádio ( $\mathrm{Ti}-\mathrm{K} \beta$ e $\mathrm{V}$-Ka) tornando fácil a identificação e quantificação destes elementos. O espectro foi obtido com tempo de aquisição de cinco segundos, tensão do feixe de $20 \mathrm{kV}$ e uma corrente de aproximadamente 1,5 nA. Como esses picos não podem ser separados de forma visível por EDS, é preciso contar com as rotinas de deconvolução para a correta identificação e quantificação do espectro EDS.

A FIGURA 34 mostra o Espectro de Energia Dispersiva (EDS) obtido após a microanálise de superfície, no Detector X-Max Silicon, onde se observa a sobreposição dos picos dos elementos químicos Ti e $\mathrm{V}$, presentes na amostra de Ti-6Al-4V.

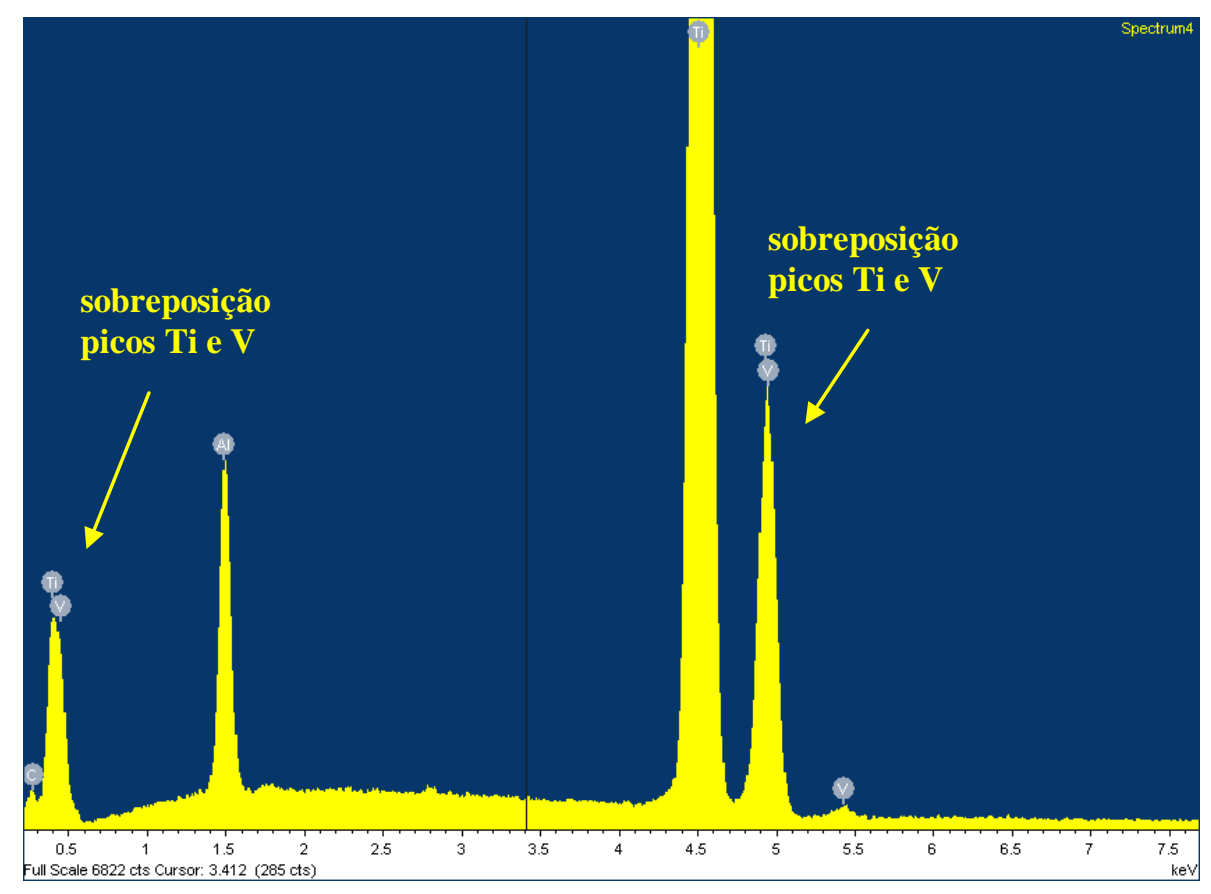

FIGURA 34: Espectro de Energia Dispersiva (EDS) obtido após a microanálise da superfície da amostra, onde se observa a sobreposição dos picos dos elementos químicos Ti e $\mathrm{V}$, presentes na amostra de Ti-6Al-4V. 
A Tabela 6 apresenta a variação, em diferentes pontos da superfície da amostra Ti-6Al-4V, dos elementos químicos $\mathrm{Ti}$, Al e $\mathrm{V}$ confirmando os valores obtidos nas micro análises realizadas distintamente nas regiões claras e escuras, apresentadas em 5.2.1.

TABELA 6: Resultado da análise quantitativa relativo ao EDS, conforme espectro mostrado na FIGURA 34.

\begin{tabular}{|c|c|c|c|c|}
\hline Espectro & $\mathrm{Al}$ & $\mathrm{Ti}$ & $\mathrm{V}$ & Total \\
\hline & & & & \\
\hline Espectro 1 & 6,11 & 90,02 & 3,86 & 100,00 \\
\hline Espectro 2 & 6,16 & 89,71 & 4,13 & 100,00 \\
\hline Espectro 3 & 6,29 & 89,71 & 4,00 & 100,00 \\
\hline Espectro 4 & $6 ., 14$ & 90,12 & 3,74 & 100,00 \\
\hline & & & & \\
\hline Média & 6,18 & 89,89 & 3,93 & 100,00 \\
\hline S & 0,08 & 0,21 & 0,17 & \\
\hline Max. & 6,29 & 90,12 & 4,13 & \\
\hline Min. & 6,11 & 89,71 & 3,74 & \\
\hline
\end{tabular}

* resultados expressos em porcentagem de massa. 


\subsection{Microscopia Eletrônica de Varredura (MEV) associada à Difração de Elétrons Retroespalhados (EBSD)}

A análise pelo MEV/EBSD requer cuidados especiais na fase de lixamento e polimento, pois a superfície da amostra deve estar perfeitamente plana e atacada para a visualização dos padrões de difração dos elétrons retroespalhados (EBSD). A amostra de titânio da liga Ti-6Al-4V, como recebida, foi preparada para a análise no MEV/EBSD.

Para a análise da superfície da amostra, utilizou-se o MEV, da marca Philips, modelo XL30, com câmera CCD e sistema para a interpretação da Difração de Elétrons Retroespalhados (EBSD) da marca TSL (TexSEM Laboratories Inc.). Para a operação do equipamento, utilizou-se corrente do feixe de elétrons da ordem de 5 nA e tensão de aceleração de $30 \mathrm{kV}$. A amostra foi montada no suporte do MEV com uma distância de trabalho aproximada de 20 $\mathrm{mm}$ e inclinação de $75^{\circ}$, em relação ao feixe incidente, durante a análise da superfície, para se visualizar a distribuição da fase $\beta$ e da fase $\alpha$ na superfcie da amostra.

A FIGURA 35 mostra a micrografia eletrônica relativa aos padrões obtidos por EBSD, para a fase $\beta$ presente na ísiquedta liga de titânio Ti-6Al-4V. Observa-se a distribuição da fase $\beta$ dispersa na matriz de fase $\alpha$. $O$ tamanho de grão e as orientações inerentes a fase $\beta$ dependem da temperatura de tratamento da amostra. A fase $\alpha$ e a fase $\beta$, presentes na amostra da liga de Ti-6Al-4V, se diferenciam pela estrutura cristalina. A fase $\alpha$ apresenta estrutura hexagonal compacta (hc) e a fase $\beta$ apresenta estrutura cúbica de corpo centrado (ccc).

Na região A da FIGURA 35 observa-se uma concentração da fase $\beta$, indicando a retenção dessa fase, possivelmente em função do tratamento térmico a que foi submetida a amostra. Verifica-se que a distribuição da fase $\beta$, presente na amostra, está disposta na forma de faixas contínuas, seguindo-se aos contornos de grãos da fase $\alpha$ (região escura). 


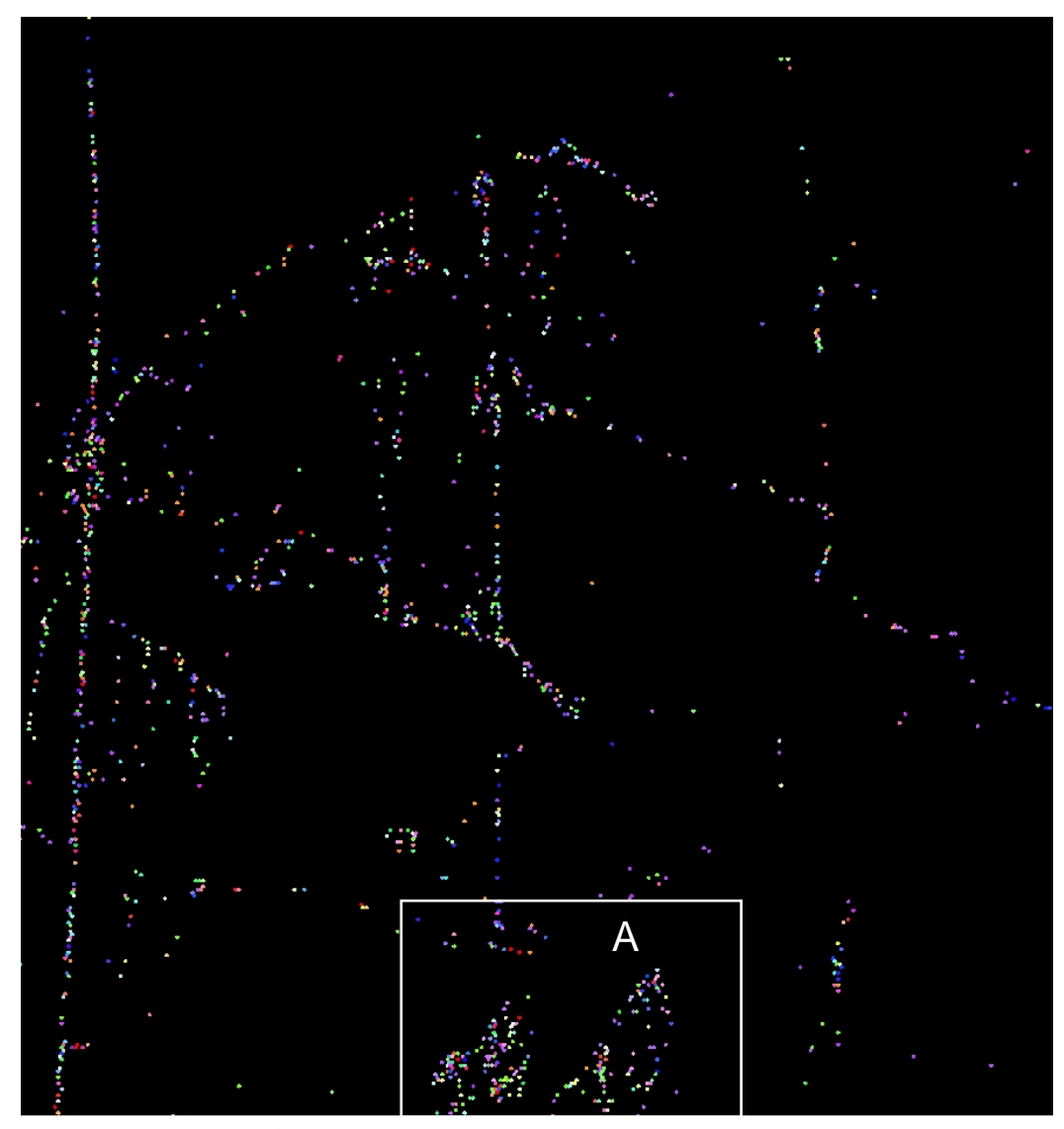

$70.00 \mu \mathrm{m}=70$ steps $\quad$ IPF [001]

FIGURA 35: Micrografia eletrônica da amostra de Ti-6Al-4V (como recebida), onde se observa as regiões contendo a presença da fase $\beta$ ao longo da superfície da amostra, obtidas por MEV/EBSD. 

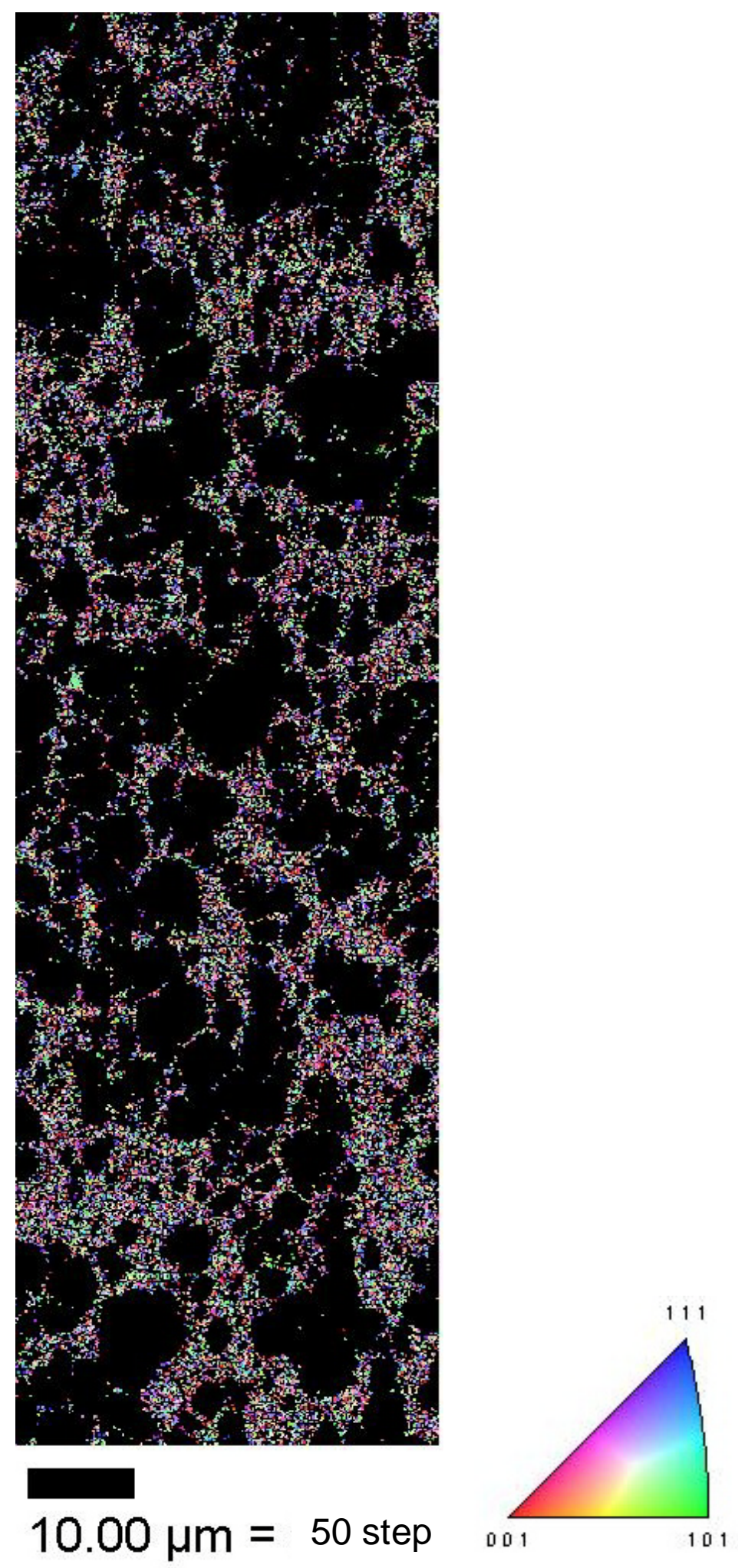

FIGURA 36: Micrografia eletrônica da amostra de Ti-6Al-4V das regiões contendo a presença da fase $\beta$ nesta liga de titânio e o respectivo triângulo de referência de orientações dos respectivos planos apresentados, obtido por MEV/EBSD. 
A Figura 36 mostra os padrões obtidos por EBSD, para a fase presente na liga de titânio Ti-6Al-4V. Observa-se a existência de regiões contínuas formando uma colônia de fase $\beta$, no contorno de grão da fase $\alpha$. Através da distribuição de cores apresentada pela fase $\beta$, observa-se uma maior densidade do plano (001) nos contornos dos grãos.

Como a distribuição e o tamanho da fase a presente na amostra Ti-6Al-4V é bem maior em comparação à fas $\beta$, pode -se visualizar facilmente a fase $\alpha$ presente na amostra, indicada pelas cores: vermelho, cinza e roxo e a distribuição da fase $\beta$ nos contornos de grão, como mostra a FIGURA 37.

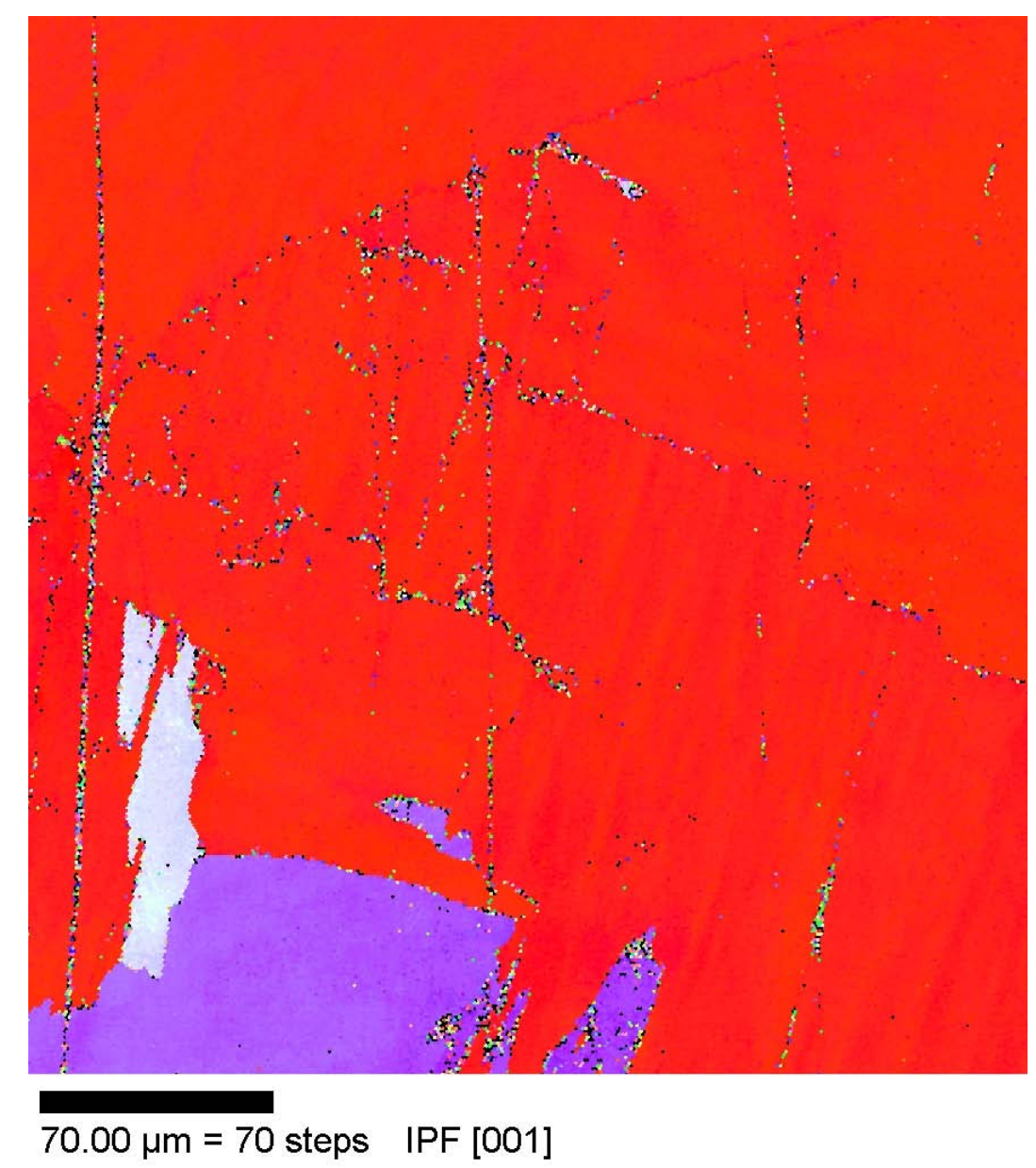

FIGURA 37: Micrografia eletrônica da amostra de Ti-6Al-4V de regiões com a presença da fase $\alpha$ do titânio (vermelho, cinza e roxo) e da fase $\beta$ distribuída nos contornos de grão da fase $\alpha$, obtida por MEV/EBSD. 
Na FIGURA 38 pode-se visualizar a presença da fase $\alpha$ do titânio ao longo da superfície da amostra, bem como a orientação cristalográfica desta fase, através da variação de cor, de acordo com o respectivo triângulo de referência de orientação dos planos cristalinos.

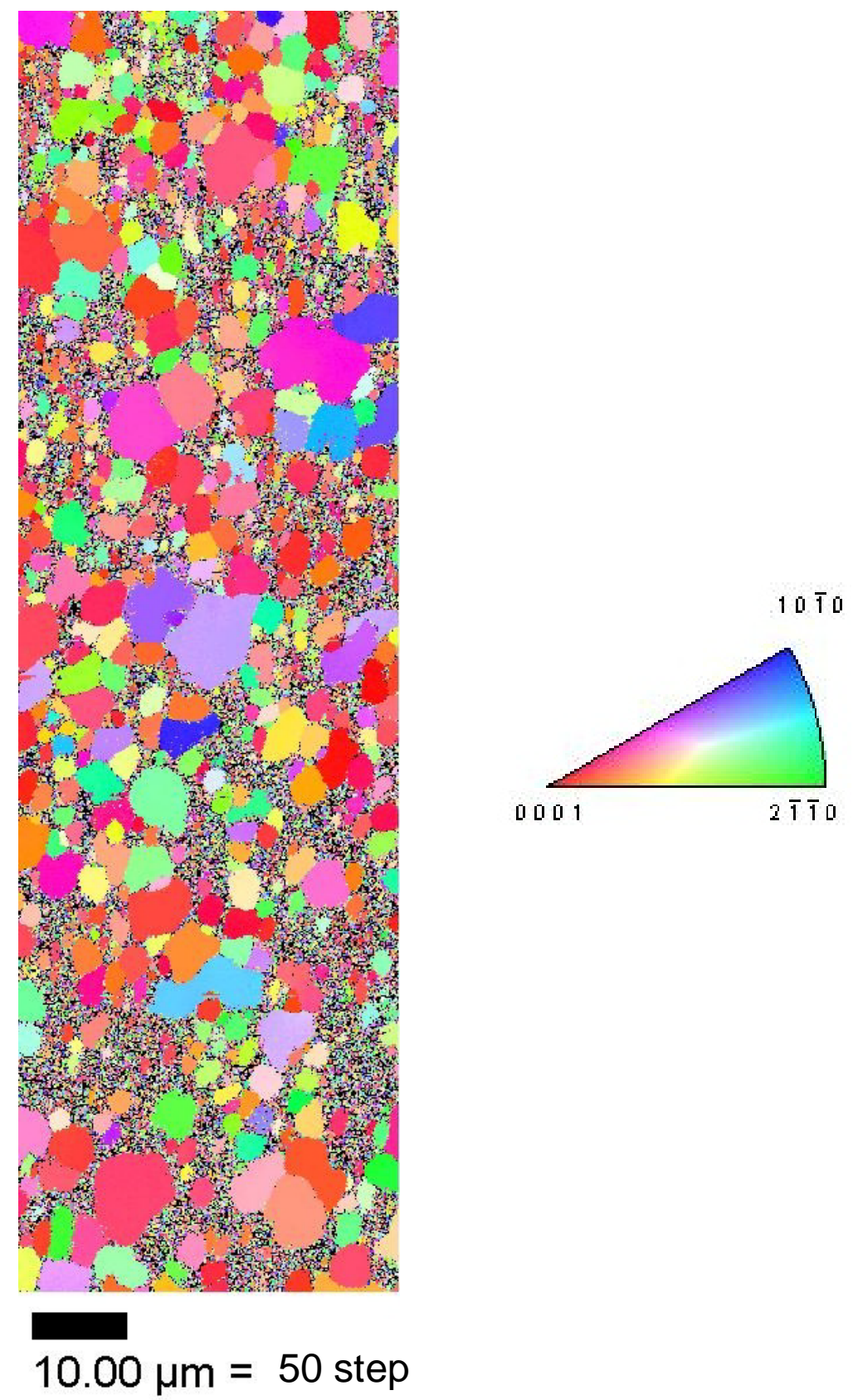

FIGURA 38: Micrografia eletrônica da amostra de Ti-6Al-4V das regiões com a presença da fase d a liga de titânio Ti-6Al-4V e o respectivo triângulo de referência de orientações dos planos cristalinos dispostos na superfície da amostra, obtido por MEV/EBSD. 
A partir das medidas obtidas por EBSD foi possível identificar a presença de pequenos grãos da fase $\beta$, distribuídos no contorno de grão da fase $\alpha$ na amostra analisada. Estas informações corroboram com as análises realizadas na amostra, descritas no item 5.2. 


\subsection{Difração de Raios X (DRX)}

Com o objetivo de estudar a presença das fases $\alpha$ e $\beta$ existentes na amostra de Ti-6Al-4V, como recebida, foram realizadas análises utilizando-se a Difração de Raios X (DRX), após o preparo da amostra, conforme descrito anteriormente em 4.3.1.

A FIGURA 39 mostra a Curva de Difração obtida na análise por DRX da amostra de Ti-6Al-4V e sua respectiva interpretação, a partir dos dez picos obtidos, com intensidades distintas, sendo estes picos determinados após análise e confronto com o banco de dados das fichas do "Joint Commite on Powder Diffractions Standards (JCPDS)".

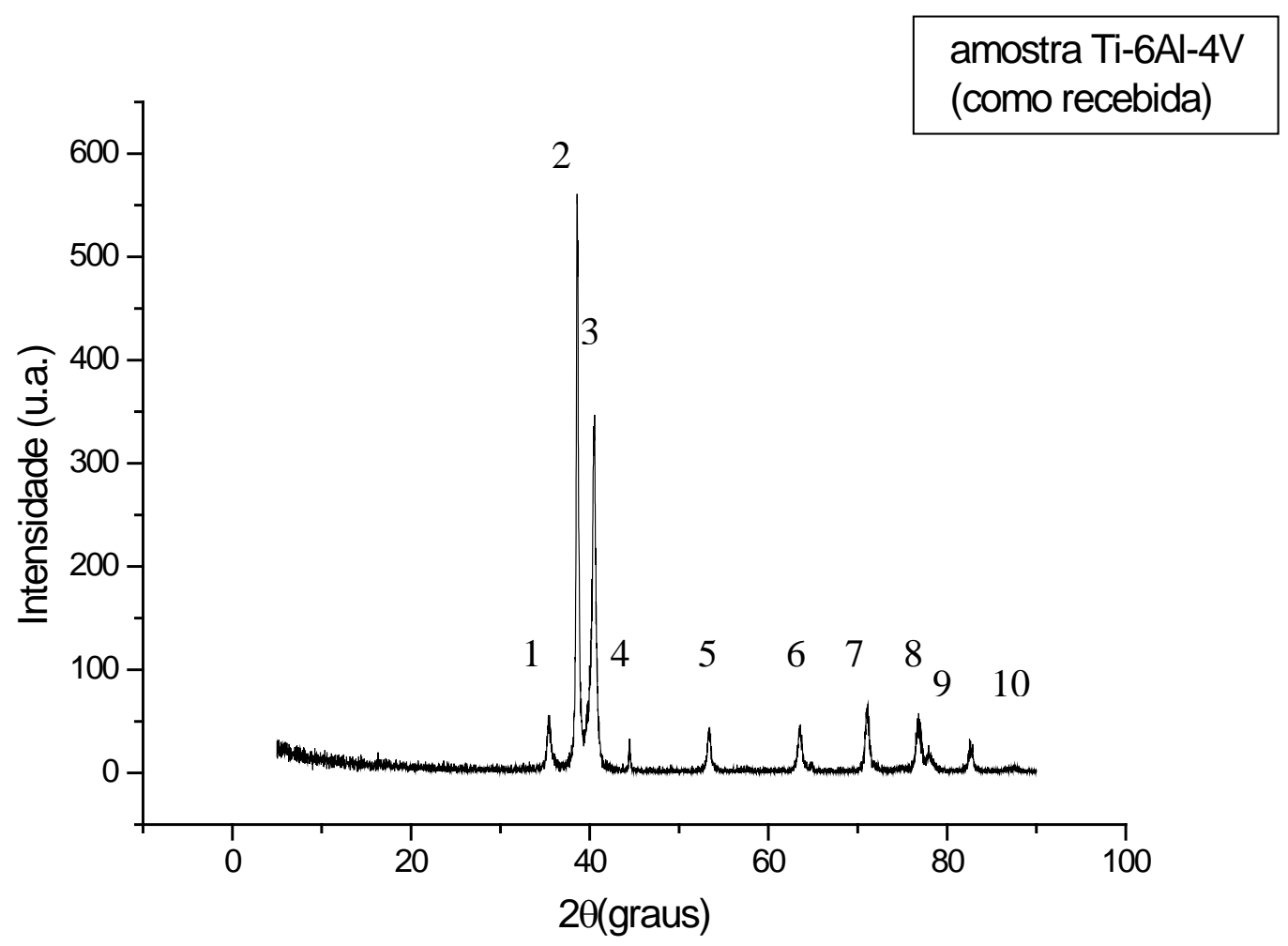

FIGURA 39: Curva de Difração de Raios X obtida por DRX da liga de titânio Ti-6Al-4V, da amostra como recebida recozida a $800^{\circ} \mathrm{C}$ por 2 horas. Velocidade de varredura para análise de $2^{\circ}$ por minuto. 
Na TABELA 7 são apresentados os valores obtidos, relacionando-se os diversos picos determinados, em função da intensidade, do ângulo $2 \theta$ e da distância interplanar (d), apresentados na Curva de Difração de Raios X e as possíveis correspondências das fases $\alpha$ e $\beta$, encontradas na amostra de Ti-6Al4V, para o titânio.

TABELA 7: Resultados obtidos a partir da Curva de Difração de Raios $X$ da Figura 39 relacionando-se o valor da distância interplanar (d) e o ângulo $2 \theta$ (graus).

\begin{tabular}{|c|c|c|c|c|}
\hline Pico & $\begin{array}{c}2 \theta \\
\text { (graus) }\end{array}$ & Valor d & Intensidade & Fase encontrada \\
\hline 1 & 35,500 & 2,5266 & 56 & Ti $\alpha$ (hc) \\
\hline 2 & 38,580 & 2,3317 & 561 & $\mathrm{Ti} \beta$ (ccc) \\
\hline 3 & 40,540 & 2,2234 & 347 & Ti $\alpha(h c)$ \\
\hline 4 & 44,460 & 2,0360 & 41 & Ti $\alpha(h c)$ \\
\hline 5 & 53,420 & 1,7137 & 41 & Ti $\alpha(h c)$ \\
\hline 6 & 63,470 & 1,4589 & 37 & Ti $\alpha(h c)$ \\
\hline 7 & 71,120 & 1,3245 & 66 & Ti $\alpha(h c)$ \\
\hline 8 & 76,920 & 1,2385 & 40 & Ti $\alpha(h c)$ \\
\hline 9 & 77,960 & 1,2245 & 20 & Ti $\alpha(h c)$ \\
\hline 10 & 82,540 & 1,1678 & 23 & $\mathrm{Ti} \beta(\mathbf{c c c})$ \\
\hline
\end{tabular}

Analisando-se os valores para os dez picos obtidos na curva de difração de Raios X da FIGURA 39, e comparando-os com os valores da distância interplanar (d) e o ângulo 20, apresentados na Tabela 6, pôde-se indexá-los com as fichas do "Joint Committe on Powder Diffraction Standards" (JCPDS), e determinar a presença da fase para o titânio $\alpha$, que apresenta estrutura hexagonal compacta (hc), bem como para o titânio $\beta$, que apresenta estrutura cúbica de corpo centrado (ccc). Pode-se observar que o pico número dois, como mostra a 
FIGURA 39 e apresentado na TABELA 7, característico para o titânio fase beta (Tiß-ccc), é o mais intenso e corresponde ao plano de reflexão (110). Este plano de reflexão, mais intenso para a fase beta do titânio (Tiß-ccc) possui uma posição coincidente ao plano (002) para o titânio de fase alfa (Ti $\alpha$-hc). O pico número dez, como mostra a FIGURA 39 e está apresentado na TABELA 7, é característico para o titânio de fase beta (Tiß-ccc) e corresponde ao plano de reflexão (220), sendo perfeitamente identificado sem que haja coincidência com planos da fase alfa do titânio (Ti $\alpha-h c)$.

Com o objetivo de se avaliar a presença da fase $\beta$, presente na amostra de Ti-6Al-4V, realizou-se o tratamento térmico da mesma. A amostra foi submetida a uma temperatura de $1000^{\circ} \mathrm{C}$ durante uma hora e resfriada em água, conforme descrito no item 4.4. O intuito do presente tratamento térmico foi obter um aumento da fase $\beta$ e a sua retenção durante o processo de resfriamento. A amostra de Ti-6Al-4V, após o tratamento térmico, foi submetida à análise por DRX, obtendo-se a curva de difração de Raios X da FIGURA 40.

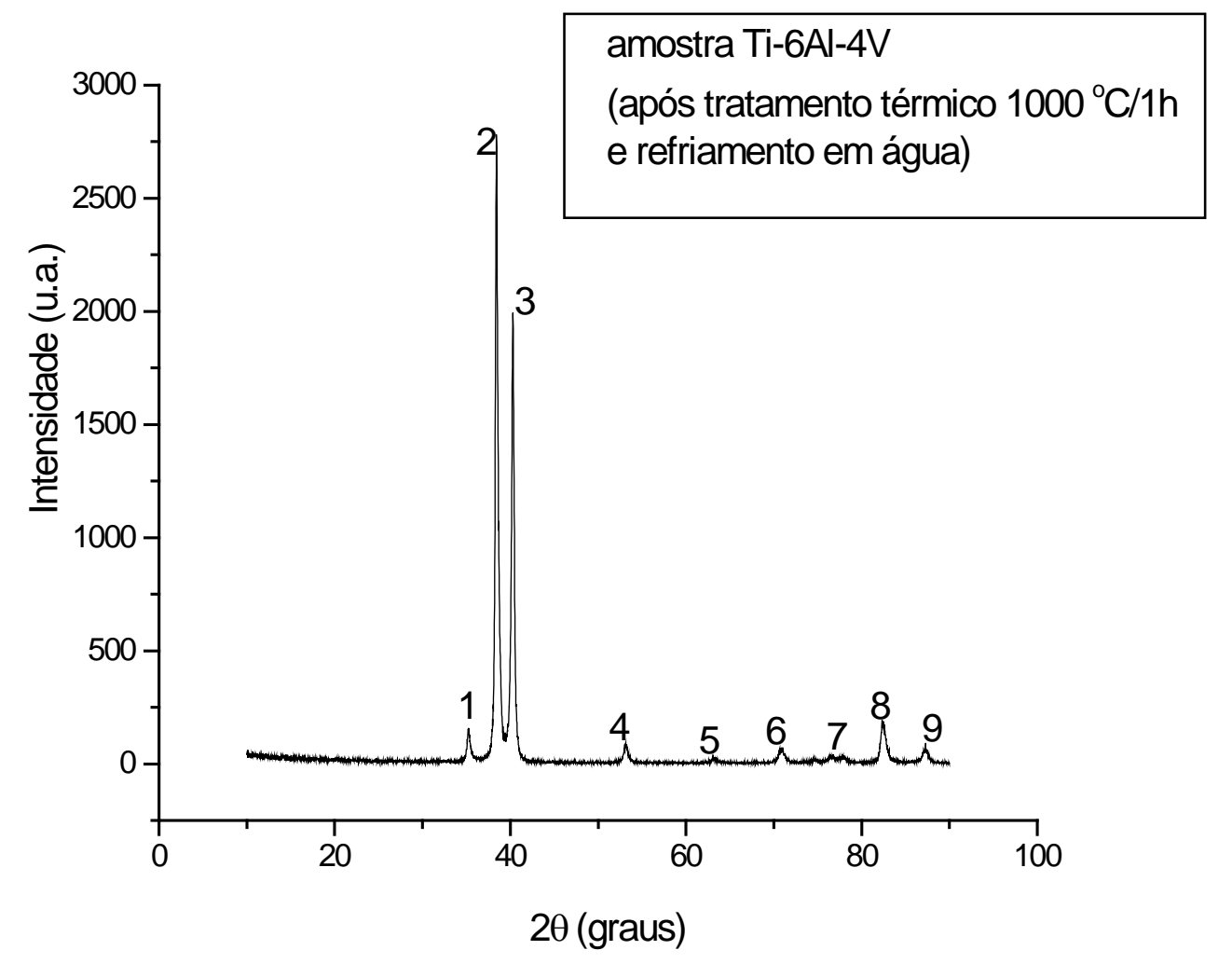

FIGURA 40: Curva de Difração de Raios X da liga de titânio Ti-6Al-4V, da amostra tratada a $1000^{\circ} \mathrm{C}$ por 1 hora e resfriada em água. Velocidade de varredura para análise de $2^{\circ}$ por minuto. 
A Curva de Difração de Raios $\mathrm{X}$ obtida da amostra de Ti-6Al-4V, conforme mostra a Figura 40, comparando-se com a Curva de Difração de Raio X da Figura 39, apresenta uma certa alteração nas intensidade e quantidades de picos obtidos.

A TABELA 8 apresenta os resultados obtidos na determinação das fases presentes na amostra, a partir do difratograma obtido, conforme mostra a Figura 40, relacionando-se os valores da distância interplanar (d) e o ângulo $2 \theta$ (graus), bem como, as intensidades correspondentes aos nove picos obtidos.

TABELA 8: Resultados obtidos a partir da Curva de Difração de Raios $X$ da análise da amostra Ti-6Al-4V (Figura 40), tratada termicamente a $1000{ }^{\circ} \mathrm{C}$ por uma hora e resfriada em água, relacionando os valores da distância interplanar (d) e o ângulo $2 \theta$ (graus).

\begin{tabular}{|c|c|c|c|c|}
\hline Pico & $\begin{array}{c}2 \theta \\
\text { (graus) }\end{array}$ & Valor d & Intensidade & Fase encontrada \\
\hline 1 & 35,240 & 2,54468 & 141 & $\operatorname{Ti\alpha }(\mathrm{hc})$ \\
\hline 2 & 38,420 & 2,34106 & 2542 & $\mathrm{Ti} \beta$ (ccc) \\
\hline 3 & 40,300 & 2,23607 & 1810 & $\operatorname{Ti\alpha }(\mathrm{hc})$ \\
\hline 4 & 53,120 & 1,72270 & 79 & $\operatorname{Ti\alpha }(\mathrm{hc})$ \\
\hline 5 & 63,060 & 1,47297 & 22 & Ti $\alpha(h c)$ \\
\hline 6 & 70,460 & 1,33521 & 58 & Ti $\beta(c c c)$ \\
\hline 7 & 77,220 & 1,23439 & 22 & $\operatorname{Ti\alpha }(\mathrm{hc})$ \\
\hline 8 & 82,360 & 1,16988 & 173 & Ti $\beta(c c c)$ \\
\hline 9 & 87,280 & 1,11615 & 63 & $\operatorname{Ti\alpha }(\mathrm{hc})$ \\
\hline
\end{tabular}


Analisando-se os valores para os nove picos obtidos na Curva de Difração de Raio X da Figura 40, e comparando-os com os valores da distância interplanar (d) e o ângulo 2 $\theta$, apresentados na Tabela 8, e após indexá-los com as fichas do JCPDS, foi possível determinar a presença da fase $\alpha$ (Ti $\alpha$-hc) nos picos 1, 3, 4, 5, 7 e 9, bem como a presença da fase $\beta$ (Ti $\beta$-ccc) apresentada nos picos 2, 6 e 8. O resultado obtido para a identificação da fase $\beta$ apresenta os planos de reflexão: (110), (211) e (220), respectivamente relacionados aos picos 2, 6 e 8 , conforme mostra a Figura 40.

Comparando-se os resultados obtidos a partir das análises de DRX aplicadas à amostra, como recebida, e à amostra tratada termicamente, verificase a presença da fase $\beta$, porém o plano de reflexão para a fase $\beta$ (211), correspondente ao pico 6 , tem posição coincidente ao plano de reflexão da fase $\alpha$ (103), mascarando-se o resultado obtido, para este plano de reflexão.

Realizou-se um novo tratamento térmico na amostra da liga de titânio Ti-6Al-4V, partindo-se da liga como recebida. A amostra, como recebida, foi inserida em um tubo de quartzo, retirando-se o ar e selando-a no tubo. Após este procedimento, a mesma foi tratada termicamente, a uma temperatura de $1000^{\circ} \mathrm{C}$ por duas horas e posteriormente resfriada em água, conforme descrito em 4.4. Com a amostra preparada, de acordo com 4.3.1., a mesma foi submetida à análise por DRX. A FIGURA 41 mostra o difratograma obtido, para a análise realizada, onde se obteve a presença de nove picos. 


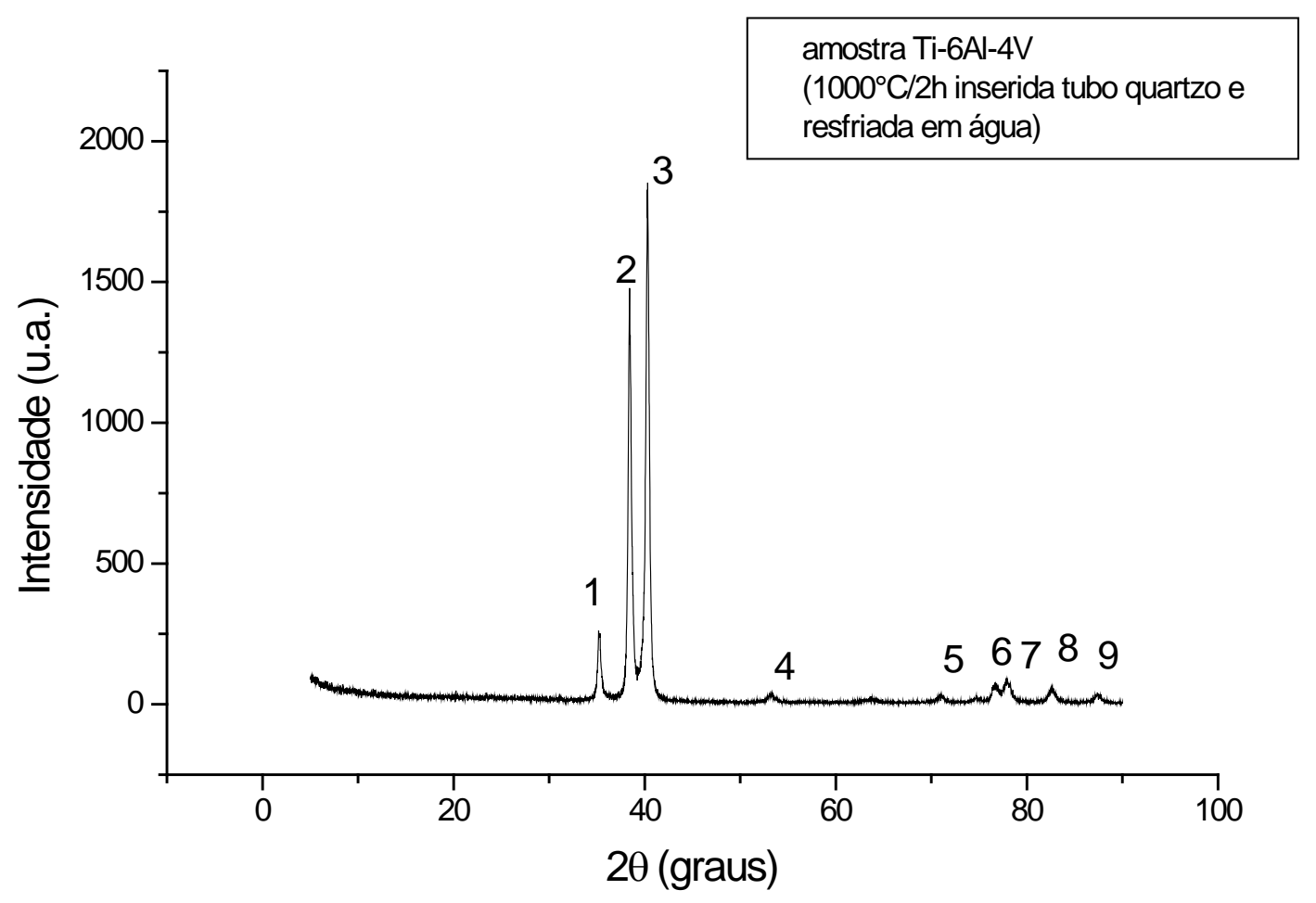

FIGURA 41: Curva de Difração de Raios X da liga de titânio Ti-6Al-4V, da amostra tratada a $1000^{\circ} \mathrm{C}$ por 2 horas em tubo de quartzo e resfriada em água. Velocidade de varredura para análise de $2^{\circ}$ por minuto.

A TABELA 9 apresenta os resultados obtidos na determinação das fases presentes na amostra, a partir do difratograma obtido, conforme mostra a FIGURA 41, relacionando-se os valores da distância interplanar (d) e o ângulo $2 \theta$ (graus), bem como, as intensidades correspondentes aos nove picos obtidos. 
TABELA 9: Resultados obtidos a partir da Curva de Difração de Raios X da análise da amostra Ti-6Al-4V (Figura 41), tratada termicamente a $1000{ }^{\circ} \mathrm{C}$ por duas horas em tubo de quartzo e resfriada em água, relacionando os valores da distância interplanar (d) e o ângulo $2 \theta$ (graus).

\begin{tabular}{|c|c|c|c|c|}
\hline Pico & $\begin{array}{c}2 \theta \\
\text { (graus) }\end{array}$ & Valor d & Intensidade & Fase encontrada \\
\hline 1 & 35,280 & 2,54468 & 250 & Ti $\alpha$ (hc) \\
\hline 2 & 38,480 & 2,33750 & 1480 & $\mathrm{Ti} \beta$ (ccc) \\
\hline 3 & 40,320 & 2,23607 & 1840 & $\mathrm{Ti} \alpha(\mathrm{hc})$ \\
\hline 4 & 53,120 & 1,72270 & 22 & Ti $\alpha(h c)$ \\
\hline 5 & 70,161 & 1,3402 & 30 & $\mathrm{Ti} \beta(\mathrm{ccc})$ \\
\hline 6 & 76,220 & 1,2480 & 115 & Ti $\alpha(h c)$ \\
\hline 7 & 77,220 & 1,23439 & 126 & Ti $\alpha(h c)$ \\
\hline 8 & 82,444 & 1,16988 & 119 & Tiß(ccc) \\
\hline 9 & 87,280 & 1,11615 & 63 & Ti $\alpha(h c)$ \\
\hline
\end{tabular}

Analisando-se os valores para os nove picos obtidos na Curva de Difração de Raios X da Figura 41, e comparando-os com os valores da distância interplanar (d) e o ângulo 20, apresentados na Tabela 8, e após indexá-los com as fichas do JCPDS, foi possível determinar a presença da fase $\alpha$ (Ti $\alpha$-hc) nos picos $1,3,4,6,7$ e 9, bem como a presença da fase $\beta$ (Ti $\beta$-ccc) apresentada nos picos 2, 5 e 8. O resultado obtido para a identificação da fase $\beta$ apresenta os planos de reflexão: (110), (211) e (220), respectivamente relacionados aos picos 2, 5 e 8, conforme mostra a Figura 41.

Comparando-se os resultados obtidos, a partir das análises de DRX, aplicadas à amostra da liga de Ti-6Al-4V, como recebida, e às amostras tratadas termicamente, verifica-se que houve uma retenção da fase $\beta$ (Ti $\beta$-ccc) sendo possível a determinação desta fase. 


\subsection{Microscopia Eletrônica de Transmissão (MET)}

A utilização da Microscopia Eletrônica de Transmissão (MET) no presente trabalho, permitiu o estudo da microestrutura e dos micromecanismos de deformação e fratura da amostra de Ti-6Al-4V (como recebida) e das demais amostras de Ti-6Al-4V submetidas ao tratamento térmico, conforme descrito em 4.4 .

Com a utilização da difração de elétrons por área selecionada, associada à imagem de campo claro e campo escuro, foi possível a determinação das fases $\alpha$ e $\beta$ no interior dos grãos e sub-grãos das amostras analisadas.

\subsubsection{Análise microestrutural de grãos}

Para a análise microestrutural de grãos, a amostra de Ti-6Al-4V (como recebida), foi inserida em tubo de quartzo lacrado sob vácuo para a realização do tratamento térmico, sendo submetida à temperatura de $1000^{\circ} \mathrm{C}$ por duas horas, e posteriormente resfriada em água. Após o tratamento térmico, seguiu-se a etapa do preparo de amostras para observação no MET, conforme já descrito em 4 materiais e métodos experimentais.

$\mathrm{O}$ tratamento térmico aplicado à liga de titânio Ti-6Al-4V, teve como finalidade verificar a mudança na estrutura e o comportamento das fases $\alpha$ e $\beta$ da liga.

As ligas Ti-6Al-4V quando tratadas termicamente, segundo Jovanovié et al. (2004), a partir de temperatura de $1100^{\circ} \mathrm{C}, 950{ }^{\circ} \mathrm{C}$ e $900^{\circ} \mathrm{C}$ com resfriamentos bruscos (resfriamento em água), formam respectivamente as estruturas martensitica $\alpha$, uma mistura de $\alpha \operatorname{com} \beta$ com placas de $\alpha$ dentro e no contorno de grão de $\beta$ primário e uma mistura de $\alpha \operatorname{com} \beta$ com placas de $\alpha$ dentro e no contorno de grão de $\beta$ primário, sendo a proporção da fase alfa maior a $900^{\circ} \mathrm{C}$ do que a $950^{\circ} \mathrm{C}$.

A FIGURA 42 mostra uma região da amostra contendo grãos alongados, com dimensão aproximada de 1,2 $\mu \mathrm{m}$. Observa-se também a existência de subestruturas de discordâncias, onde se pode verificar a sua 
heterogeneidade e também a formação de grossas paredes nas subestruturas de discordâncias apresentadas.

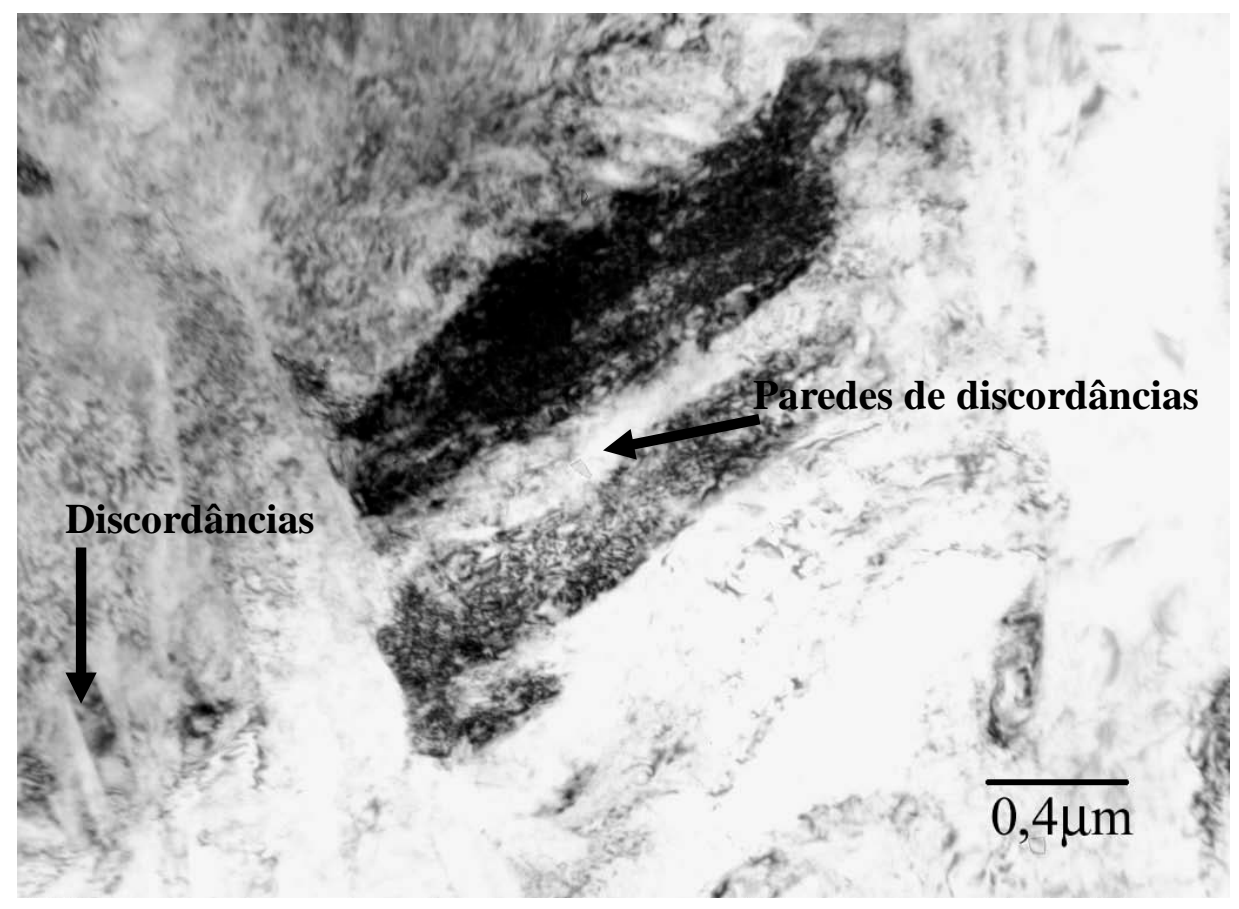

FIGURA 42: Micrografia obtida por Microscopia Eletrônica de Transmissão (MET) da amostra de Ti-6Al-4V $\left(1000^{\circ} \mathrm{C} / 2 \mathrm{~h}\right)$, contendo grãos alongados, paredes grossas e sub estruturas de discordâncias.

Utilizou-se a técnica de campo escuro, para a visualização do contorno de grão da partícula e detalhe da sua dimensão. Observa-se a presença da fase $\beta$ identificada a partir da realização da difração de elétrons na região delineada na FIGURA 43. 


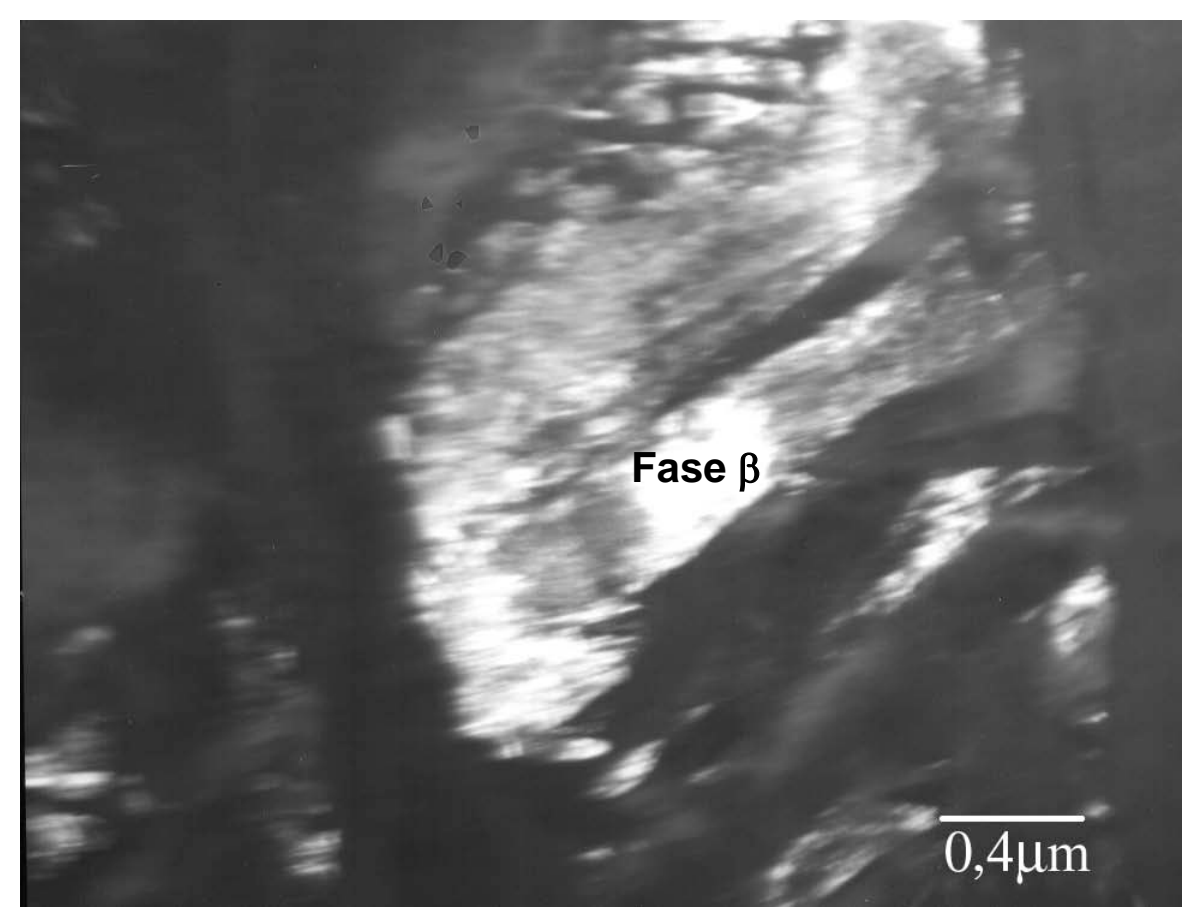

FIGURA 43: Micrografia obtida por microscopia eletrônica de transmissão (MET) em campo escuro da amostra de Ti-6Al-4V $\left(1000^{\circ} \mathrm{C} / 2 \mathrm{~h}\right)$. Na região em destaque realizou-se a difração de elétrons.

A FIGURA 44 mostra o padrão de difração de elétrons da área selecionada na partícula, como demonstrado na FIGURA 43. Após a indexação do padrão de elétrons, como mostra a FIGURA 44, foi identificado a presença da fase $\beta$. 


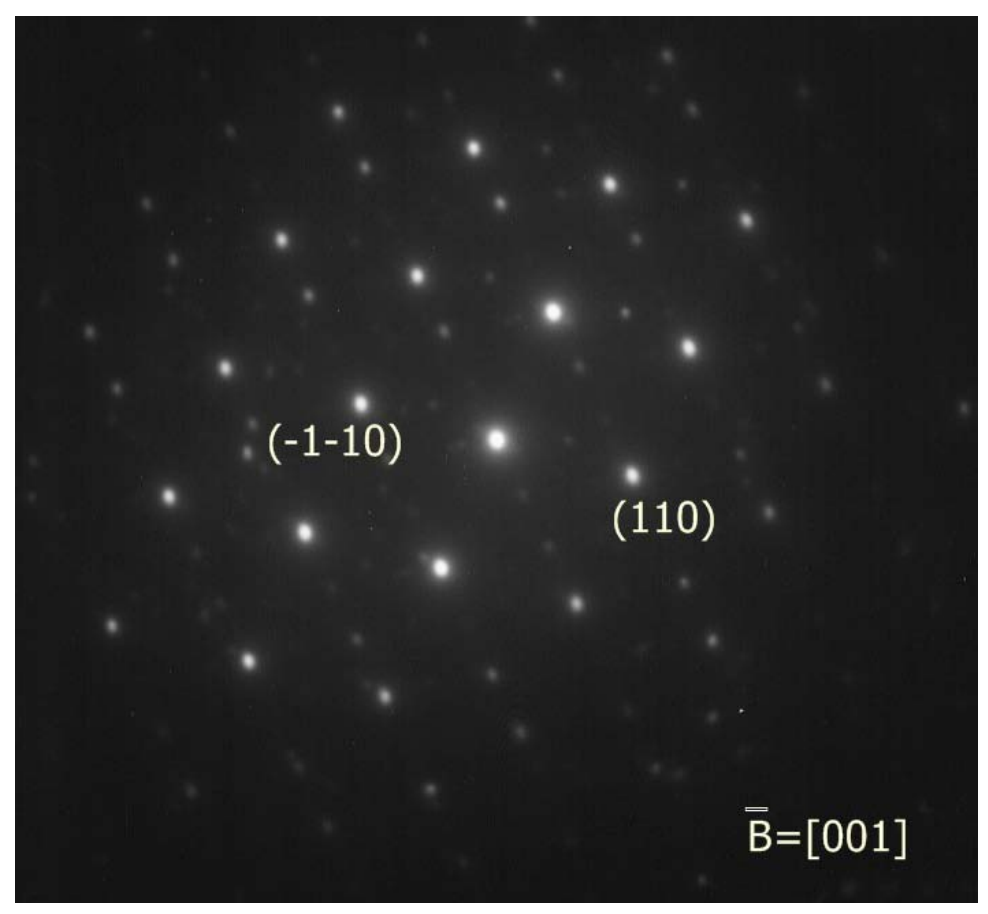

FIGURA 44: Padrão de difração de elétrons realizado na área selecionada da Figura 43, sendo identificada a presença da fase beta (ccc), após a indexação.

A FIGURA 45 mostra a existência de discordâncias de uma forma lamelar $\alpha$, como mostra a FIGURA 46 em campo escuro, da FIGURA 45. Realizou-se a difração de elétrons por área selecionada nas fases, conforme mostra a FIGURA 46, e após a indexação pode-se determinar a fase $\alpha$ presente na lamela observada na FIGURA 45. 


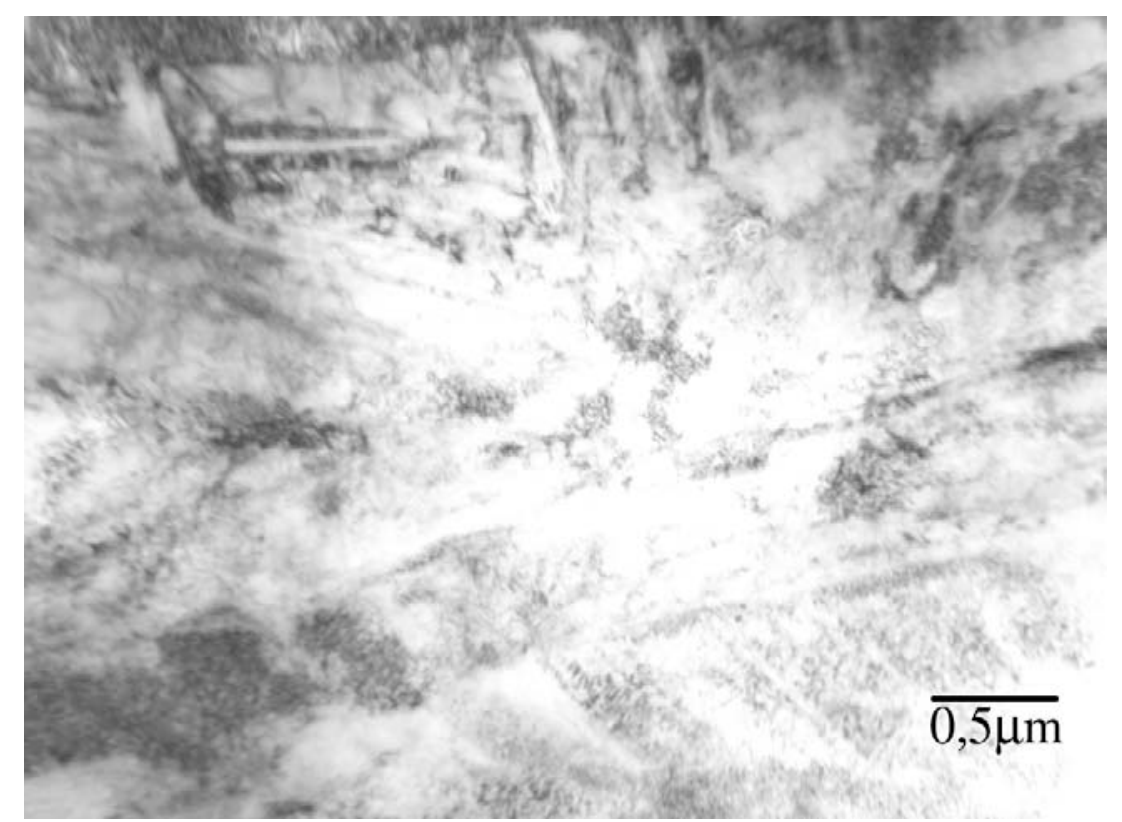

FIGURA 45: Micrografia obtida por Microscopia Eletrônica de Transmissão (MET) em campo claro da amostra de Ti-6Al-4V $\left(1000^{\circ} \mathrm{C} / 2 \mathrm{~h}\right)$.

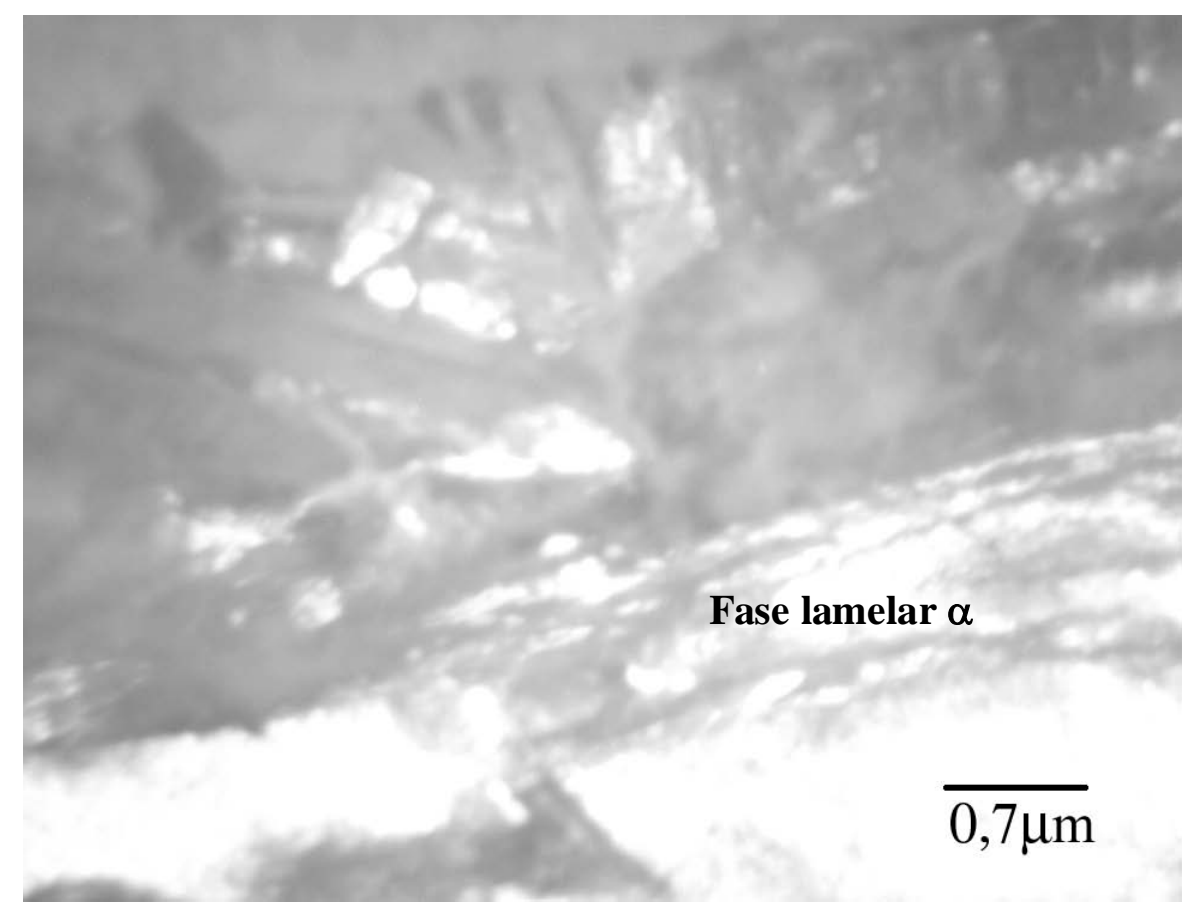

FIGURA 46: Micrografia obtida por Microscopia Eletrônica de Transmissão (MET) em campo escuro da amostra de Ti-6Al-4V $\left(1000^{\circ} \mathrm{C} / 2 \mathrm{~h}\right)$, relativa à Figura 45 evidenciando a existência da fase lamelar alfa. 
A indexação da FIGURA 47 permitiu comprovar a presença da fase lamelar alfa da FIGURA 46 devido a presença da fase hexagonal compacta característica da estrutura da fase alfa.

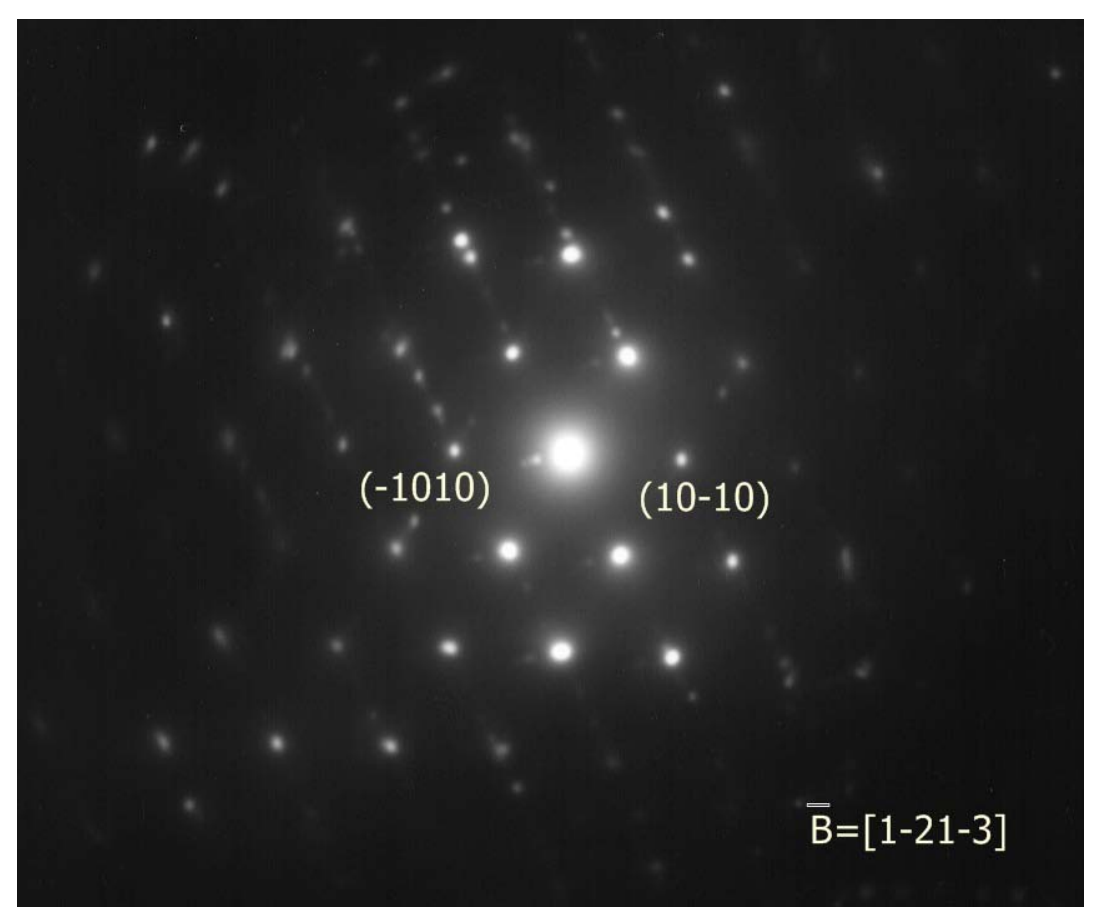

FIGURA 47: Padrão de difração de elétrons realizado na área selecionada da Figura 46 sendo identificada a presença da fase alfa (hc), após a indexação.

Ahmed \& Rack (1998) ao analisarem a liga de Ti-6Al-4V por MET confirmaram uma diferente seqüência de nucleação relacionada com a taxa de resfriamento da liga e mostraram que essa morfologia alfa tinha uma aparência de blocos com uma estrutura lamelar com deslocamentos internos. A análise de difração de elétrons da área selecionada confirmou, ainda que estas placas alfa possuíssem uma estrutura cristalina hexagonal idêntica ao da martensita alfa acicular observadas com maior taxa de resfriamento. As características cristalográficas e morfológicas associadas a esta morfologia alfa secundária sugeriu que a mesma é formada como uma transformação competitiva. O crescimento, das lamelas alfa, é dependente da taxa de resfriamento imposta à liga. 
As micrografias das FIGURAS 48 e 49, obtidas por MET, mostram a existência de lamelas alfa típicas de uma estrutura martensítica. Nestas estruturas pode-se observar a existência de discordâncias formadas no material durante o processo de resfriamento imposto a amostra. Observa-se também a existência de interfaces entre as lamelas e grãos retidos próximos a estas lamelas.

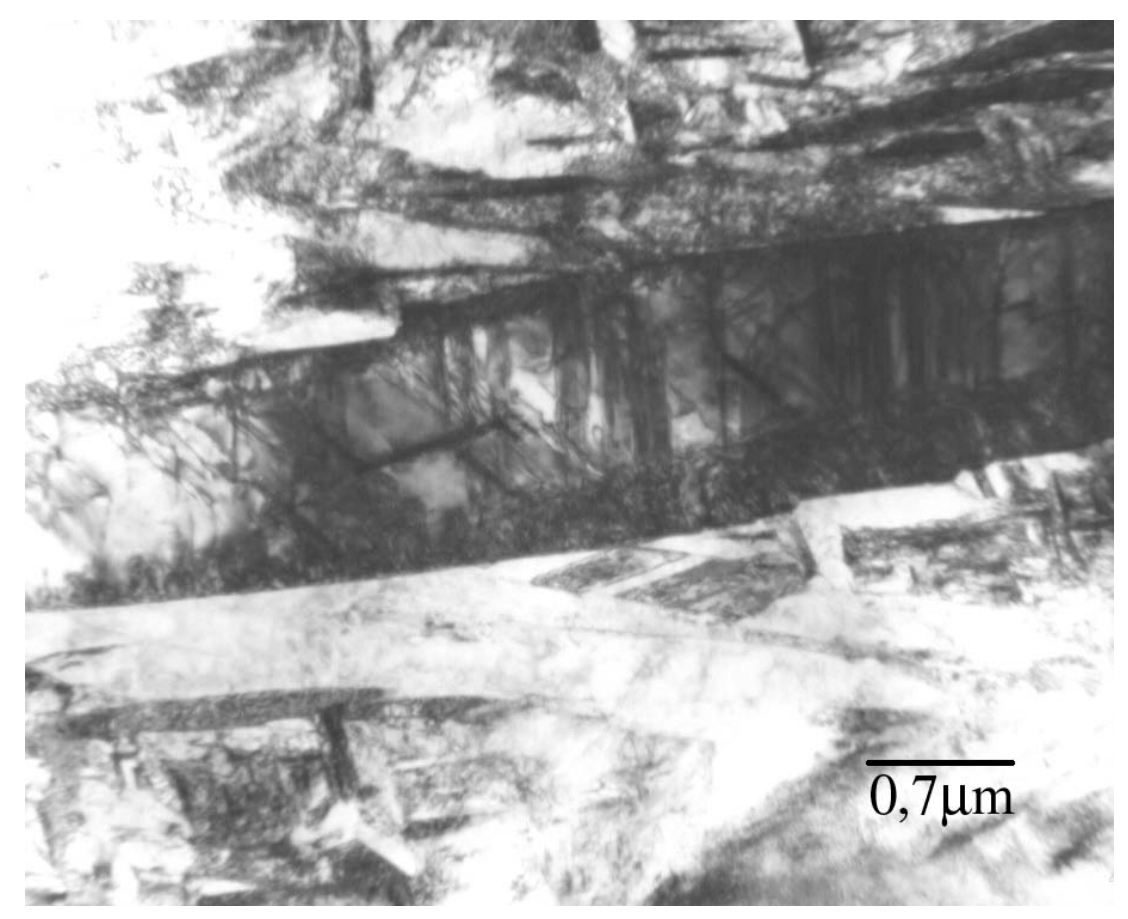

FIGURA 48: Micrografia obtida por Microscopia Eletrônica de Transmissão (MET) da amostra de Ti-6Al-4V $\left(1000^{\circ} \mathrm{C} / 2 \mathrm{~h}\right)$, mostrando as lamelas $\alpha \mathrm{e}$ discordâncias (campo claro). 


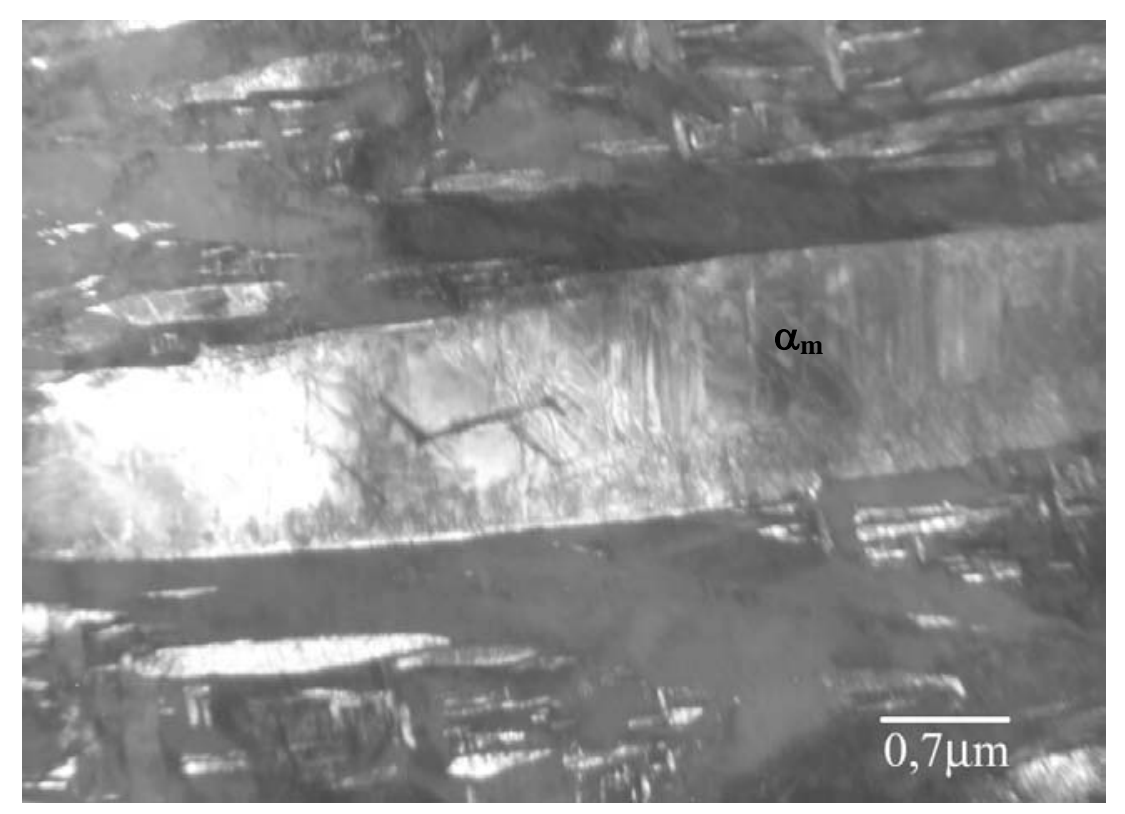

FIGURA 49: Micrografia obtida por Microscopia Eletrônica de Transmissão (MET) da amostra de Ti-6Al-4V $\left(1000^{\circ} \mathrm{C} / 2 \mathrm{~h}\right)$, mostrando as lamelas $\alpha \mathrm{e}$ discordâncias (campo escuro).

Salem \& Semiatin (2009) relatam que ambas as microestruturas lamelar e bimodal $(\alpha+\beta)$, possuem lamelas hexagonais compactas de fase $\alpha$ em uma matriz cúbica de corpo centrado de fase $\beta$. A microestrutura lamelar é formada durante o resfriamento no campo $\beta$, a taxas de resfriamento baixas e médias, onde a fase lamelar $\alpha$ e a matriz de fase $\beta$, que foram formadas seguem a orientação de Burgers na qual o plano (0001) $\alpha$ está paralelo ao plano (101) $\beta$ e a direção $[2 \overline{1} \overline{1} 0] \alpha$ está paralela à direção $[1 \overline{1} \overline{1}] \beta$.

A FIGURA 50 mostra regiões existentes próximas às lamelas, onde se realizou o padrão de difração (FIGURA 51), em regiões próximas às lamelas, obtendo-se como resultado do padrão de difração de elétrons a confirmação da fase beta, que coexiste na estrutura da amostra. A existência da fase beta determina que na amostra haja transformação de parte da sua estrutura alfa secundária em beta, retida entre as lamelas de alfa. 


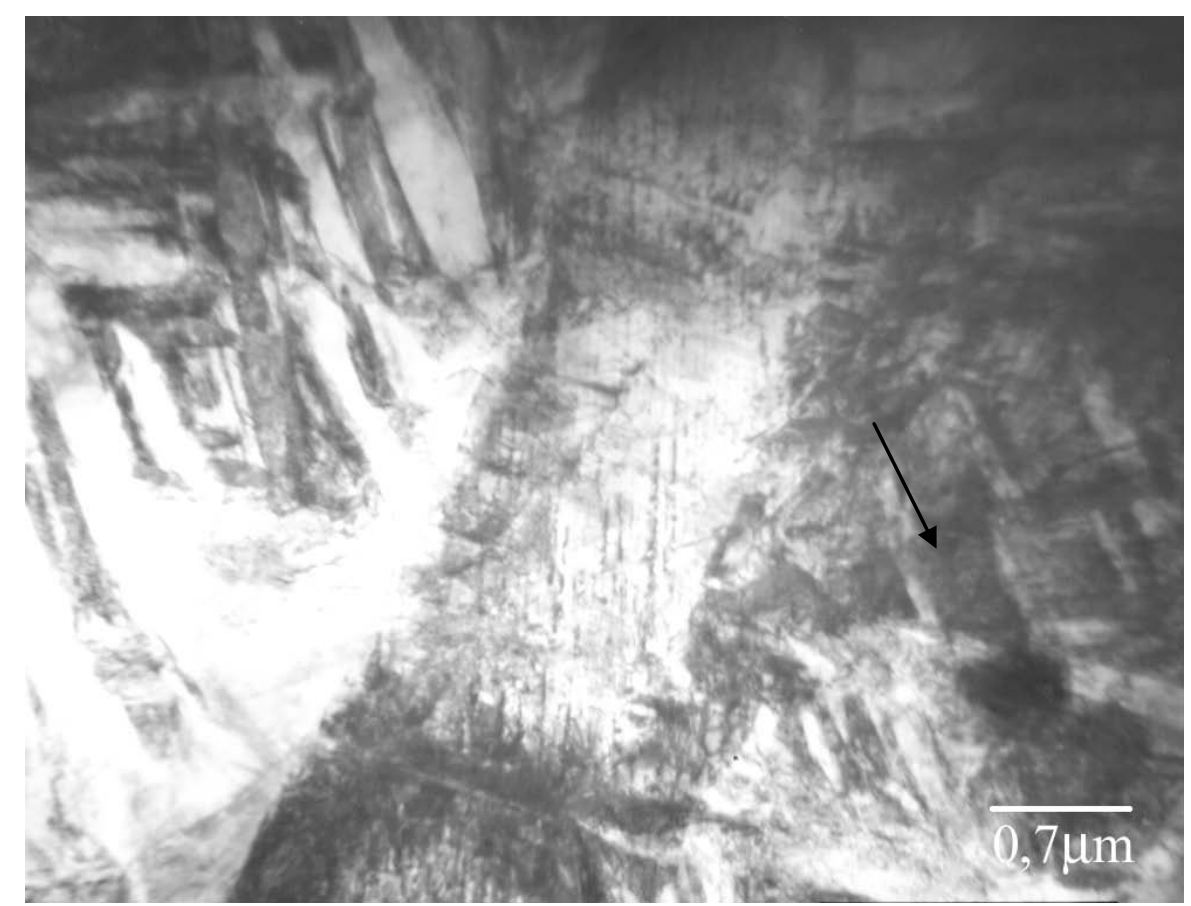

(A)

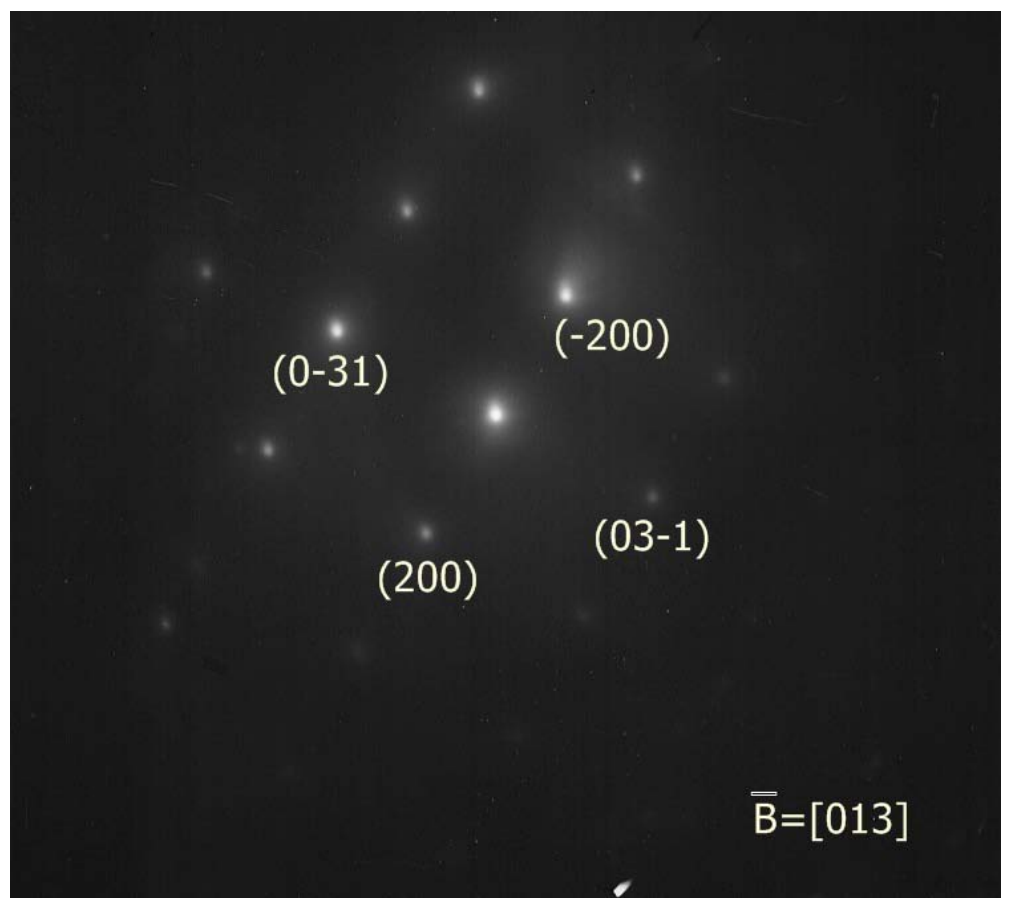

(B)

FIGURA 50: (A) Micrografia obtida por microscopia eletrônica de transmissão (MET) da amostra de Ti-6Al-4V $\left(1000^{\circ} \mathrm{C} / 2 \mathrm{~h}\right)$, evidenciando a interface lamelar e (B) respectivo padrão de difração de Micrografia obtida por Microscopia Eletrônica de Transmissão (MET) da amostra de Ti-6Al-4V $\left(1000^{\circ} \mathrm{C} / 2 \mathrm{~h}\right)$, evidenciando na interface lamelar elétrons da área selecionada da Figura $50(A)$, identificação da presença da fase beta (ccc). 


\subsubsection{Tração in situ e fractografia}

Realizou-se no presente trabalho estudos para a determinação dos mecanismos de deformação e fratura, aplicando-se a técnica de tração in situ em temperatura ambiente, utilizando-se a microscopia eletrônica de transmissão. Para a realização dos ensaios, foi utilizada a amostra de titânio da liga Ti-6Al-4V tratada termicamente a $1000^{\circ} \mathrm{C}$ por uma hora e resfriada em água, conforme descrito no item 4.4.

Em metais que apresentam estrutura hexagonal compacta, diferentes modos de deformação podem ser ativados durante a deformação plástica: processos de deslizamento e de maclação.

A FIGURA 51 mostra os possíveis sistemas de escorregamento em metais com estrutura cristalina hexagonal compacta (hc), estudado por Bridier et al.(2005), relativos aos sistemas de escorregamento: basal, prismático e piramidal de primeira ordem com o vetor de Burgers $\vec{a}=\frac{1}{3}\langle 11 \overline{2} 0\rangle$, bem como os sistemas piramidal de primeira e segunda ordem com o vetor de Burgers $\vec{c}+\vec{a}=\frac{1}{3}\langle 11 \overline{2} 3\rangle$.
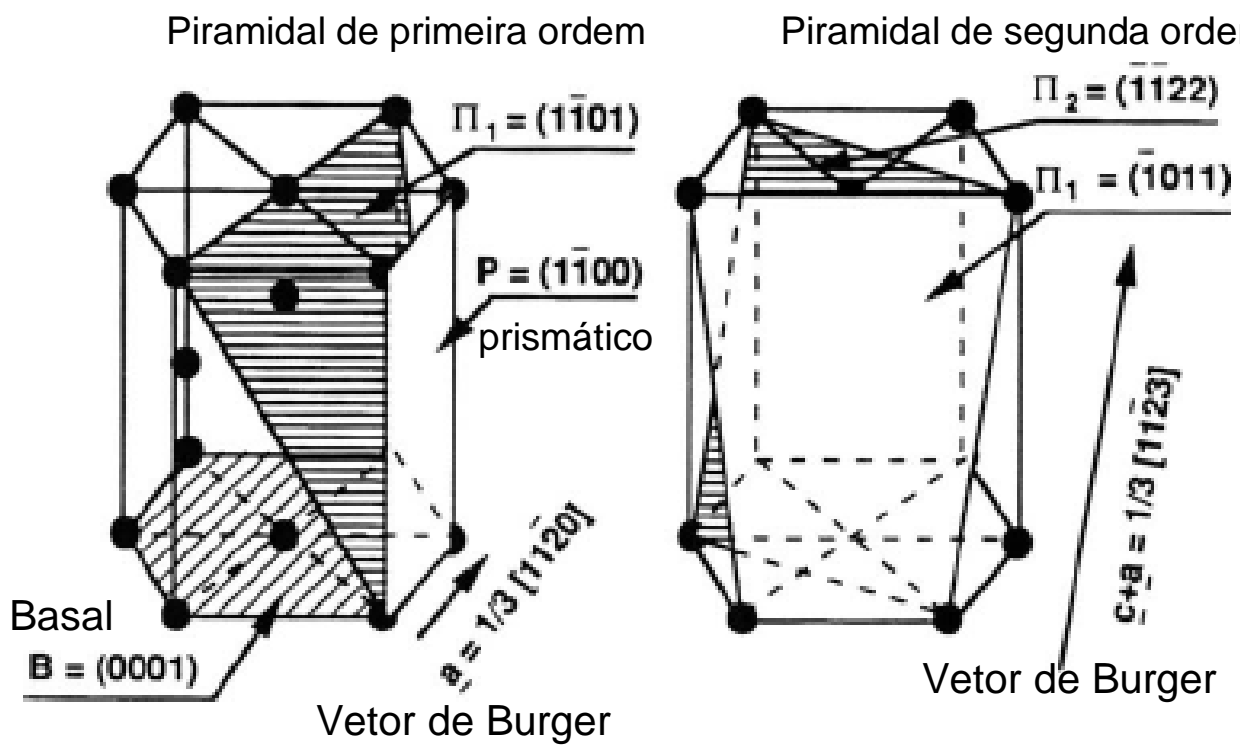

FIGURA 51: Modelo utilizado para representar os sistemas de escorregamento em metais (hc) (Bridier et al.,2005). 
A possibilidade de o escorregamento ocorrer nos planos prismáticos, piramidal ou basal está geralmente associada com a análise da tensão de cisalhamento. Uma das dificuldades de identificar os mecanismos de deformação no titânio puro ou em suas ligas está relacionada com a complexa competição entre os diferentes sistemas de escorregamento (Bridier et al.,2005).

A FIGURA 52 (A) apresenta a amostra de Ti-6Al-4V tensionada no Microscópio Eletrônico de Transmissão (MET). A seta indica a região de análise.

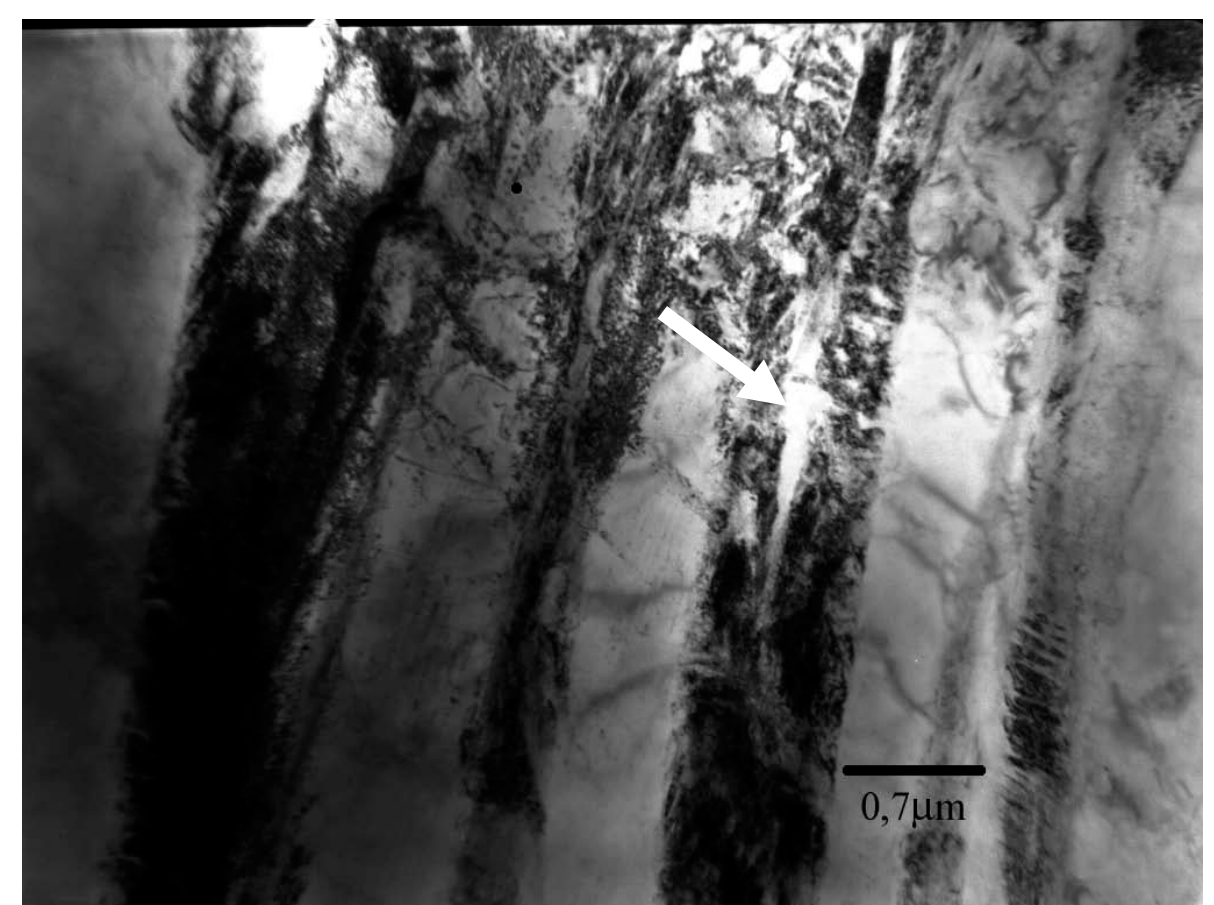

(A)

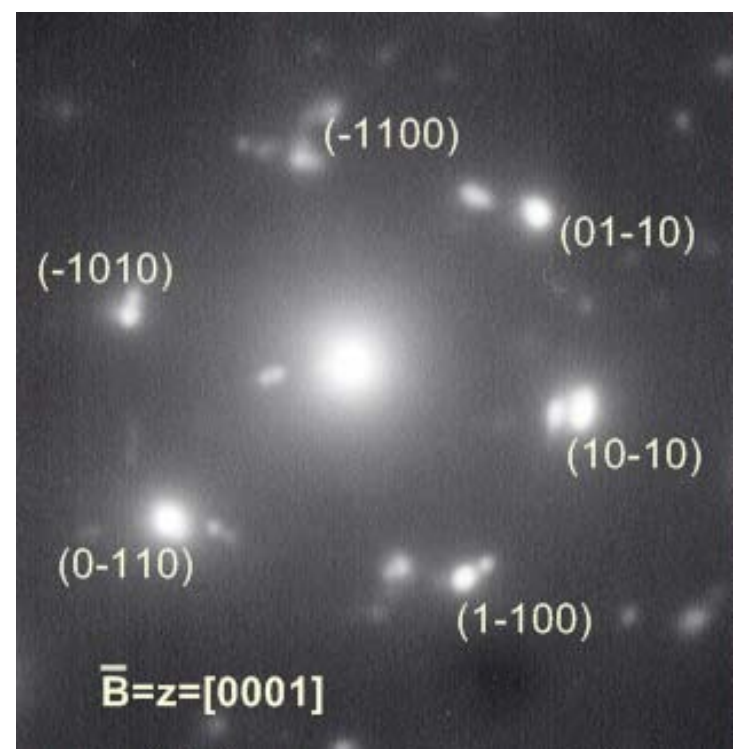

(B)

FIGURA 52: (A) Micrografia eletrônica da amostra de Ti-6Al-4V e (B) o respectivo padrão de difração realizado na região indicada em (A). 
Realizou-se a indexação do padrão de difração de elétrons, FIGURA 52 (B), da área selecionada relativa à FIGURA 52(A) e obteve-se como resultado o padrão relativo à fase $\alpha(\mathrm{hc})$ da amostra da liga de Ti-6Al-4V. A partir da direção de observação $\vec{B}=[0001]$, verifica-se o escorregamento dos planos prismáticos $(1 \overline{1} 00)$ e $(10 \overline{1} 0)$, de acordo com a FIGURA 52 (B).

A FIGURA 52(A) mostra lamelas (verticais em relação ao plano de visualização) onde coexistem regiões da fase $\alpha$ e fase $\beta$. Durante o ensaio de tração foi escolhida uma região da amostra, onde se observa o início da deformação sofrida pela amostra durante o ensaio de tração in situ, sendo aplicados deslocamentos de $0,05 \mathrm{~mm}$ a partir da posição inicial, gerando deslocamentos cumulativos de :0,05mm, 0,10mm, 0,15mm, 0,20mm e 0,25mm. A tração aplicada à amostra ocorre perpendicularmente à direção de observação $\vec{B}=[0001]$.

A evolução do comportamento da amostra sob tensão, no ensaio de tração in situ, pode ser observada nas FIGURAS 53 até 58. 


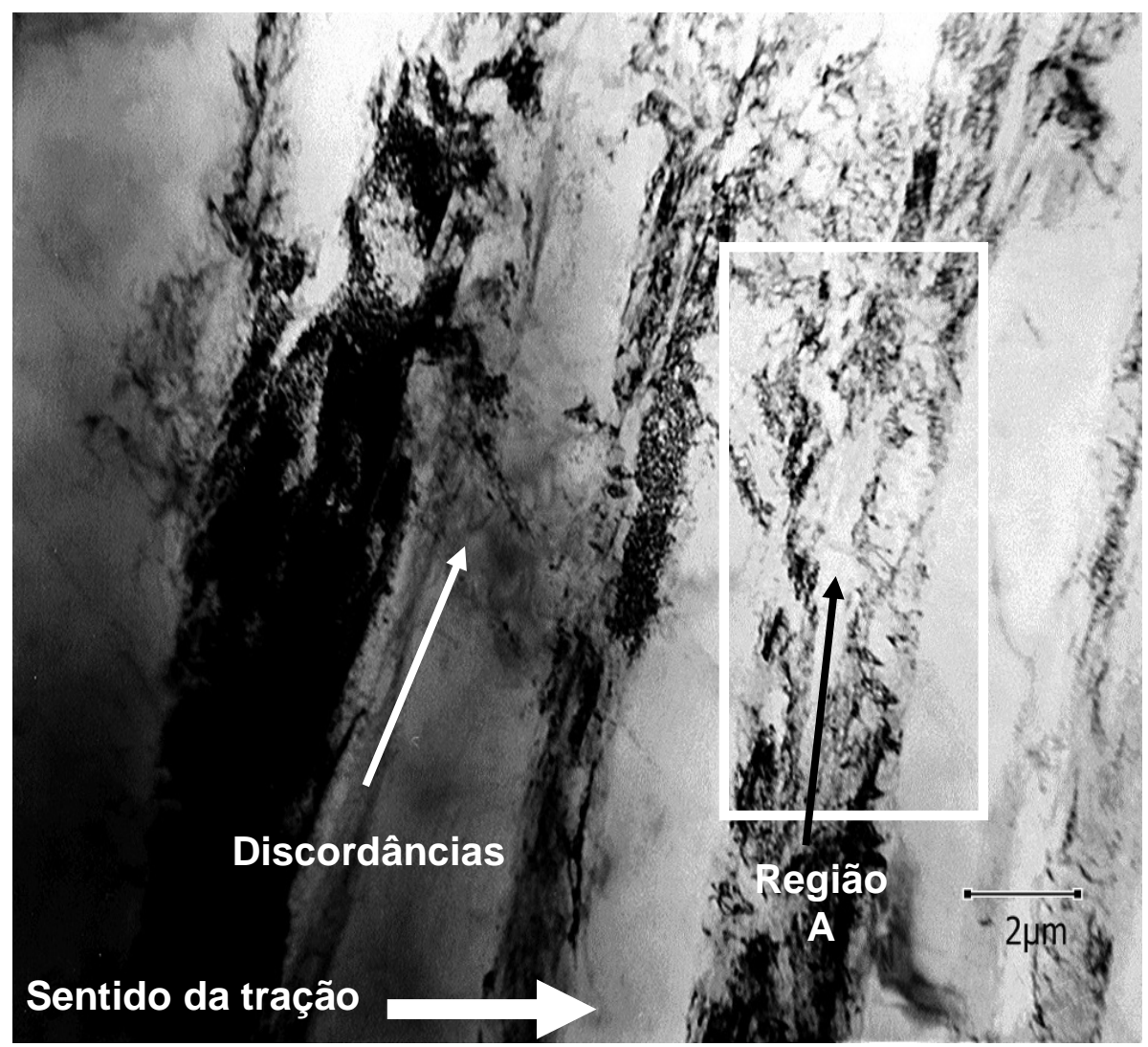

FIGURA 53: Micrografia eletrônica da amostra de Ti-6Al-4V, relativa à análise de tração in situ para um deslocamento de $0,05 \mathrm{~mm}$ em relação à posição inicial.

A FIGURA 53 mostra o aumento de discordâncias causado pelo carregamento aplicado à amostra, obtendo-se um deslocamento de 0,05mm. $\mathrm{Na}$ Região A indicada na FIGURA 53 observa-se o deslizamento dos planos lamelares existentes na amostra. 


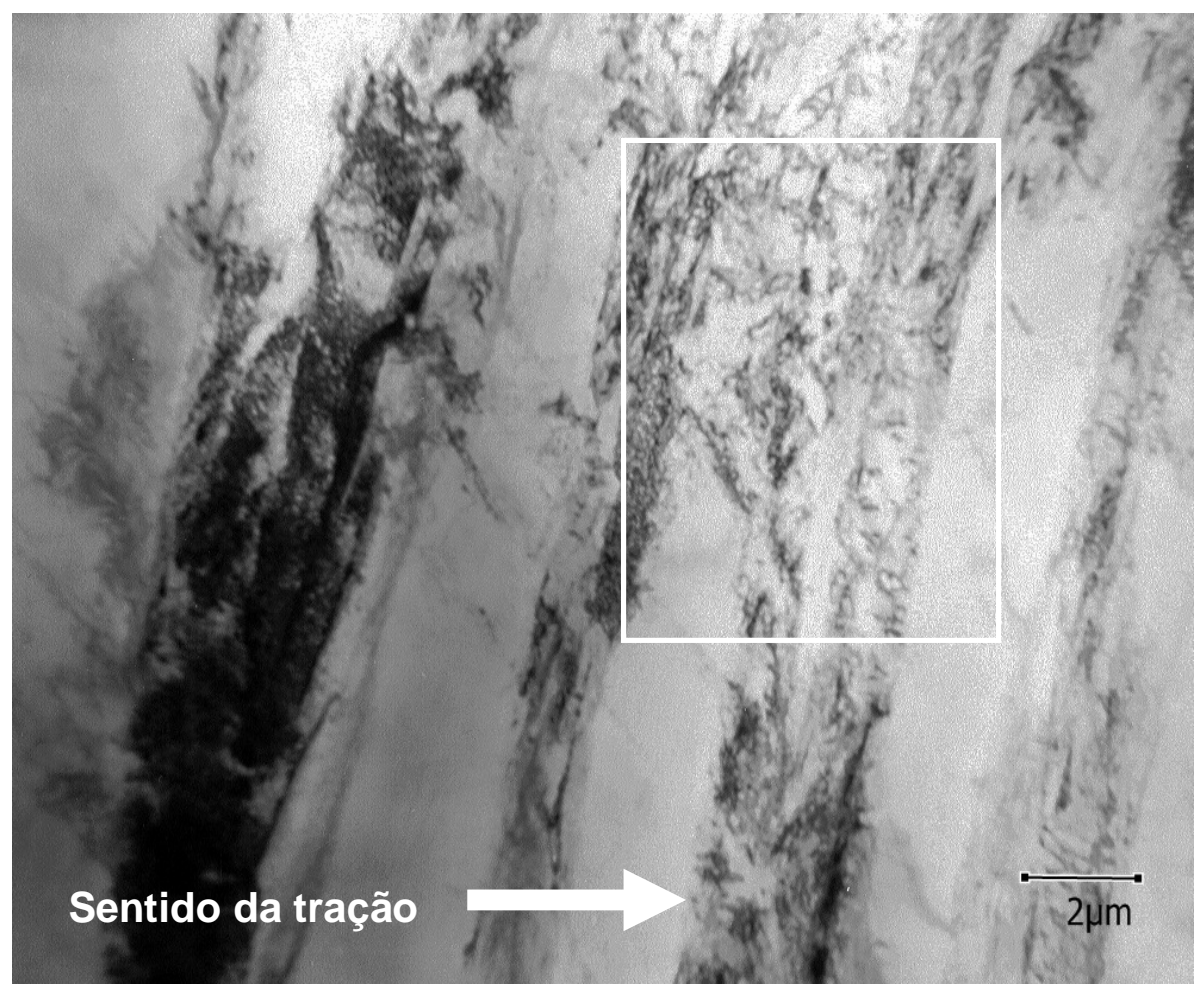

FIGURA 54: Micrografia eletrônica da amostra de Ti-6Al-4V, relativa à análise de tração in situ para um deslocamento de $0,10 \mathrm{~mm}$ em relação à posição inicial.

A FIGURA 54 mostra o surgimento de discordâncias entre as lamelas, conforme região delineada na figura. Após o carregamento aplicado, houve um deslocamento de $0,010 \mathrm{~mm}$ em relação a posição inicial. 


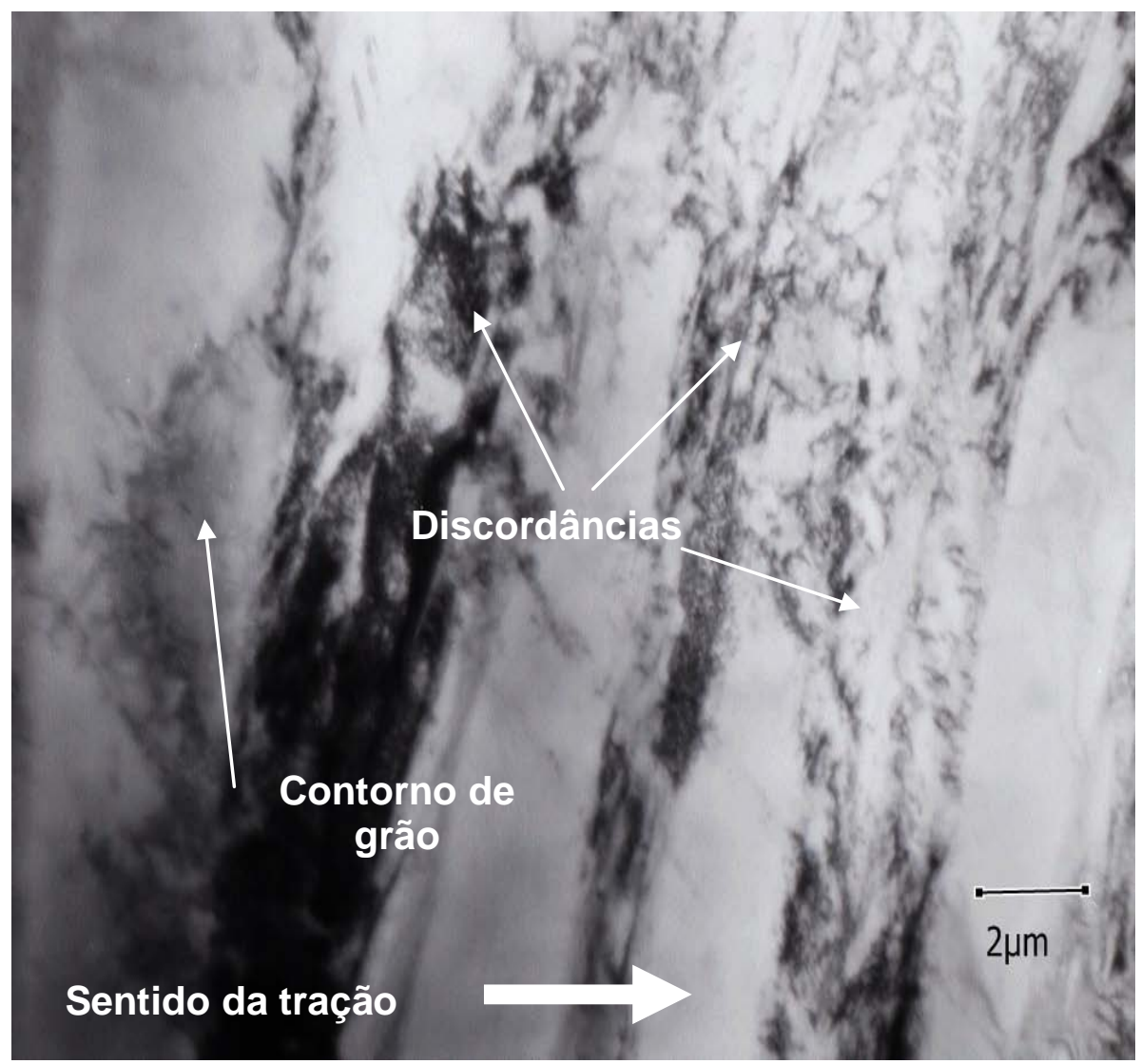

FIGURA 55: Micrografia eletrônica da amostra de Ti-6Al-4V, relativa à análise de tração in situ para um deslocamento de $0,15 \mathrm{~mm}$ em relação à posição inicial.

A FIGURA 55 mostra o aparecimento de novas discordâncias, conforme indicado pelas setas na figura e observa-se também a existência de um contorno de grão disposto entre as placas lamelares, após tração in situ para um deslocamento de $0,15 \mathrm{~mm}$ em relação à posição inicial. 


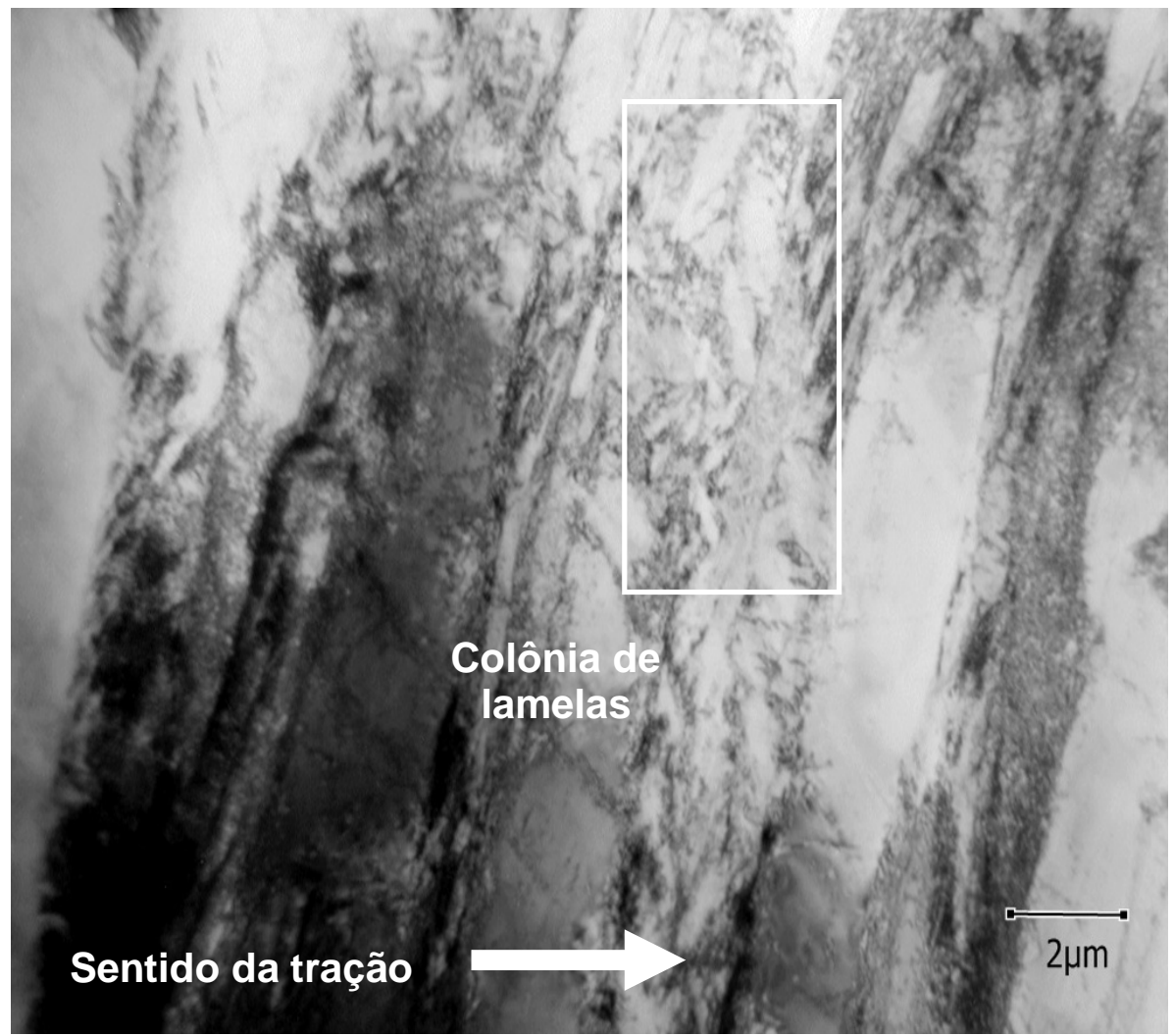

FIGURA 56: Micrografia eletrônica da amostra de Ti-6Al-4V, relativa à análise de tração in situ para um deslocamento de $0,20 \mathrm{~mm}$ em relação à posição inicial.

A FIGURA 56 mostra a presença de deslocamentos dos planos devido a uma deformação, gerada pela tração in situ, a partir de um deslocamento de $0,020 \mathrm{~mm}$ em relação à posição inicial mostrando também a existência de colônias de lamelas .

As FIGURAS 57 e 58 mostram o deslocamento dos planos e a deformação de lamelas presentes na amostra, após a tração in situ, para um deslocamento de $0,25 \mathrm{~mm}$ em relação à posição inicial. 


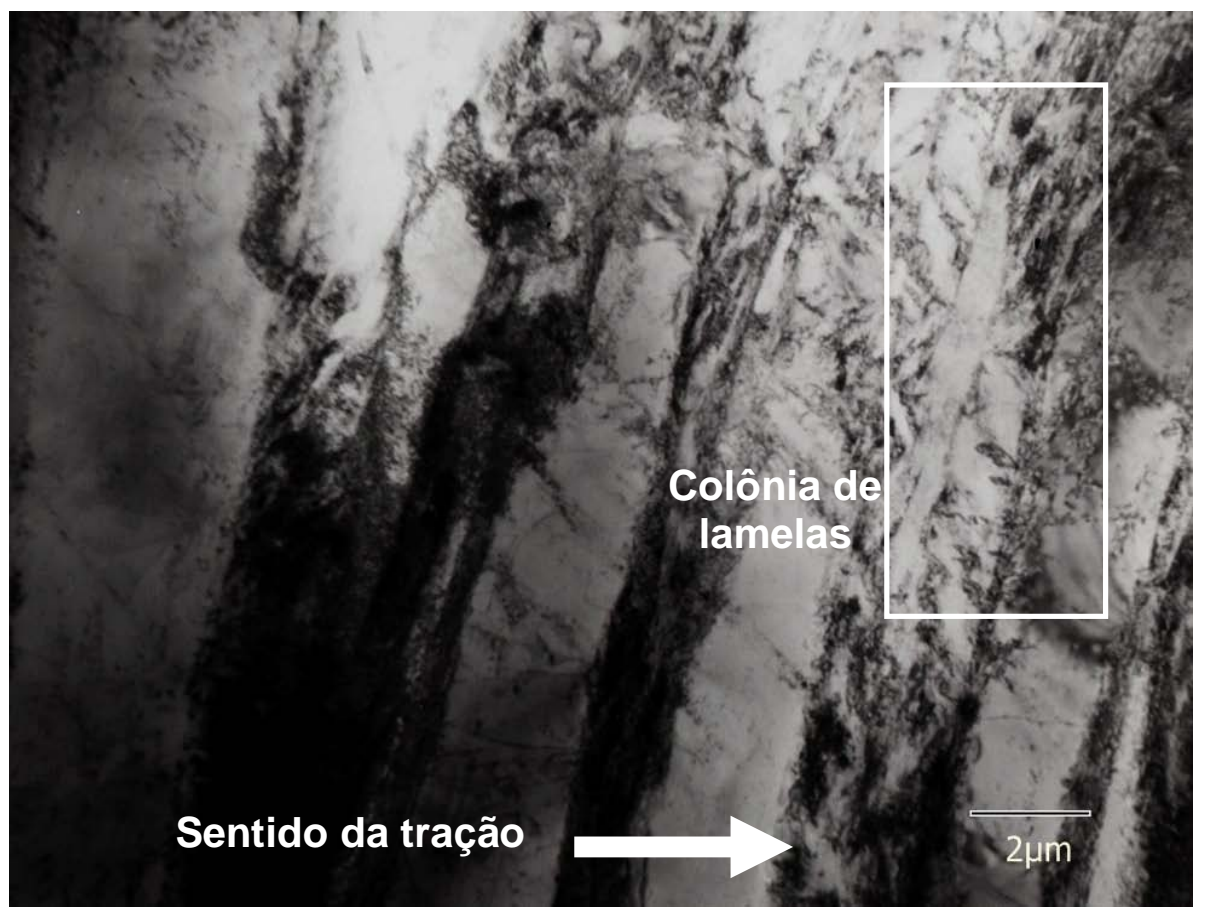

FIGURA 57: Micrografia eletrônica da amostra de Ti-6Al-4V, relativa à análise de tração in situ para um deslocamento de $0,25 \mathrm{~mm}$ em relação à posição inicial.

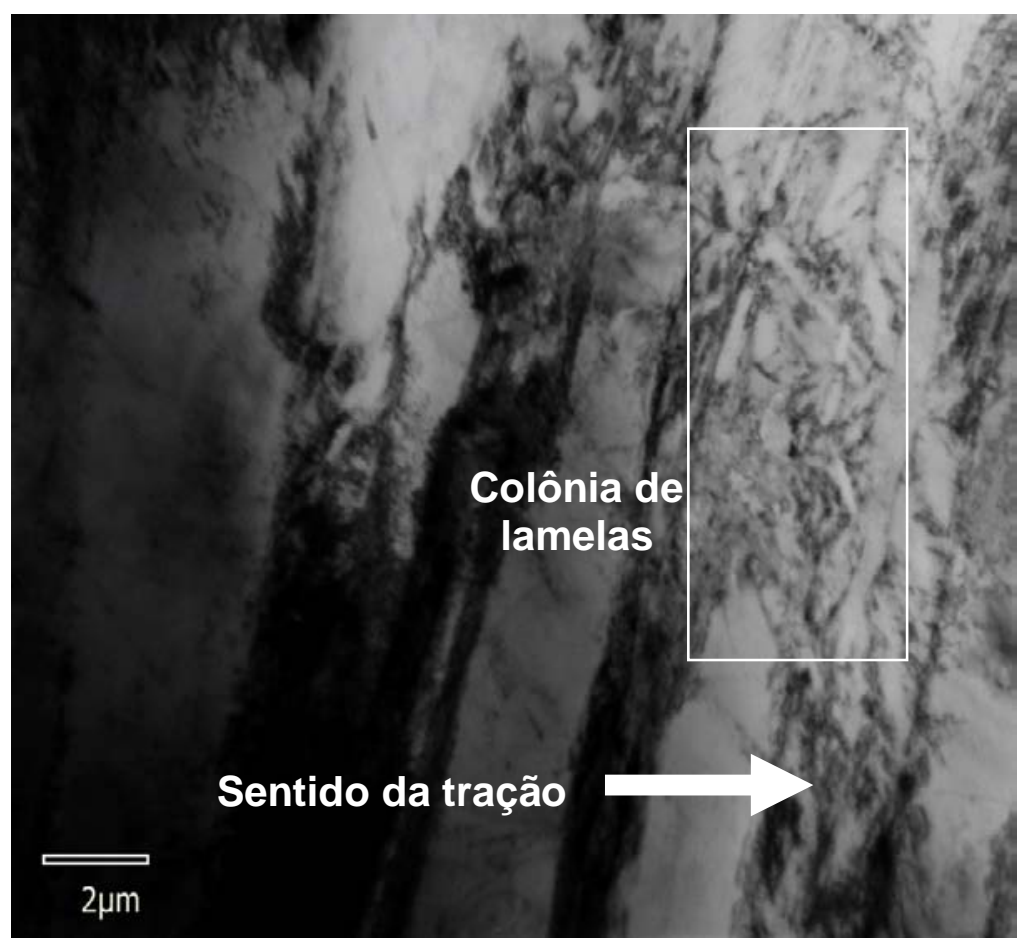

FIGURA 58: Micrografia eletrônica da amostra de Ti-6Al-4V, relativa à análise de tração in situ para um deslocamento de $0,25 \mathrm{~mm}$ em relação à posição inicial. 


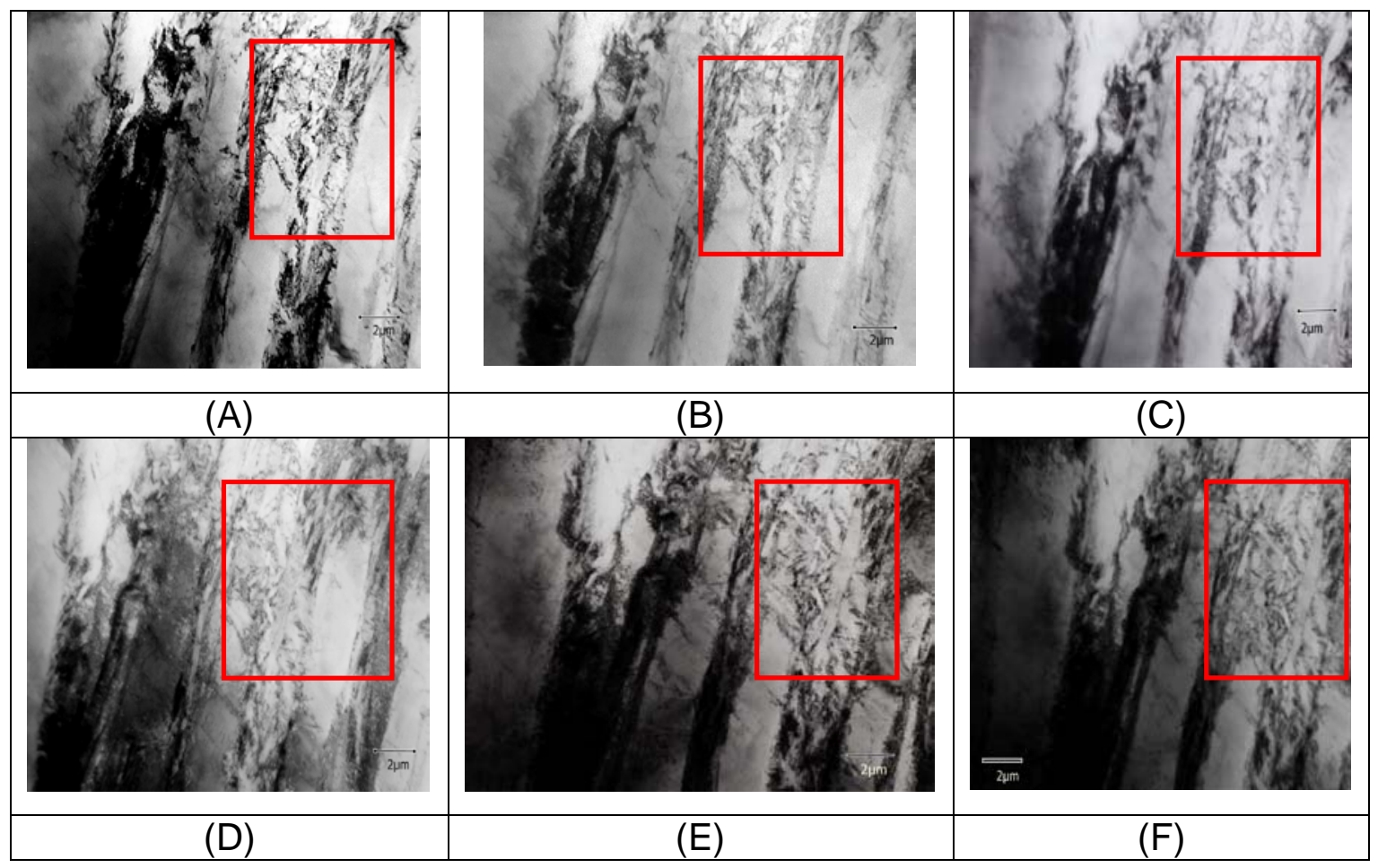

FIGURA 59: Micrografias da amostra de Ti-6Al-4V relativas às análises de tração in situ para diferentes deslocamentos: (A) 0,05 mm, (B) 0,10 mm, (C) 0,15 mm, (D) 0,20 mm, (E) e (F) 0,25 mm

A FIGURA 59 (A) até (F) mostra que após a aplicação do deslocamento houve a formação de discordâncias, que se tornam mais intensas à medida que a tração aplicada aumenta. Observa-se também que além do deslocamento dos planos ocorre uma deformação dos grãos existentes na amostra.

Após o rompimento da amostra, analisou-se a superfície da fratura, conforme mostra a FIGURA 60, por Microscopia Eletrônica de Varredura (MEV). 


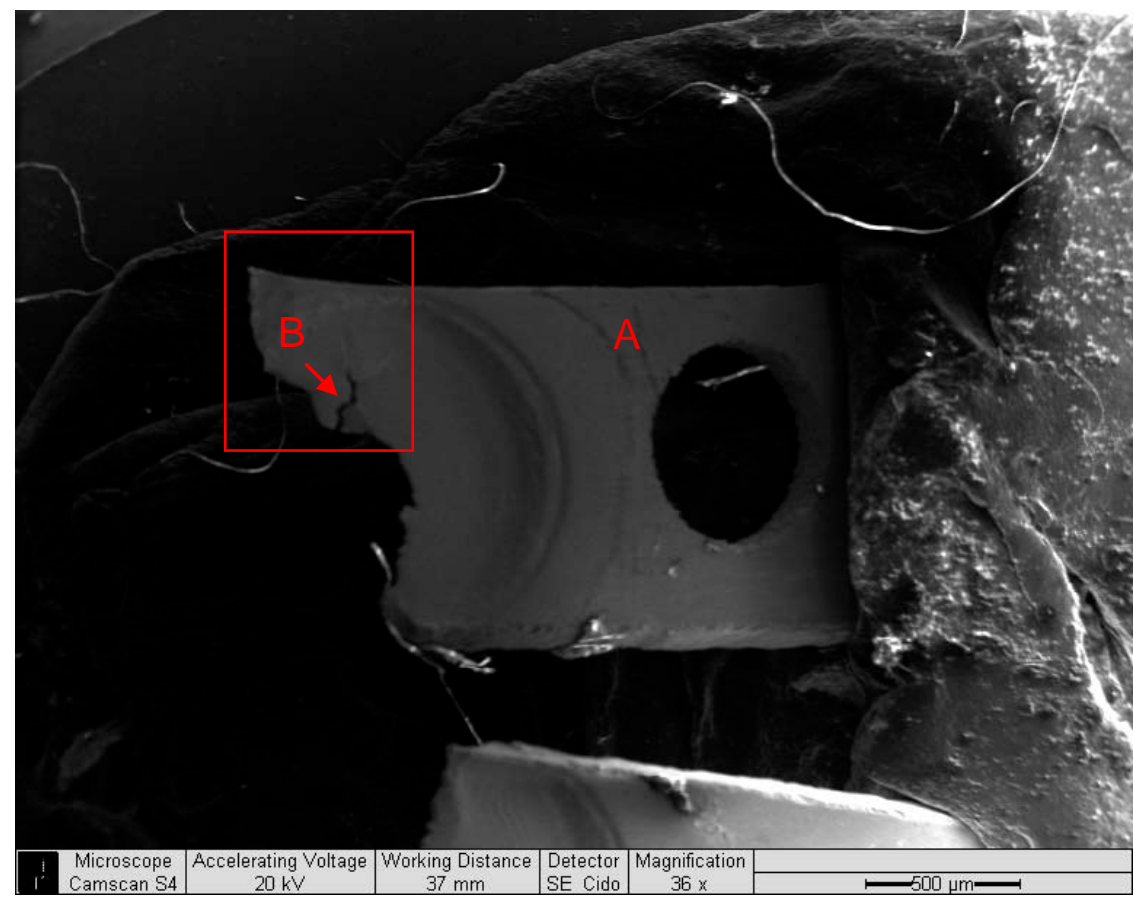

FIGURA 60: Micrografia eletrônica da face (A) da amostra de Ti-6Al-4V utilizada no ensaio de tração "in situ"; (B) Detalhe da região de área fina da amostra de Ti-6Al-4V,onde se observa in situ o início da fratura.

Ao descrever o comportamento local da fratura em liga de titânio de pureza comercial, Baptista (2000) verificou que parâmetros contínuos de dano podem ser empregados na modelagem da propagação de trincas, sob diferentes tipos de carregamento, sendo que se inclui numa área específica a Mecânico do Dano denominada "concepção local da fratura". Nestas condições a fratura geralmente ocorre sem a formação de uma trinca principal e se desenvolve lentamente através do crescimento de microcavidades nos grãos (fratura dúctil transgranular) simultaneamente ao crescimento de microtrinca nas fronteiras de grãos (fratura frágil intergranular), ou seja, ela é caracterizada pela evolução de descontinuidades microscópicas num volume relativamente grande de material.

A superfície de fratura revela a presença de grandes áreas com degraus de mesma orientação e zonas de falhas de tração associada com estrias em diferentes ângulos na direção de crescimento da fratura, como mostram as FIGURAS 61 e 62. 


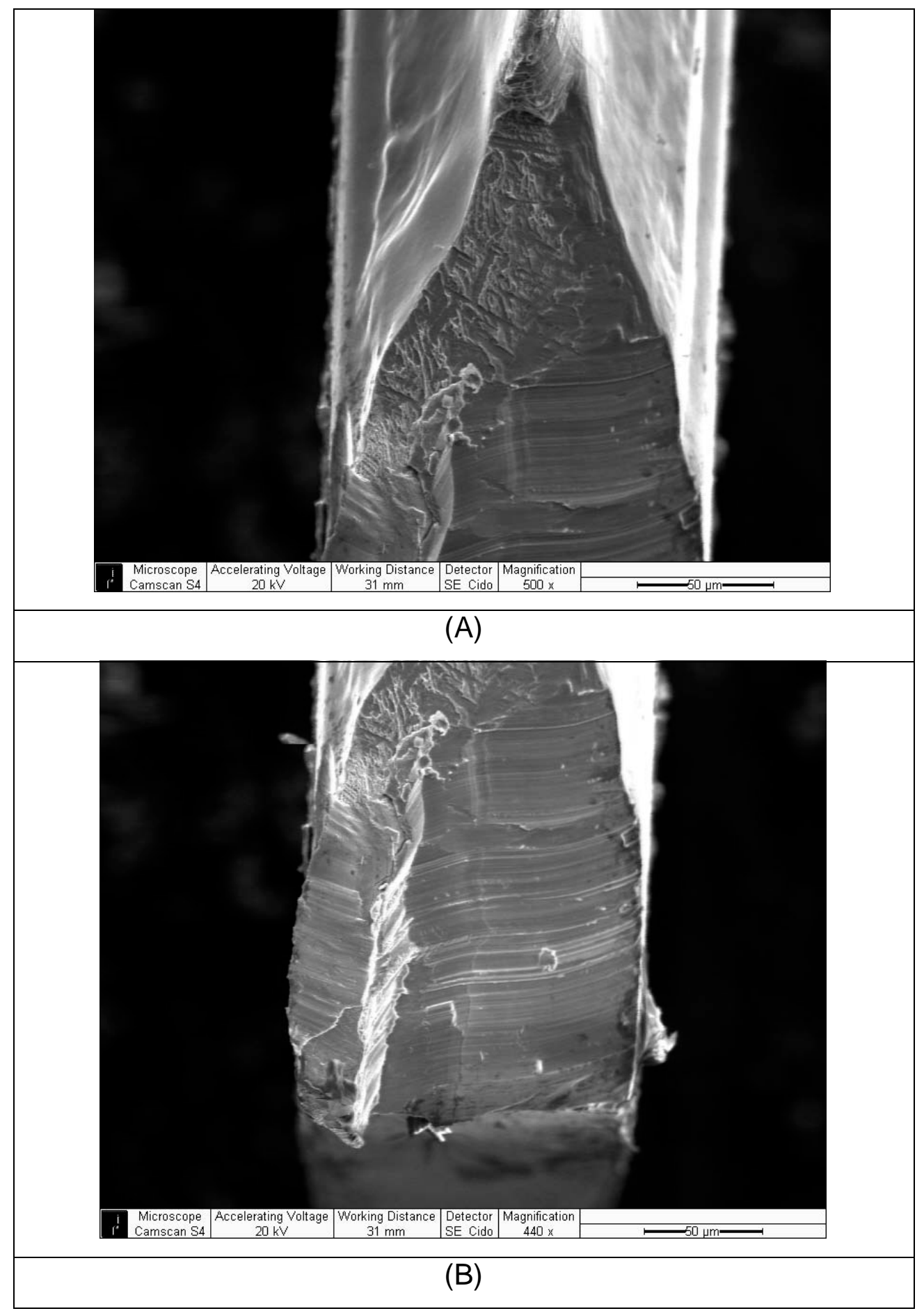

FIGURA 61: Micrografia eletrônica em detalhe da região de área fina da amostra de Ti-6Al-4V, análise por MEV, onde se observa in situ o início da fratura, (A) área fina superior e (B) área fina inferior (aumento 440 vezes) 


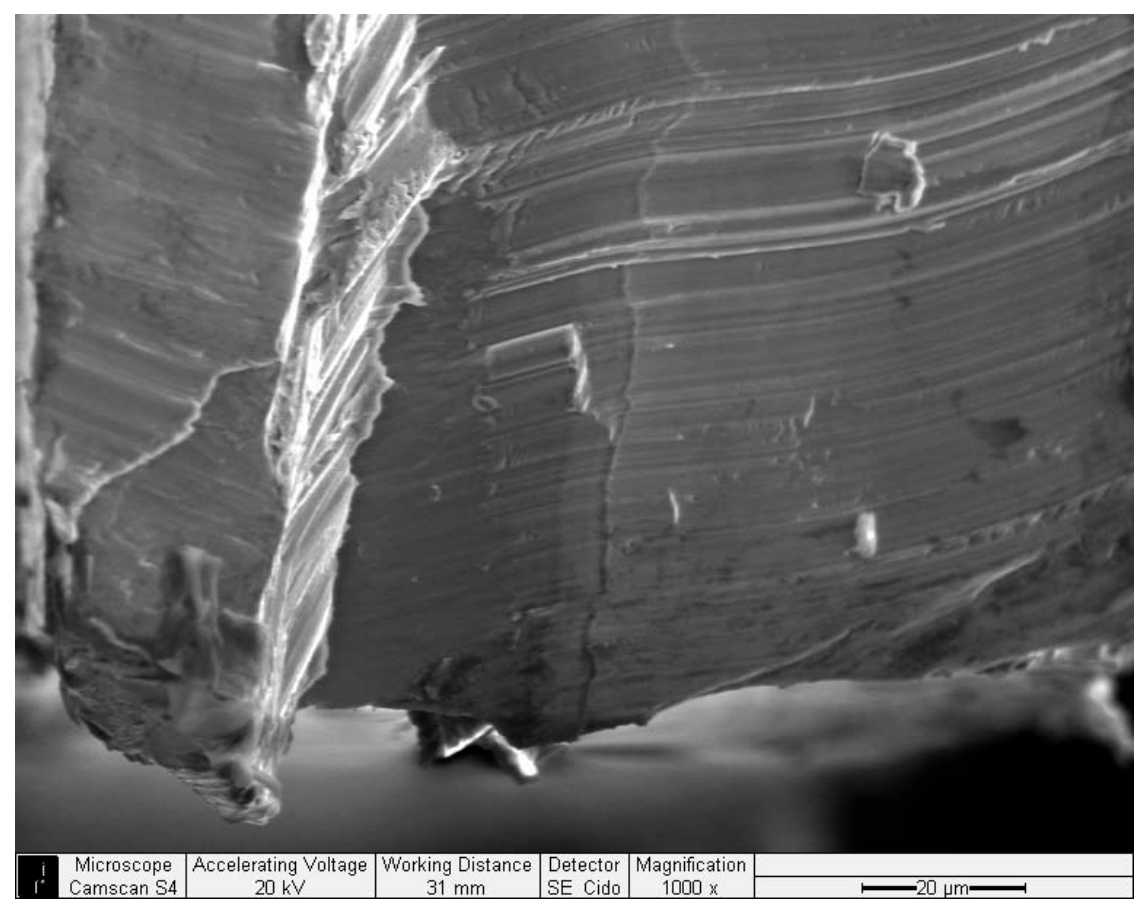

FIGURA 62: Micrografia eletrônica em detalhe da região de área fina da amostra de Ti-6Al-4V, análise por MEV, onde se observa in situ o início da fratura.

Bantounas et al. (2007) estudaram os mecanismos de fratura em ligas de Ti-6Al-4V por MEV e mostraram que a morfologia dos degraus na superfície de fratura depende da orientação de carregamento e da eficácia dos sistemas de deslizamento tanto no cristal quanto na textura do titânio. 


\subsubsection{Transformação de fase in situ}

Para a realização do ensaio de transformação de fase in situ utilizou-se a amostra de Ti-6Al-4V, tratada termicamente a $1000^{\circ} \mathrm{C}$ por duas horas, conforme descrito no item 4.4.

Poorganji et al.(2009) e Mironov et al (2009) estudaram a microestrutura de ligas de titânio $\alpha+\beta$, e observaram que diferentes microestruturas podem ser obtidas pela mudança do processo de tratamento térmico. A estrutura lamelar $\alpha$ começa a se formar a partir do contorno dos grãos $\beta$, pelo resfriamento da fase $\beta$ solubilizada. A estrutura lamelar $\alpha+\beta$ possui a mesma orientação da fase lamelar $\alpha$. O tamanho final da fase lamelar $\alpha$ pode ser controlada pela taxa de resfriamento aplicada.

A FIGURA 63 mostra uma microestrutura intragranular composta de placas de fase $\alpha$ primária, longas e paralelas e com a retenção da fase $\beta$ entre as placas de fase $\alpha$.

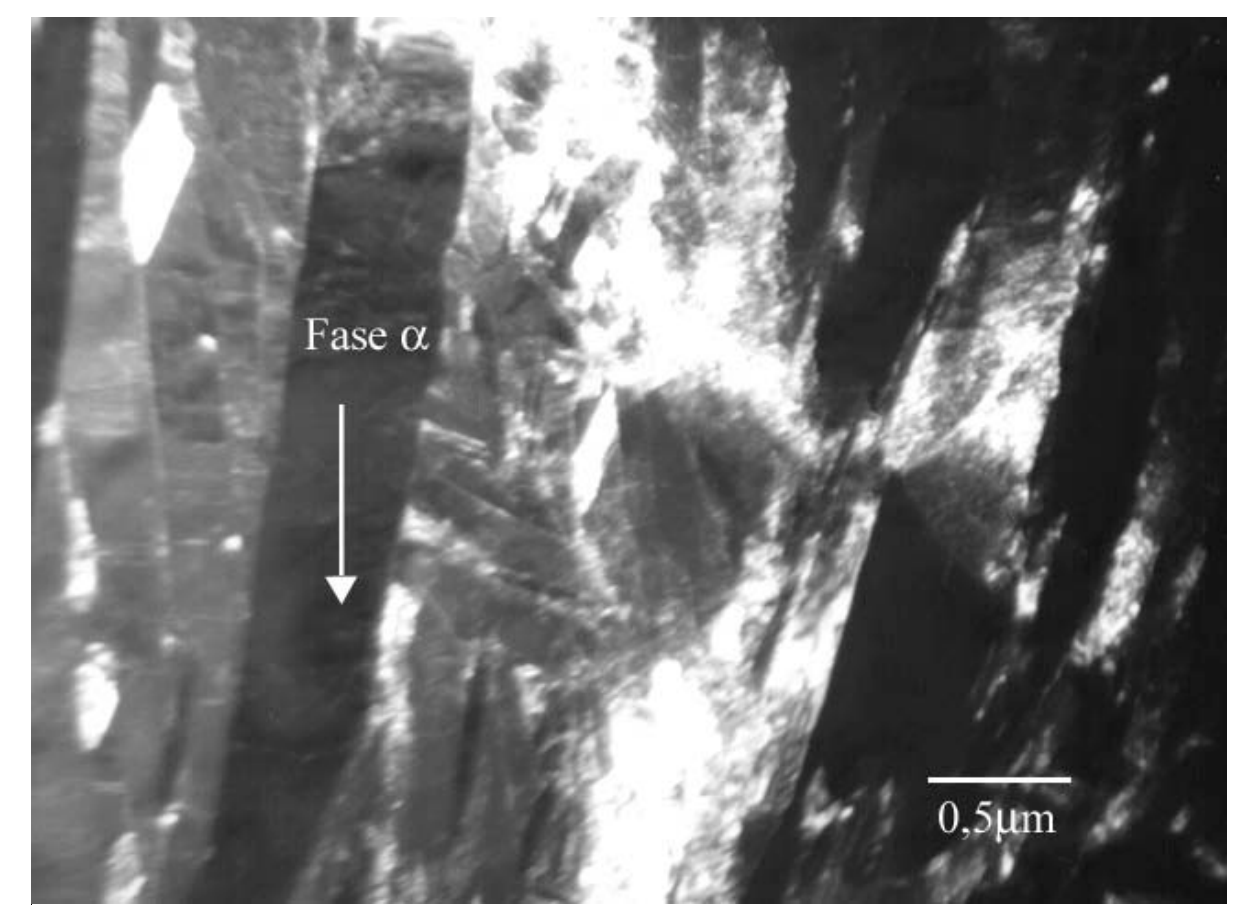

FIGURA 63: Micrografia eletrônica em campo escuro da amostra de Ti-6Al-4V apresentando em sua estrutura lamelas longitudinais. 
As transformações que ocorrem no Titânio e suas ligas são dependentes da temperatura de trabalho, da taxa de resfriamento e microestrutura inicial.

No presente trabalho, para o estudo da transformação de fase in situ, iniciou-se o ensaio observando-se a amostra à temperatura ambiente, conforme mostra a FIGURA 63. A partir das lamelas observadas na micrografia realizou-se o padrão de difração de elétrons para se determinar a fase compreendida pela lamela conforme mostra a FIGURA 64. Após a indexação do padrão de difração de elétrons, pôde-se confirmar a presença da fase $\alpha$ na estrutura.

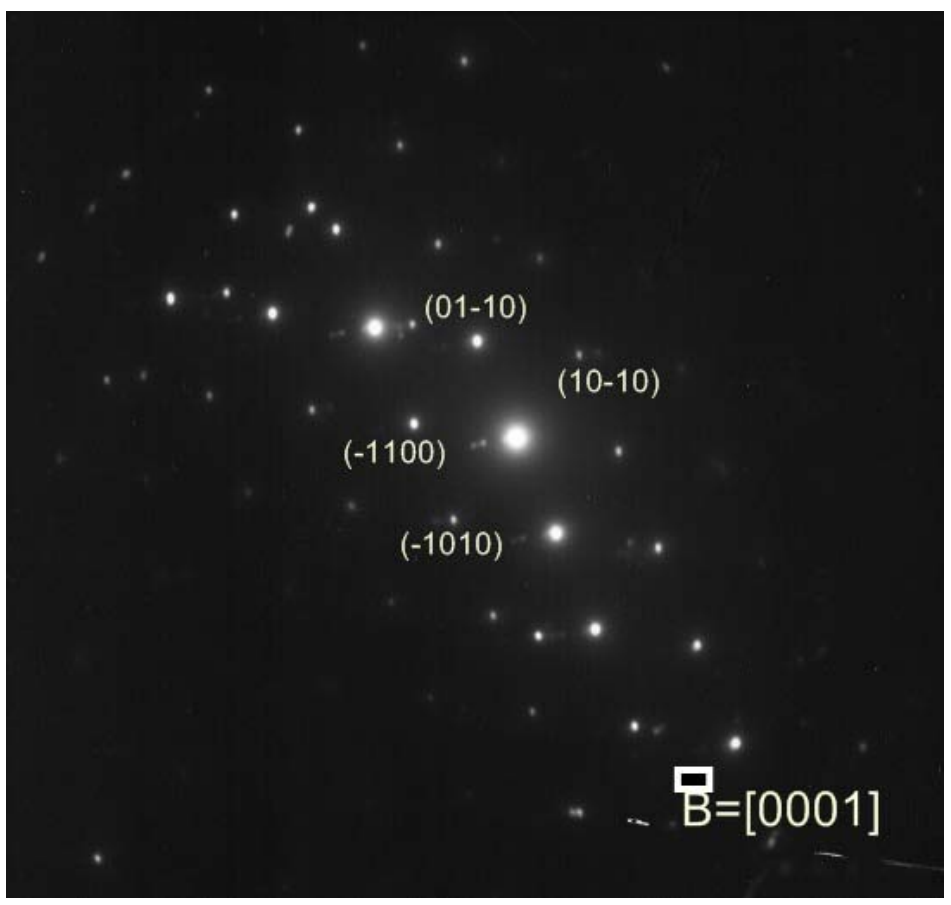

FIGURA 64: Padrão de difração de elétrons realizado na área selecionada da Figura. 63 , sendo identificada a presença da fase alfa (hc), após a indexação.

A FIGURA 65(A), micrografia eletrônica em campo claro da FIGURA 63, mostra a retenção de placas entre as lamelas longitudinais alfa. 


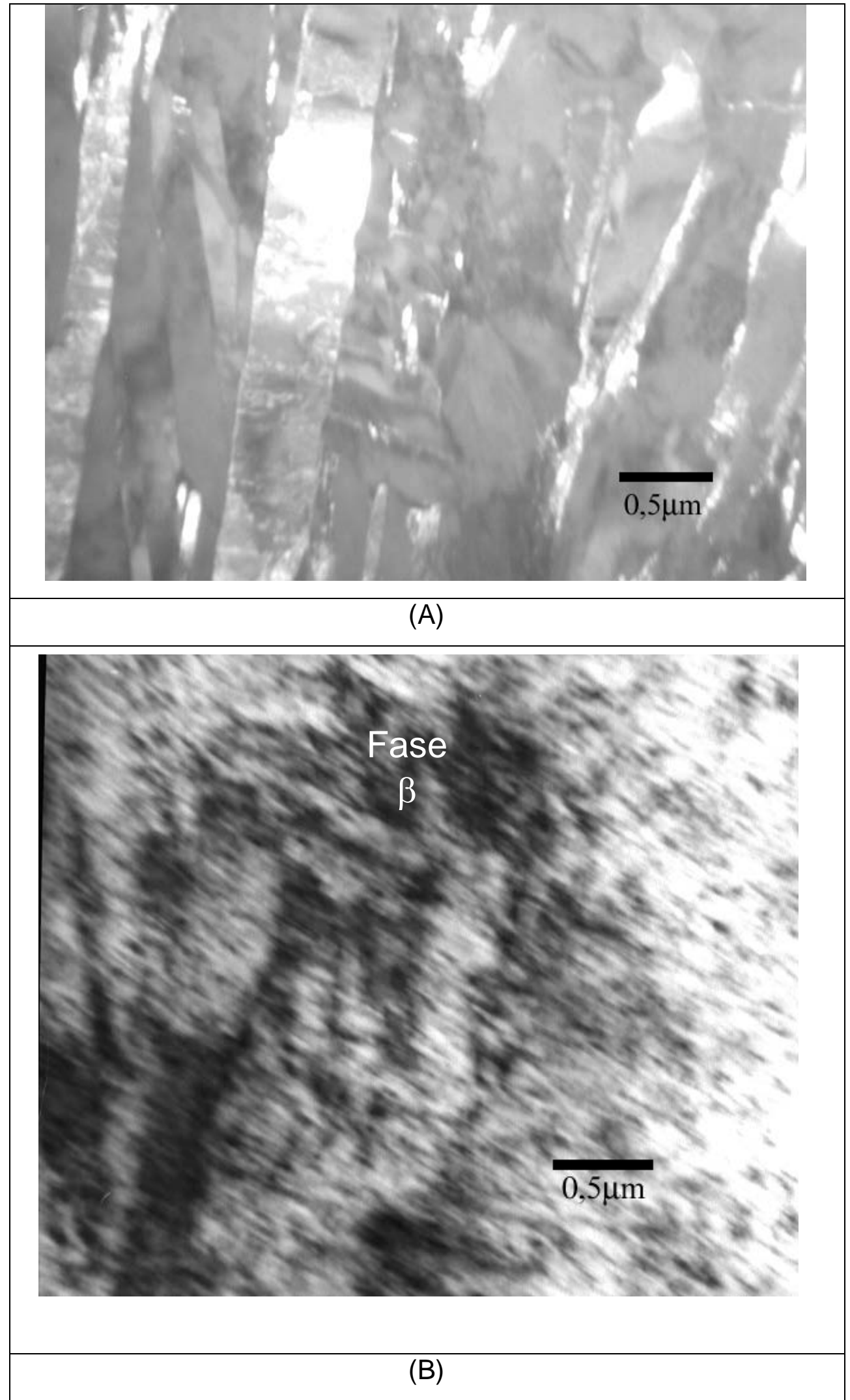

FIGURA 65: Micrografia eletrônica da amostra de Ti-6Al-4V, (A) amostra no início do ensaio e (B) após a elevação da temperatura in situ aplicada à amostra de $600^{\circ} \mathrm{C}$. 
Para registrar a transformação de fase, na FIGURA 65 (B), elevou-se a temperatura in situ até $600^{\circ} \mathrm{C}$, sendo que o aquecimento aplicado à amostra foi realizado, variando-se a temperatura em patamares de $50^{\circ} \mathrm{C}$ até atingir a temperatura de $600^{\circ} \mathrm{C}$. Durante o ensaio observou-se a mudança da estrutura interna da amostra a partir da temperatura de $600^{\circ} \mathrm{C}$. Comparando-se as FIGURAS 65 (A) e (B) observa-se a mudança da estrutura. Durante o ensaio, partindo-se da nova estrutura obtida, conforme mostra a FIGURA 65 (B), realizouse o padrão de difração de elétrons na nova estrutura observada.

A FIGURA 66 mostra o padrão de difração de elétrons na nova estrutura formada. Após a indexação do padrão de difração de elétrons foi determinada a presença da fase $\beta$ (ccc), indicando a mudança da fase in situ.

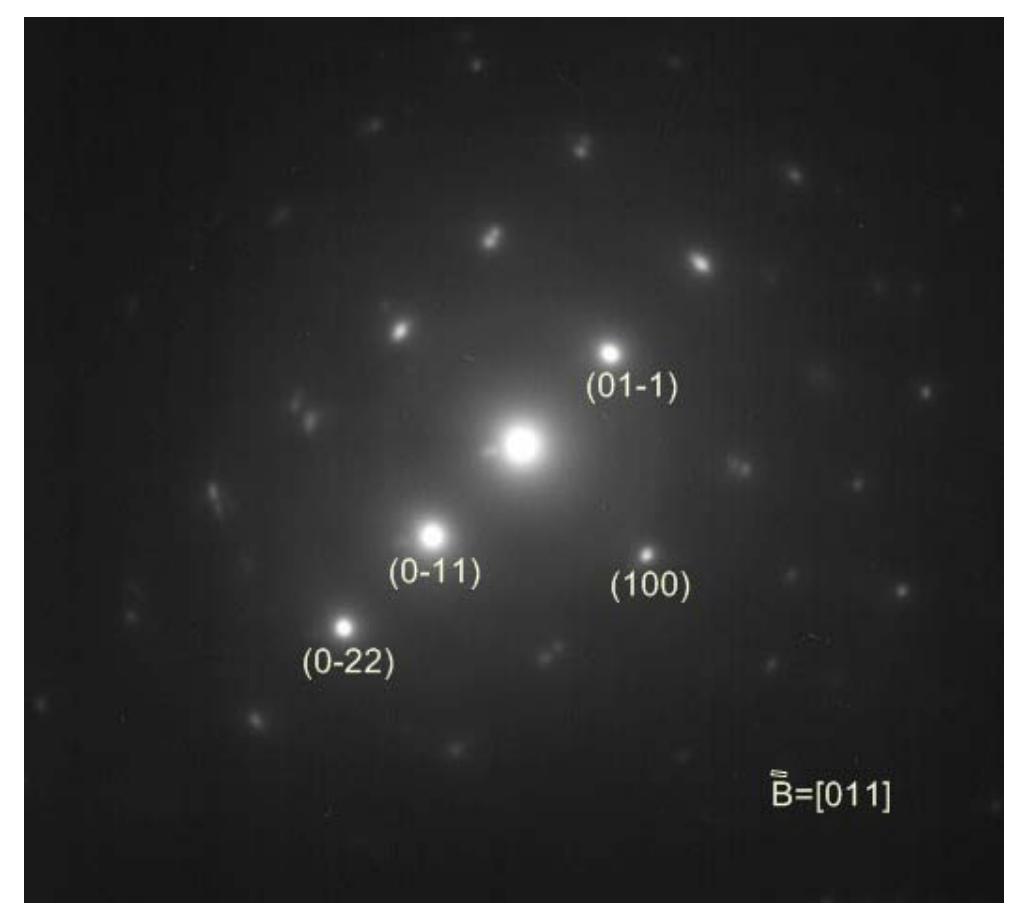

FIGURA 66: Padrão de difração de elétrons realizado na área selecionada da Figura 65 (B) sendo identificada a presença da fase beta (ccc), após a indexação.

Em função do processo de obtenção de imagem ser dinâmico, na FIGURA 65 (B), observa-se um realinhamento da microestrutura interna do material podendo-se visualizar a formação de grãos com dimensões distintas. 


\subsubsection{Análise de sub-grãos utilizando-se Microscopia Eletrônica de Transmissão de Alta Resolução (MET-AR)}

As amostras de Ti-6Al-4V foram preparadas para observação e análise no Microscópio Eletrônico de Transmissão de Alta Resolução (MET-AR) analítico Jeol 200kV, CCTM/IPEN, seguindo-se as etapas de preparação da amostra para MET-AR, conforme descrita em 4 Materiais e métodos experimentais. Foram obtidos discos com $3 \mathrm{~mm}$ de diâmetro e espessura aproximada da área fina de 2 $\mathrm{mm}$. Para a obtenção dos discos com $3 \mathrm{~mm}$ de diâmetro utilizou-se a eletroerosão. Na redução da espessura iniciou-se com o lixamento do disco em lixa $600 \mu \mathrm{m}$ e, para obtenção da área fina utilizou-se o equipamento TENUPOL no afinamento eletrolítico da amostra, com o intuito de obter a área fina de observação e análise no MET-AR analítico.

Nesta etapa do trabalho foram utilizadas amostras da liga de titânio Ti-6Al-4V na condição inicial, ou seja, recozidas a $800^{\circ} \mathrm{C}$ por duas horas e amostras tratadas termicamente, utilizando-se a temperatura de $1000^{\circ} \mathrm{C}$ por uma hora, realizando-se o resfriamento das mesmas em água. As amostras, após o tratamento térmico foram preparadas para a análise no MET analítico. As micrografias eletrônicas a seguir revelam a alteração sofrida pela liga de titânio após o tratamento térmico, ao qual foi submetida.

A FIGURA 67 apresenta a micrografia da amostra de Ti-6Al-4V, recozida a $800^{\circ} \mathrm{C}$ por duas horas (como recebida). Observamos que a microestrutura apresenta regiões onde ocorreu o encruamento. Verificamos discordâncias causadas na conformação mecânica aplicada ao material.

A FIGURA 68 mostra em detalhe franjas de discordâncias, onde se verifica planos sobrepostos na amostra. 


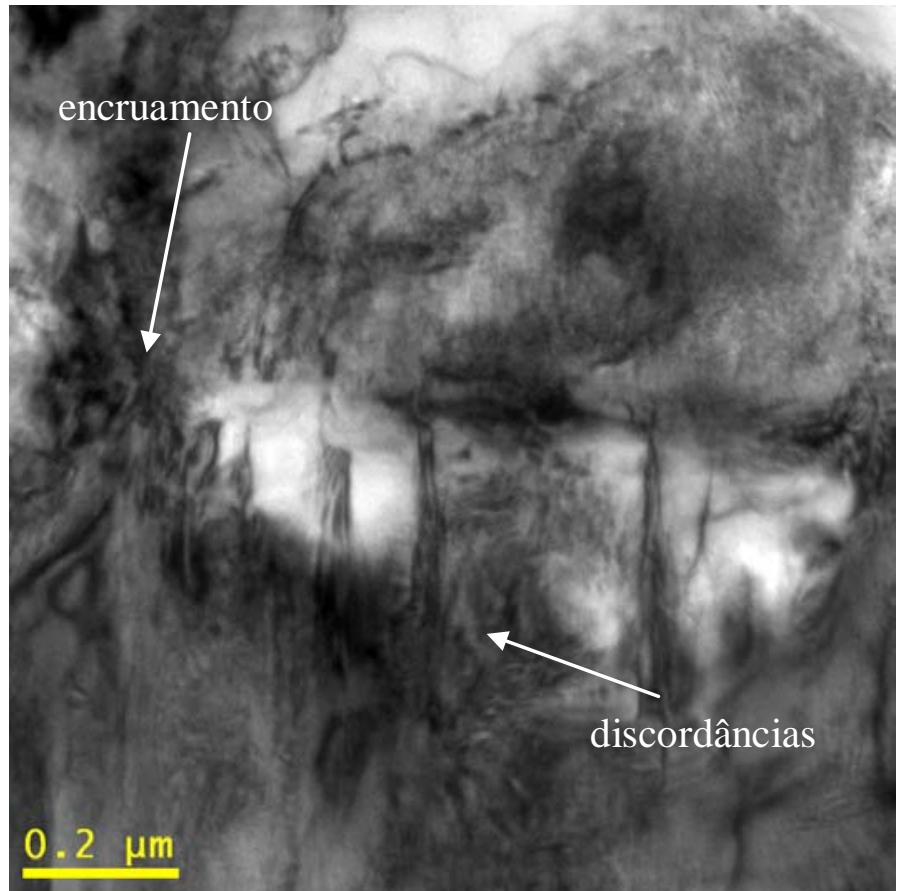

FIGURA 67: Micrografia eletrônica da amostra de Ti-6Al-4V recozida $800^{\circ} \mathrm{C}$ por duas horas.

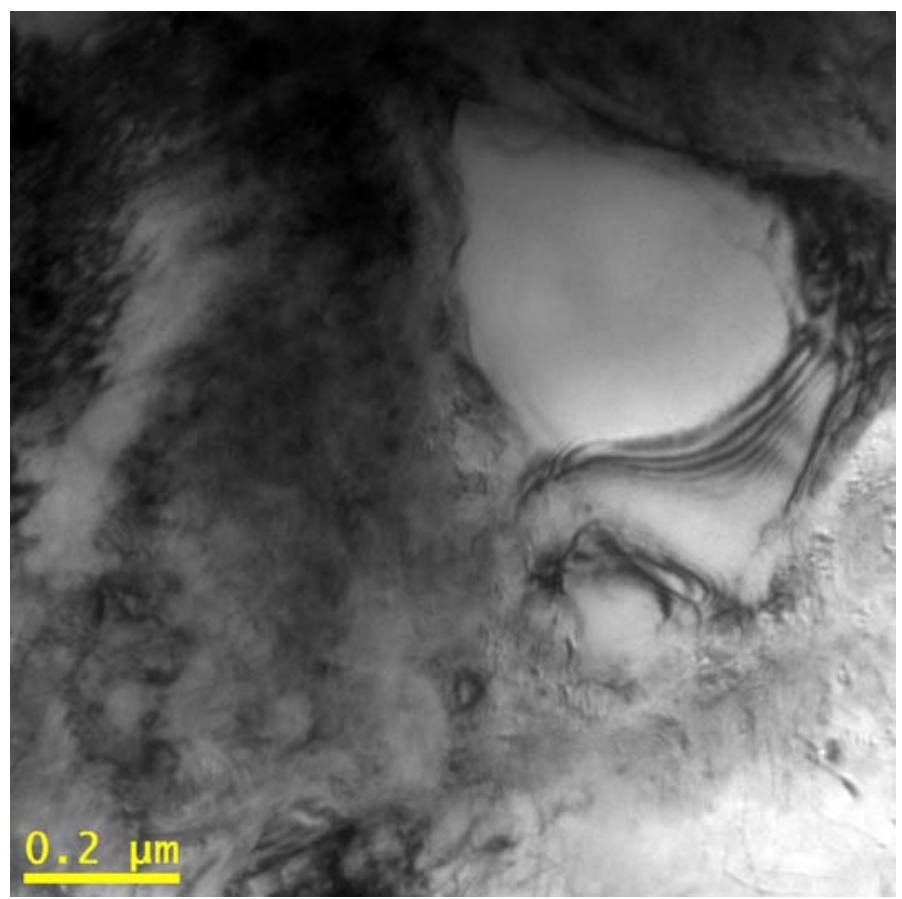

FIGURA 68: Micrografia eletrônica da amostra de Ti-6Al-4V recozida a $800^{\circ} \mathrm{C}$ por duas horas, apresentando franjas. 
A FIGURA 69 (A) mostra uma região contendo sub-grãos, com uma região escura que se assemelha a uma estrutura lamelar. Em (B) tem-se uma região formada por sub-grãos na face e algumas franjas de discordância, e em (C) mostra regiões contendo discordâncias seguidas de planos sobrepostos.

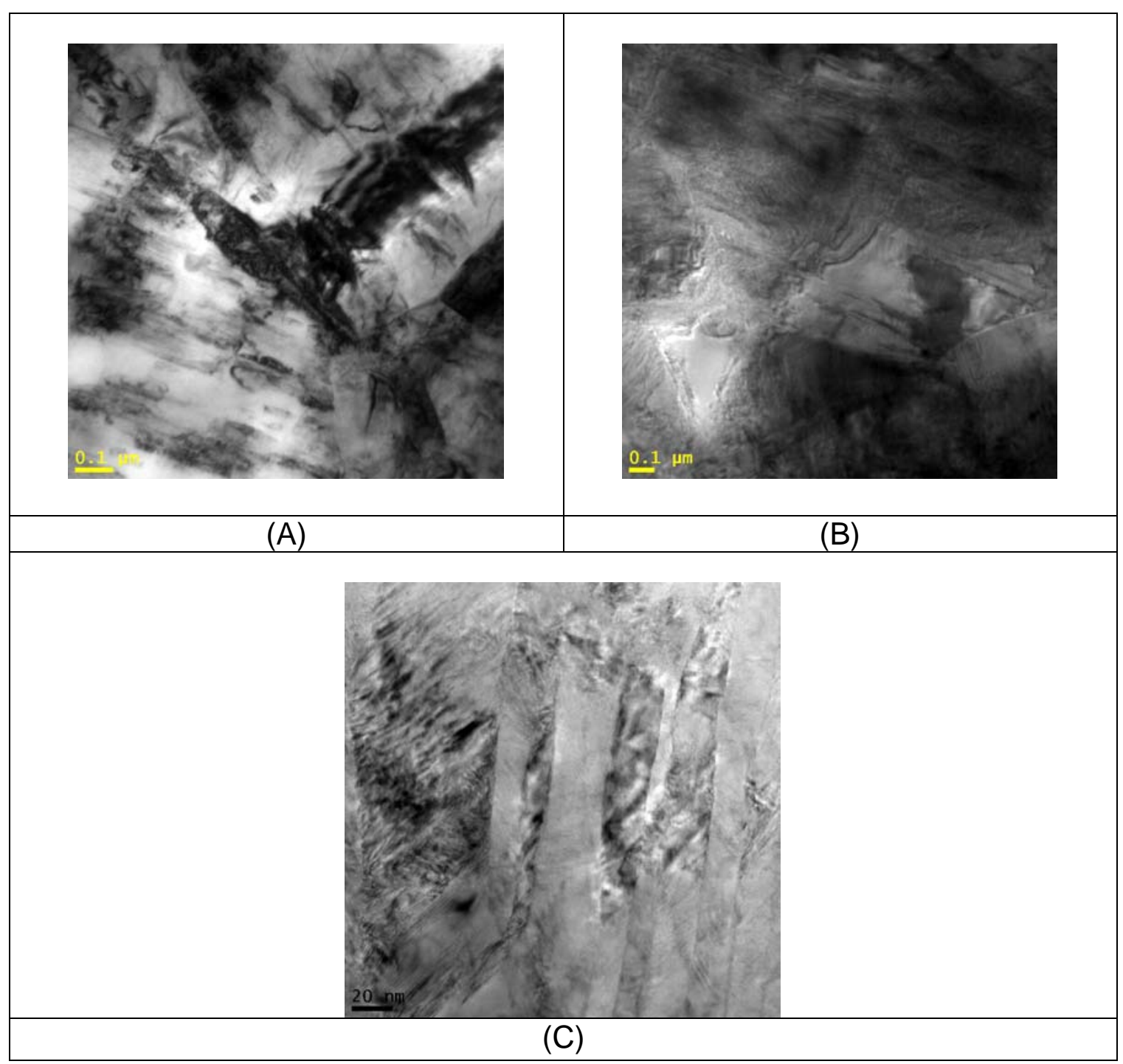

FIGURA 69: Micrografia eletrônica da amostra de Ti-6Al-4V recozida a $800^{\circ} \mathrm{C}$ por duas horas

Na FIGURA 70, a qual foi obtida no modo de alta resolução, pode se constatar a presença de maclas ao longo das micrografias (A) e (B). Em (A) percebe-se um tipo de borda na interface com pequeno defeito 


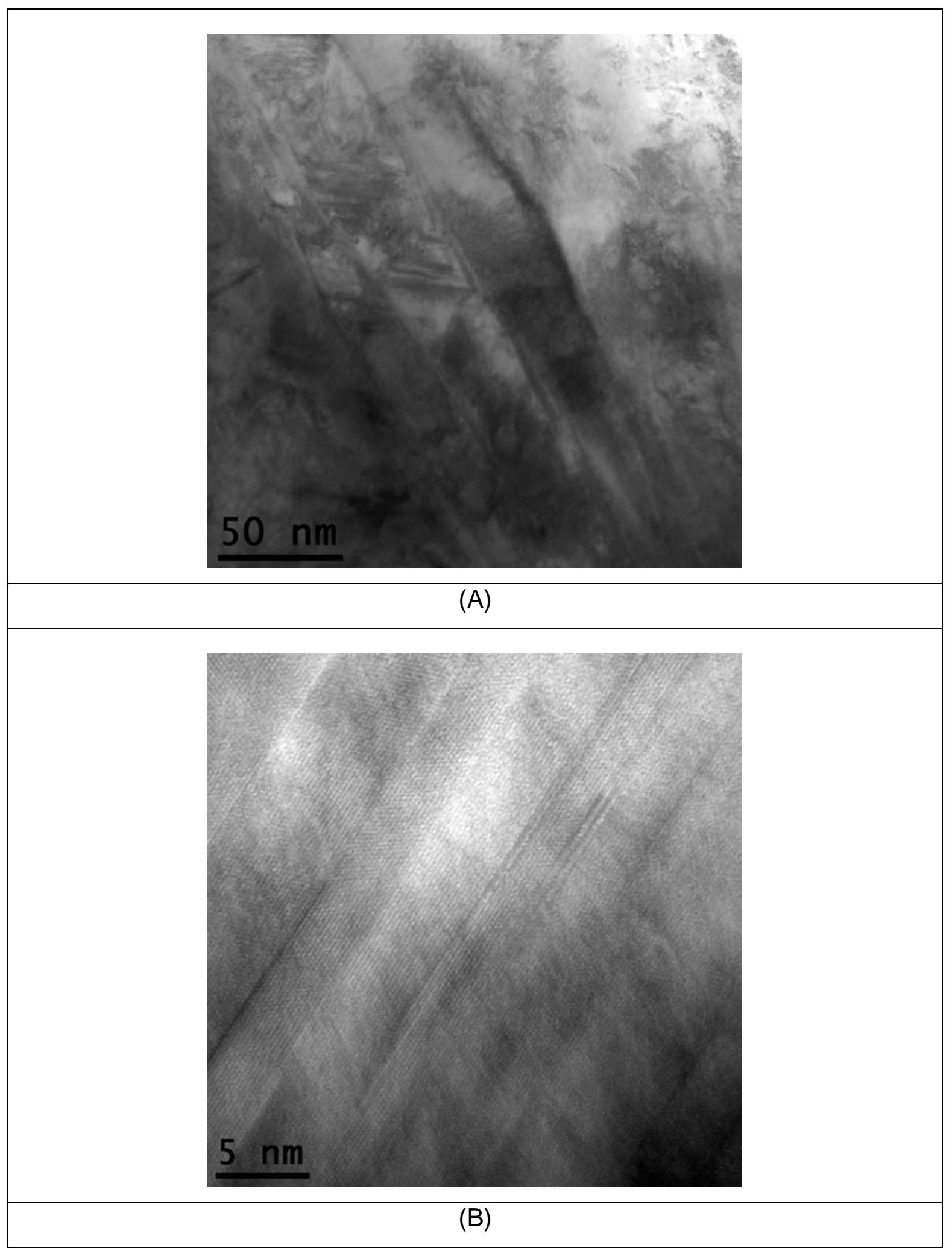

FIGURA 70: Micrografia eletrônica da amostra de Ti-6Al-4V, após o tratamento térmico $1000^{\circ} \mathrm{C} / 1 \mathrm{~h}$ e resfriamento rápido em água, apresentando maclas longitudinais em $(A)$ e $(B)$. 
Manero et al. (2000) relatam que no caso do titânio puro existem fatores microestruturais, tais como a prévia existência de deslocamentos nas interfaces dos contornos dos planos martensíticos de $\alpha^{\prime}$. Acredita-se que apesar de em testes realizados com titânio puro não ser possível esta observação existem fatores na microestrutura martensítica de $\alpha^{\prime}$, mo a existência de deslocamentos e interfaces $\alpha^{\prime} / \alpha^{\prime}$, que podem reduzir a energia de ativação necessária para a nucleação dos planos das maclas em (1011).

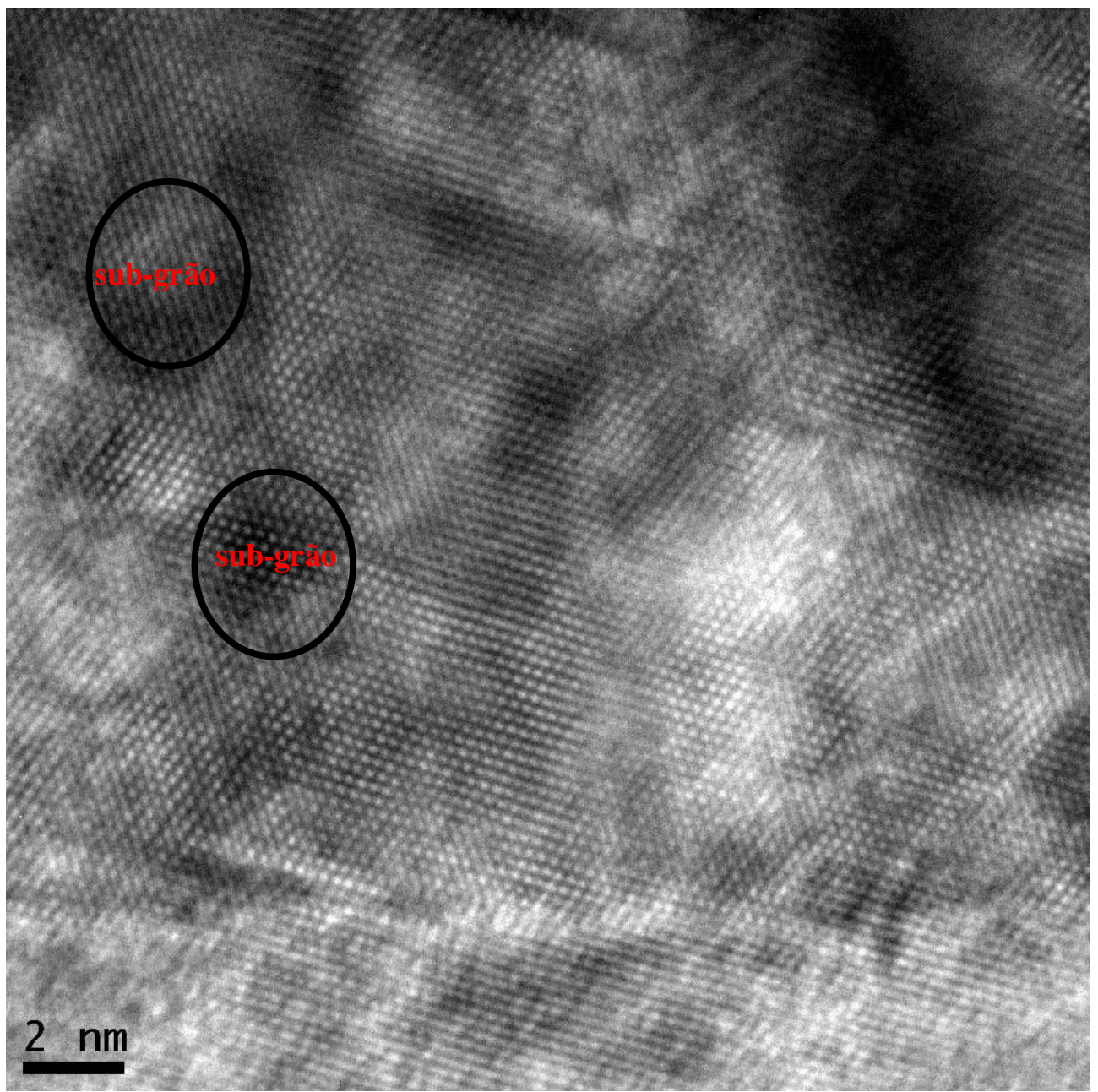

FIGURA 71: Micrografia eletrônica da amostra de Ti-6Al-4V, após o tratamento térmico $1000^{\circ} \mathrm{C} / 1 \mathrm{~h}$ e resfriamento rápido em água. 
Na FIGURA 71, obtida no modo de alta resolução, é visível a orientação dos planos cristalinos existentes na amostra de Ti-6Al-4V, observa-se a presença de sub-grãos na região escura. Ao se medir os ângulos formados entre os planos valores que variam de $60^{\circ}$ a $70^{\circ}$ são encontrados, preponderando o ângulo de $65^{\circ}$. Esta variação pode ser explicada pela proximidade com regiões onde há a presença de sub-grãos.

A FIGURA 72 mostra planos sobrepostos com a formação de maclas e zonas de discordâncias, sendo possível observar a variação no tamanho das maclas. Este comportamento pode ser atribuído a taxa de resfriamento imposta à amostra.

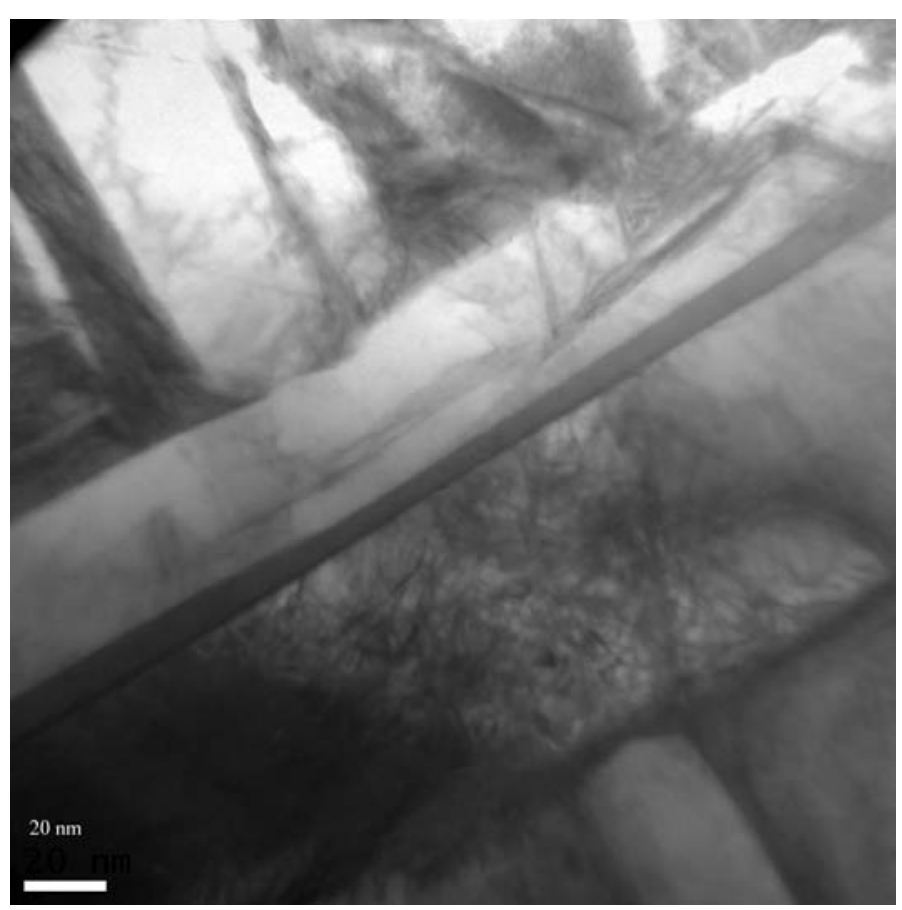

FIGURA 72: Micrografia eletrônica da amostra de Ti-6Al-4V ,após o tratamento térmico $1000^{\circ} \mathrm{C} / 1 \mathrm{~h}$ e resfriamento rápido em água. 
Na FIGURA 73 observa-se maclas dispostas longitudinalmente com dimensão aproximada de $2,5 \mathrm{~nm}$, bem como discordâncias e a deformação do plano.

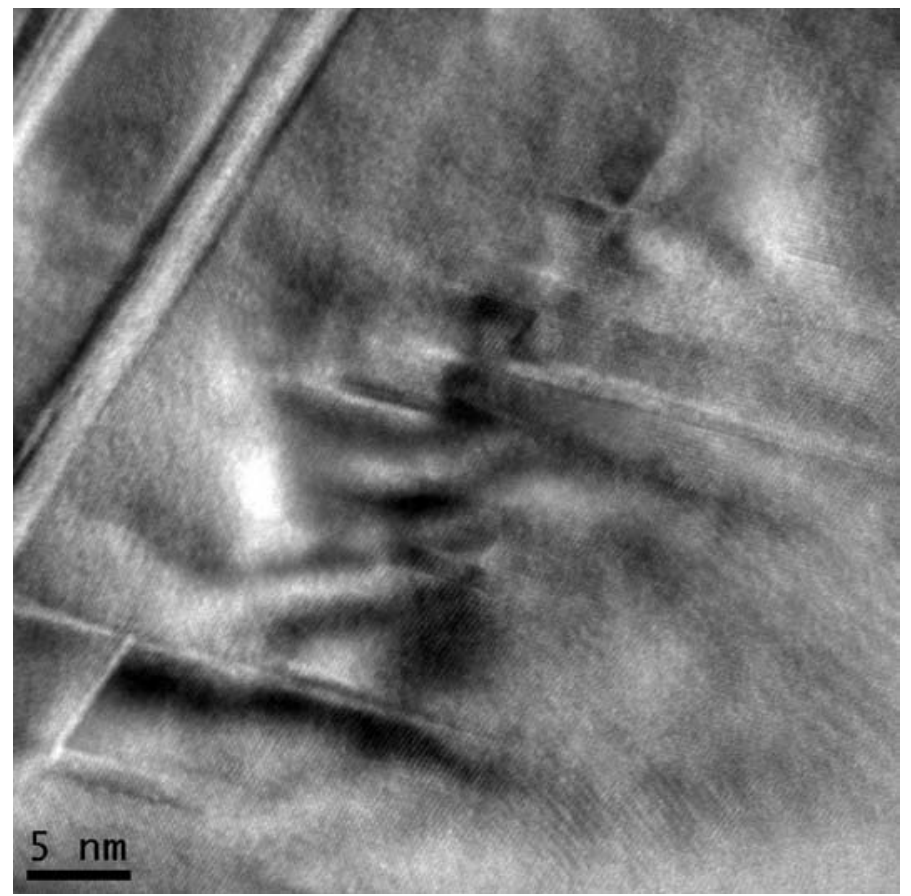

FIGURA 73: Micrografia eletrônica da amostra de Ti-6Al-4V, após o tratamento térmico $1000^{\circ} \mathrm{C} / 1 \mathrm{~h}$ e resfriamento rápido em água. 


\section{CONCLUSÕES}

Para a liga de titânio Ti-6Al-4V, objeto de estudo do presente trabalho, a partir da amostra como recebida, tratada a $800^{\circ} \mathrm{C}$ por duas horas, foram realizados os tratamentos térmicos, aplicando-se a temperatura de $1000^{\circ} \mathrm{C}$ por uma hora e resfriamento rápido em água e $1000^{\circ} \mathrm{C}$ por duas horas, com a amostra mantida sob vácuo em tubo de quartzo selado e resfriada em água. Os tratamentos térmicos realizados promoveram a mudança da microestrutura da amostra, formando plaquetas de martensita, com a retenção da fase $\beta$ (ccc) e transformando parte da estrutura $\alpha$ (hc) secundária existente em uma estrutura $\beta$, que se encontrava retida entre as lamelas de alfa.

Para a caracterização da microestrutura da amostra como recebida e após os tratamentos térmicos, foram realizadas as análises com a liga de titânio Ti-6Al-4V, utilizando-se o MEV/EDS/EBSD, onde se pôde determinar a presença da fase $\alpha$ e caracterizar a fase $\beta$ nos contornos de grãos da fase $\alpha$. Utilizou-se a técnica de DRX para a análise das fases $\alpha$ e $\beta$ presentes na amostra, cujos resultados revelam a presença da fase $\beta$ em uma matriz de fase $\alpha$.

Para os estudos in situ de deformação e fratura, transformação de fase, caracterização microestrutural e nanoestrutural das amostras, utilizou-se o MET convencional e MET-AR. Esta técnica permitiu a determinação da presença da fase $\alpha$ com morfologia lamelar, formada heterogeneamente na transição $\beta \rightarrow \alpha$ e a formação da fase $\alpha$ secundária, formada a partir da taxa de resfriamento aplicada à amostra no campo $\alpha+\beta$. Observa-se a presença de maclas e discordâncias, no ensaio de tração in situ gerado pelo deslizamento do plano basal e prismático da fase $\alpha$, presente na amostra, em função desses planos requererem baixa tensão crítica de cisalhamento.

Análises por MEV/EDS/EBDS - Nas análises por microscopia eletrônica de varredura, associada à espectroscopia de energia dispersiva e difração de elétrons retroespalhados, verifica-se a presença da fase $\alpha$ do titânio, sendo 
possível identificar os planos cristalográficos hexagonal compacto (hc), bem como a presença da fase $\beta$, cúbica de corpo centrado (ccc) presentes na amostra.

- As análises por microscópia eletrônica de transmissão de alta resolução permitem o estudo nanocristalino da amostra.

- Os estudos de deformação e fratura da amostra "in situ" no MET permite que o trabalho seja uma contribuição original para o entendimento na escala nanométrica dos micromecanismos de deformação e fratura da liga de titânio Ti-6Al-4V.

- As análises por microscópia eletrônica de transmissão de alta resolução permitem o estudo nanocristalino da amostra.

- Observou-se a presença da microestrutura lamelar, formada durante o resfriamento no campo $\beta$, promovendo a transformação de parte da estrutura alfa secundária em beta, que se encontrava retida entre as lamelas de alfa.

- Para as diferentes condições de tratamento térmico aplicado à liga metálica, foram observadas as variações entre a quantidade das fases $\alpha \mathrm{e}$ $\beta$, em relação à microestrutura original do material

- TRABALHOS FUTUROS

- Estudo para grãos nanométricos aplicados à liga Ti-6Al-4V.

- Considerações teóricas do modelo macroscópico aplicados à tração, para a escala nanométrica. 


\section{REFERÊNCIAS BIBLIOGRÁFICAS}

AHMED, T. \& RACK, H. J. Phase transformations during cooling in $\alpha+\beta$ titanium alloys MATERIALS SCIENCE \& ENGINEERING, 243, 206-211, 1998.

AMERICAN SOCIETY FOR METALS (ASM). Metals handbook, ed.9, v.9, 458$475,1980$.

AKAHORI, T.; NIINOMI, M. Fracture characteristics of fatigued Ti-6Al-4V ELI as an implant materials. MATERIALS SCIENCE \& ENGINEERING, 243, 237-243, 1998.

BALAZIC, M., KOPAC, J.,JACKSON, M.J. and AHMED, W. 'Review: titanium and titanium alloy applications in medicine', Int. J. Nano and Biomaterials, v. 1, n. 1, p.3-34, 2007.

BANTOUNAS, I.; LINDLEY, T.; RUGG, D.; DYE, D. Effect of microtexture on fatigue cracking in Ti-6Al-4V. ACTA MATERIALIA, 55, 5655-5665, 2007.

BAPTISTA, C. A. R. P. Modelagem preditiva do comportamento de trincas de fadiga com aplicação ao titânio de pureza comercial. 2000. Tese (Doutorado). Faculdade de Engenharia Química de Lorena, Lorena, São Paulo.

BLACKWOOD, D.J., Biomaterials: Past successes and future problems, CORROSION REVIEWS, 21 (2-3):97-124, 2003.

BRAGA, N. A.; FERREIRA, N. G.; CAIRO, C. A. A. Obtenção de titânio metálico com porosidade controlada por metalurgia do pó. QUím. NOVA, São Paulo, v. 30, n. 2, 2007 .

BRIDIER, F.; VILLECHAISE, P.; MENDEZ, J. Analysis of the different slip systems activated by tension in a $\alpha \beta$ titanium alloy in relation with local crystallographic orientation. ACTA MATERIALIA, 53, 555-567, 2005.

CASTANY, P., PETTINARI-STURMEL, F.; DOUIN. J.; COUJOU, A. In situ transmission electron microscopy deformation of the titanium alloy Ti-6Al-4V: Interface behaviour. MATERIALS SCIENCE \& ENGINEERING A, v.483-487, 719722, 2008.

COUTO, A. A.; FALDINI, S.B.; ALMEIDA, G.F.C.; SEKERES, T.S.; KUNIOSHI, C.T.; MORCELLI, A.E.; LIMA, N.B. Caracterização microestrutural da liga Ti-6Al$4 \mathrm{~V}$ comercial utilizada como biomaterial. In: $17^{\circ}$ Congresso Brasileiro de Engenharia e Ciências dos Materiais,15-19 de novembro,2006, Foz do Iguaçu, 
Paraná, Brasil. p. 4365-4376.

CHANG, E. \& LEE, T.M. Effect of surface chemistries and characteristics of Ti6Al4V on the $\mathrm{Ca}$ and $\mathrm{P}$ adsorption and ion dissolution in Hank's ethylene diamine tetra-acetic acid solution. BIOMATERIALS, 23, 2917-2925, 2002.

DING, R.; GUO, Z.; WILSON,A. Microstructural evolution of a Ti-6Al-4V alloy during themomechanical processing. MATERIALS SCIENCE \& ENGINEERING, 327, 233-245, 2002.

DUISABEAU, L.; COMBRADE, P.; FOREST, B. Environmental effect on fretting of metallic materials for orthopaedic implants, WEAR, 259, 805-81, 2004.

EISENBARTH, E., VELTEN, D., MÜLlER, M., THULL, R., BREME, J. Biocompatibility of $\beta$-stabilizing elements of titanium alloys. BIOMATERIALS. 25 , 5705-5713, 2004.

GEETHA, M., SINGH, A.K., ASOKAMANI, R., GOGIA, A.K. Ti based biomaterials, the ultimate choice for orthopaedic. implants - A review. PROGRESS IN MATERIALS SCIENCE, 54, 397-425, 2009.

GURAPPA, I. Characterization of different materials for corrosion resistance under simulated body fluid conditions. MATERIALS CHARACTERIZATION, 49, 73-79, 2002

IORIO, S. D., BRIOTTET, L., RAUCH, E.F., GUICHARD, D. Plastic deformation, damage and rupture of $\mathrm{PM} \mathrm{Ti}-6 \mathrm{Al}-4 \mathrm{~V}$ at $20 \mathrm{~K}$ under monotonic loading. ACTA MATERIALIA. 55, 105-118, 2007.

JESUINO, G.A.; RIBEIRO, L.M.F., NAKAZATO, R.Z.; CODARO, E.N.; O.HEIN, L.R. Propriedades mecânicas e resistência à corrosão da liga Ti-4Al-4V obtida da reciclagem da liga Ti-6Al-4V. MAT. RES., São Carlos, v. 4, n. 2, 63-69, 2001.

KATZ, J. L. Anisotropy of Young's modulus of bone. NATURE, 283, 106-107, 1980.

KNOLL, P.K. \& SCHAEFFER, L. Análise microestrutural da liga de titânio $\alpha+\beta$, Ti$6 \mathrm{Al}-4 \mathrm{~V}$, forjada à quente. In: $17^{\circ}$ Congresso Brasileiro de Engenharia e Ciências dos Materiais,15-19 de novembro,2006, Foz do Iguaçu, Paraná, Brasil. p. 74407451.

LONG, M. \& RACH, H. J. Titanium alloys in total joint replacement a material science perspective. BIOMATERIALS. 19, 1621-1639, 1998.

LÜTJERING, G. 'Property optimization through microstructural control in titanium and aluminum alloys', Materials Science and Engineering A, Vol. 263, p.117, 
1999.

LÜTJERING, G. AND WILLIAMS, J.C. (2003) Titanium, Berlin: Springer-Verlag

MAJORELL, A.; SRIVATSA, S.; PICU, R.C. Mechanical behavior of Ti-6Al-4V at high and moderate temperatures - part I: experimental results. MATERIALS SCIENCE \& ENGINEERING, A326, 297-305,2002.

MANERO, J.M.; GIL, F.J.; PLANELL, J.A. Deformation mechanisms of Ti-6Al-4V alloy with a maertensitic microstructure subjected to oligocyclic fatigue. ACTA MATERIALIA, 48, 3353-3359, 2000.

MARKOVSKY, P.E. Improvement of structure and mechanical properties of cast titanium alloys using rapid heat treatment, MATERIALS SCIENCE AND ENGINEERING A, v. 190, L9-L12, 1995.

MARMY, P.; LEGUEY, T. Z. Impact of irradiation on the tensile and fatigue properties of two titanium alloys. JOURNAL OF NUCLEAR MATERIALS, 296, 155-164, 2001.

MARTIN, P. Effects of hot working on the microstructure of Ti alloys. MATERIALS SCIENCE \& ENGINEERING, 243, 89-96, 1998.

MELO, P. J. Formação e caracterização de óxidos crescidos anodicamente sobre Ti e Ti6Al4V. 2003. Tese (Doutorado). Universidade Federal do Rio Grande do Sul, Rio Grande do Sul. Disponível em: < http://www.lume.ufrgs.br/handle/10183/5024>. Acesso em: 17 mar. 2009.

MELO, A.L.V. Análise das propriedades de chapas de titânio ASTM grau 5 (Ti6Al4V) soldadas a laser Nd:YAG. 2007. Dissertação (Mestrado). Instituto Militar de Engenharia, Rio de Janeiro. Disponível em: < http://www.ime.eb.br/arquivos/teses/se4/cm/analisepropriedades_alexandrelyrio.p df>. Acesso em: 22 ago. 2009.

MIRONOV, S.; MURZINOVA, M.; ZHEREBTSOV, S.; SALISHCHEV, G. A.; SEMIATIN, S.L. Microstructure evolution during warm working of Ti-6Al-4V with a colony- $\alpha$ microstructure. ACTA MATERIALIA, 57, 2470-2481, 2009.

MORAIS, L.S.; SERRA, G.G.; MULLER, C.A..;PALERMO, E.F.A.; ANDRADE, L.R.; MEYERS, M.A.; ELIAS, C.N. Liberação in vivo de íons metálicos por miniimplantes ortodônticos de Ti-6Al-4V, REVISTA MATÉRIA, v.12, 290-297, 2007.

MURR, LU.; QUINONES, S.A.; GAYTAN, S.M.; LOPEZ, M.I.; RODELA, A.; MARTINEZ, E.Y.; HERNANDEZ, D.H.; MARTINEZ, E.; MEDINA, F.; WICKER, R.B. Microstructure and mechanical behavior oh Ti-6Al-4V produced by rapid-layer manufacturing, for biomedical applications. J. MECH. BEHAVIOR BIOMED. 
MATER. 2,20-32, 2009.

NAN, H.; YUANRU, C.; GUANGJUN, C.; CHENGGANG. L.; ZHONGGUANG, W.; GUO, Y.; HUEBE, S.; XIANGHUAI, L.; ZHIHONG, Z. Research on the fatigue behavior of titanium based biomaterial coated with titanium nitride film by ion beam enhanced deposition. SURFACE AND COATING TECHNOLOGY, 88, 127131, 1996.

NAKAJIMA, K.; TERAO, K.; MIYATA, T. The effect of microstructure on fatigue crack propagation. MATERIALS SCIENCE \& ENGINEERING. 243, 176-181, 1998.

NIINOMI, M. Mechanical properties of biomedical titanium alloys. MATERIALS SCIENCE \& ENGINEERING, A243, 231-236, 1998.

NIINOMI, M; KOBAYASHI, T. Fracture characteristics analysis related to the microstructures in titanium alloys. MATERIALS SCIENCE \& ENGINEERING, A213, 16-24, 1996.

OEHRING, M.; APPEL, F.; ENNIS, P. J.; WAGNER,R. A TEM study of deformations processes and microstructural changes during long-term tension creep of a two-phase $\gamma$ titanium aluminide alloy. INTERMETALLICS, 7, 335-345, 1998.

OLIVEIRA, P. T. \& NANCl, A. Nanotexturing of titanium-based surfaces upregulates expression of bone sialoprotein and osteopontin by cultured osteogenic cells. BIOMATERIALS, 25, 403-413, 2004.

PETERS, M., HEMPTENMACHER, H., KUMPFERT, J. and LEYENS, C. In C. Leyens and M. Peters (Eds). Titanium and Titanium Alloys, Wiley-VCH, pp.1-57, 2003.

POORGANJI, B.; YAMAGUCHI, M.; ITSUMI, Y.; MATSUMOTO, K.; TANAKA, T.; ASA, Y.; MIYAMOTO, G.; FURUHARA, T. Microstructure evolution during deformation of near- $\alpha$ titanium alloy with different initial structures in two-phase region. SCRIPTA MATERIALIA, 61, 419-422, 2009.

REISSIG, L.; VÖLKL, R.; MILLS, M.J.;GLATZEL,U. Investigation of near surface structure in order to determine process-temperatures during different machining processes of Ti6AI4V. SCRIPTA MATERIALIA, 50, 121-126, 2004..

SALEM, A.A. \& SEMIATIN, S.L. Anisotropy of the hot plastic deformation of Ti-6Al$4 \mathrm{~V}$ single-colony samples. MATERIALS SCIENCE AND ENGINEERING A,508, $114-120,2009$

SEMIANTIN, S.L.; SEETHARAMAN, V.; GHOSH, A.K. Plastic flow, microstructure evolution, and defect formation during primary hot working of titanium and titanium 
aluminide alloys with lamellar colony microstructures. THE ROYAL SOCIETY, A357, 1487-1512, 1999.

SERRA, A., BACON, D.J., POND, R.C. Twins as barriers to basal slip in hexagonal-closed-packed metals, METALL. MATER. TRANS , 33A(3), 809-812, 2002.

SESHACHARYULU, T.; MEDEIROS, S.C.; FRAZIER, W.G.; PRASAD, Y.V.R.K. Microstructural mechanisms during hot working of commercial grade Ti-6Al-4V with lamellar starting structure. MATERIALS SCIENCE \& ENGINEERING, A325, 112- 25; 2002.

SMITH, C. Paper Review: Nonbasal deformation modes of HCP metals and alloys:role of dislocation source and mobility, In: TMS 2008, $137^{\text {th }}$ Annual meeting \& exhibition, 2008. Disponível em: http://hrgd.mse.uuc.edu/images/pdf/hcpdef.pdf. Acesso em 20 set 2009.

SONG, Y.; XU, D.; YANG, R.; LI, D.; WU, W.;GUO, Z. Theoretical study of the effects of alloying elements on the strength .MATERIALS SCIENCE AND ENGINEERING , 260, 269-274, 1999.

TECNOLOGIA, Aços inoxidáveis austeníticos especiais para implantes ortopédicos, INOX, 9-10,set/dez, 2003.

XUE, W.; WANG, C.; CHEN, R.; DENG, Z. Structure and properties characterization of ceramic coatings produced on Ti-6Al-4V alloy by microarc oxidation in aluminate solution. MATERIALS LETTERS, 52, 435-441,2002.

YAMAGUSHI, M.; INUI H.;YOKOSHIMA, S.; KISHIDA, K.; JOHNSON, D. R. Recent progress in our understanding of deformation and fracture of two phase and single phase TiAl alloys. MATERIALS SCIENCE AND ENGINEERING , 243, 25-31, 1996.

YOO, M.H, MORRIS, J.R., HO, K.M., AGNEW, S.R. Nonbasal deformation modes of HCP metals and alloys:role of dislocation source and mobility, METALL. MATER. TRANS , 33A(3), 813-822, 2002.

YUE, T.M.; YU, J.K.; MEI, Z.; MAN, H.C. Excimer laser surface treatment of Ti6Al-4V alloy for corrosion resistance enhancement, MATERIALS LETTERS, 52, 206-212, 2002.

WANG, K. The use of titanium for medical applications in the USA, MATERIALS SCIENCE \& ENGINEERING, 213, 134-137, 1996.

WANJARA, P., BROCHU, M., JAHAZI, M. Ti-6Al-4V electron beam weld qualification using laser scanning confocal microscopy, MATERIALS 
CHARACTERIZATION 54, 254- 262, 2005.

WEISS, I. \& SEMIATIN, S. L. Thermomechanical processing of beta titanium alloys- an overview. MATERIALS SCIENCE \& ENGINEERING, 243, 46-65, 1998.

ZAEFFERER, Z. A. study of active deformation systems in titanium alloys: dependence on alloy composition and correlation with deformation texture, MATERIALS SCIENCE \& ENGINEERING, A344, 20-30, 2003. 